\section{Murature di mattoni medioevali a vista e resti di finiture a Venezia}

\section{Medieval brick walls and finishing surface remains in Venice}

Angela Squassina*

Università IUAV di Venezia (Italia)

\section{Riassunto}

Nelle «Pietre di Venezia" Ruskin già evocava le tele di Carpaccio e di Bellini, oggi custodite alle Gallerie dell'Accademia, per un'immagine documentata della policromia della città antica, quell'»Urbs picta", in cui murature e rivestmenti partecipavano in ugual misura all'articolazione delle facciate, grazie alle qualità fisiche e cromatiche dei mattoni, alle modalità di finitura dei giunti di malta, alle cromie vere e proprie e di cui sin dall'Ottocento si lamentava la frammentarietà, invocandone la conservazione.

L'interesse per la Venezia pre-rinascimentale ha continuato per più di un secolo ad alimentare la ricerca sugli assetti decorativi e relative tecniche esecutive, con studi di tipo storiografico seguiti, a partire dalla fine degli anni Settanta, da ricerche tematizzate, indagini sui conti di fabbrica di cantieri storici e forme di ricognizione e schedatura delle superfici.

Affrontare il tema delle finiture delle superfici veneziane più antiche significa quindi, da un lato, beneficiare degli esiti delle ricerche precedentemente condotte ma anche l'onere di approfondire alcun aspetti conoscitivi, senza trascurarne le possibili ricadute operative. Uno sviluppo auspicabile è la formulazione di un protocollo conoscitivo, progettuale e operativo, che abbia come referenti anche i risultati di alcuni interventi ritenuti esemplari, seppure ancora minoritari rispetto al tenore della consuetudine operativa.

Parole chiave: Finiture di superficie, paramenti a vista, laterizi.

\section{Abstract}

In his work «Stones of Venice», Ruskin already evoked to Carpaccio's and Bellini's paintings, currently at the Gallerie dell'Accademia, in order to obtain a documented image of the poly-chromy of the ancient city, that «Urbs picta», whose walls and surfaces were equally responsible for the façade articulation, thanks to the physical and chromatical quality of the bricks, to the finishing of the mortar joints, to the true colours and. Since the nineteenth century, there has been complains about the fragmentary character of the remains of the surfaces, at the same time appealing to their preservation.

For longer than one century, the interest in the facies of Venice before Renaissance has provoked several researches about its decorative arrangements and techniques and historiographical studies, followed, since the end of the 70's, by documentary research about topics such as the books account of the building workshops or the surveys and catalogues of the plaster surfaces.

Dealing with the most ancient Venetian surfaces means both making use of the results of the previous studies, but also enjoying the chance of going deeper into its knowledge, without neglecting any operative aspect. We pretend to contribute to a sort of cognitive, project and operative protocol, also referring to some model interventions, which are still regarded as exceptions in comparison to the operative habits.

Key words: Surface finishing, walls, bricks.
Nel simposio curato da F. Valcanover e W. Wolters negli anni Novanta del Novecento, sintetizzando studi precedenti ${ }^{1}$ in una corale descrizione dell'architettura gotica veneziana nei suoi vari aspetti, gli autori auspicavano il contributo di «chi, con i metodi dell'archeologo, sa decifrare il palinsesto dell'edificio, il documento più ampio, più ricco di informazioni rimastoci, ${ }^{2}$, dando spazio agli studi della Bauforschung.

Contemporaneamente giungevano a maturazione forme di censimento e schedatura delle superfici storiche precedentemente attivate, come quella dei fronti sul Canal Grande operata nel 1978 dall'Università di Venezia ${ }^{3}$ e l'indagine sugli intonaci dell'edilizia storica veneziana, condotta da E. Armani e M. Piana ${ }^{4}$ per la Sovrintendenza ai Beni Architettonici di Venezia e in seguito confluita in un programma CORILA-Università IUAV di Venezia, che ha portato alla formazione di un importante strumento conoscitivo informatizzato 5 . Insieme a interventi pilota come quelli condotti alla Scuola Grande di S. Giovanni Evangelista, e al Convento della Carità, concepiti per orientare la prassi operativa nel senso di un superamento della logica del rinnovo ${ }^{6}$.

Alcune sperimentazioni in tal senso sono state condotte nell'ambito di interventi più recenti, come quello nell'ex convento dei SS. Cosma e Damiano alla Giudecca $^{7}$, dove è stata attuata una forma di progettazione giudata dalla conoscenza stratigrafico-costruttiva delle superfici e volta alla massimizzazione della loro permanenza-leggibilità; la stratigrafia è stata adottata come strumento conoscitivo complementare anche in alcune ricerche in ambito universitario sui caratteri costruttivi e dissesti dell'edilizia civile veneziana e dei cam-

\footnotetext{
${ }^{1}$ Si riportano in bibliografia alcuni dei contributi più significativi sulla tradizione costruttiva veneziana, come gli approfondimenti tipologici e costruttivi di S. Muratori e E. R. Trincanato, gli aspetti culturali e architettonici evidenziati in E. Arslan e E. Concina e quelli insiediativi ed urbanistici analizzati, fra gli altri, da P. Maretto e W. Dorigo, ricerche tematizzate come quella di G. Gianighian e P.Pavanin e di G. Caniato e M. Dal Borgo sulla tradizione tecnologicocostruttiva; i convegni sul mattone a Venezia nel 1979 e nel 1982 e lo studio di F. Zago sulle proprietà fisiche e meccaniche delle murature in mattoni di un palazzo gotico.

${ }^{2}$ F.Valcanover e W.Wolters, 2000, p. 12.

${ }^{3}$ Il gruppo di lavoro: V. Fontana, N. Gianighian, G. Rossi, W. Dorigo (cfr. V. Fontana, 1990, pp. 719-723).

${ }^{4}$ E.Armani, M.Piana, 1984, pp. 44-54.

${ }^{5}$ M.Piana, E.Danzi, A.Ferrighi, S. De Zorzi, E. Rinaldi, «Un GIS-Web per la catalogazione degli intonaci esterni veneziani», CO.RI.LA - Università IUAV di Venezia, DSA linea 2.1 «Un millennio di costruzioni e la protezione dalle 'acque salse'», 2001-2006.

${ }^{6}$ M. Piana, 1984, p. 103.

${ }^{7}$ A. Bruschetti, F. Doglioni, 1999.
} 
panili ${ }^{8}$, i cui esiti sono stati presentati in un recente convegno?.

Il monito di Valcanover e Wolters e gli stimoli offerti dai percorsi di ricerca citati hanno indotto ad affrontare uno studio delle murature veneziane in antico a vista, comprendendo nel campo di interesse tutte le forme di finitura e nobilitazione del paramento in mattoni a vista ${ }^{10}$, attraverso specifiche modalità di posa, forme di lavorazione del laterizio e di finitura ribadita del giunto, fino agli intonachini e coloriture mimetiche che preludono alla ricopertura ad intonaco diffusa nel Rinascimento. La ricerca è stata articolata in fasi, con pre-censimento delle testimonianze individuate, seguito da approfondimenti di tipo storiografico, tecnologico, stratigrafico, finalizzati al riconoscimento dei caratteri e integrando gli esiti delle osservazioni dirette con i dati ricavati da letteratura tecnica e pubblicistica. Osservazioni stratigrafiche condotte su singoli contesti, come la chiesa dei Carmini, o classi di manufatti (i campanili ${ }^{11}$ ) hanno permesso di isolare campioni significativi di murature antiche con paramento a vista e di collocarli in una sequenza cronologica relativa nell'ambito della storia costruttiva veneziana.

Questo studio richiede un cambiamento di scala delle osservazioni, che si sposta dalla componente macroscopica della configurazione architettonica a quella del dettaglio costruttivo della muratura, per una volta non intesa come semplice struttura o supporto ma come superficie espressiva in se', avvicinata nella sua materialità. Si è rivelata utile in questo senso un 'interazione fra diversi strumenti analitici, in particolare fra un approccio storiografico e letture di tipo tecnico-costruttivo e stratigrafico, che hanno permesso di evidenziare alcune peculiarità legate al processo costruttivo e trasformativo dell'edificio.

Anche se risulta talvolta difficoltoso allontanarsi da un approccio consolidato alle murature, per cui la compagine

${ }^{8}$ Studi condotti dall'Università Iuav di Venezia: «Sicurezza e Conservazione degli edifici storici in funzione delle tipologie edilizie, della concezione costruttiva e dei materiali», responsabile scientifico F. Doglioni; "Organizzazione della conoscenza e della diagnostica per la conservazione dell'edilizia storica veneziana», responsabile scientifico G. Mirabella Roberti; "Ricerche, prove e valutazioni relative alla stabilità strutturale dei campanili di Venezia», responsabili scientifici F. Doglioni e A. Lionello. Gli esiti degli studi sono stati raccolti in due pubblicazioni: la prima a cura di F. Doglioni e G. Mirabella Roberti, 2011; la seconda a cura di A. Lionello, 2011.

9 "A Venezia per Venezia. Ricerche sulle costruzioni veneziane per la conservazione della città", convegno internazionale promosso dall'Università Iuav di Venezia (prof.F.Doglioni)-Sbbaav (arch. R.Codello)- Corila (ing.P.Campostrini), Venezia 16-17 maggio 2011

${ }^{10}$ A.Squassina, "Conoscenza e restauro delle murature in laterizio veneziane con superfici in origine finite a vista», programma di ricerca "Il restauro delle superfici di Venezia. L'intonaco e il mattone», Referente Universitario Prof. F. Doglioni, FSE Regione Veneto-Università IUAV di Venezia, 2010-2011.

${ }^{11}$ Cfr nota n.8. muraria formata da mattoni e malta è compresa in un piano esclusivamente tettonico, mentre il piano figurativo riguarderebbe solo i trattamenti/rivestimenti di superficie, gli orientamenti culturali sul tema del mattone nell'architettura medioevale tendono a coniugarne entrambe le dimensioni, quella formale e quella materico-architettonica, di cui solo sul piano analitico si possono scomporre le singole componenti ${ }^{12}$. (fig. 1a) E' necessario considerare la muratura e gli eventuali strati decorativi sovrapposti come un unicum costruttivo-espressivo, attraverso il quale possono essere traguardati anche modi di apparecchiatura, motivi tessiturali e caratteristiche di superficie dei laterizi e dei giunti che, al pari dei rivestimenti, determinano la qualità d'insieme. In effetti, la separazione fra supporto $\mathrm{e}$ superficie espressiva è netta nelle opere d'arte e negli edifici dotati di forte connotazione formale, mentre il confine diventa labile nei manufatti che hanno carattere prevalentemente materico e soprattutto nell'architettura medioevale con paramenti in mattoni a vista, dove l'articolazione delle facciate era affidata a «mezzi espressivi polimaterici differenziati $\rangle^{13}$, cioè alle modalità costruttive e tecniche di lavorazione del laterizio e del giunto di malta, nelle pareti di fondo, ravvivate da cromie e rivestimenti sottili a finta cortina, oltre che agli elementi architettonici o decorativi. E' dunque fondamentale il riconoscimento degli specifici caratteri di questo tipo di muratura e dei dati di cultura materiale e costruttiva in esso contenuti. Pur trattandosi di superfici accuratamente rifinite, nella maggior parte dei casi le murature di mattoni in antico a vista risultano molto modificate, alterate dal degrado o spesso ricomprese in contesti che le rendono non immediatamente riconoscibili. Negli interventi di restauro questi paramenti sono sovente riguardati come murature semplicemente «prive di intonaco", senza cioè riconoscerne l'intrinseca qualità di superfici connotate, giungendo così a modificarle, talvolta in modo radicale. Nella maggior parte dei casi permangono testimonianze frammentarie, brani di paramento e lacerti di rivestimenti sottili che richiedono un'osservazione accurata, nella convinzione dell'estrema significatività di queste superfici, quand'anche ridotte a lacerti. (fig. 1b).

\footnotetext{
${ }^{12}$ Sulle murature medioevali si ricordano, a titolo esemplificativo E.De Minicis, 2001 e il più recente D.Fiorani, 2005.

${ }^{13}$ V.Brunori in E.De Minicis, cit. L'accuratezza delle murature a vista medioevali viene ricondotta alla muratura lapidea isodoma romana l'opus quadratum mediante l'uso di mattoni, non a caso definiti a lungo "pietre cotte». Lo stesso Leon Battista Alberti insisteva sulla qualità di un'opera muraria, che dipenderebbe più dall'accuratezza della tecnica che dal pregio dei materiali (L.B.Alberti citato in P.N.Pagliara, "Antico e Medioevo in alcune tecniche costruttive del XV e XVI secolo, in particolare a Roma", in "Annali di Architettura», 10-11, 199899, pp.246-47).
} 

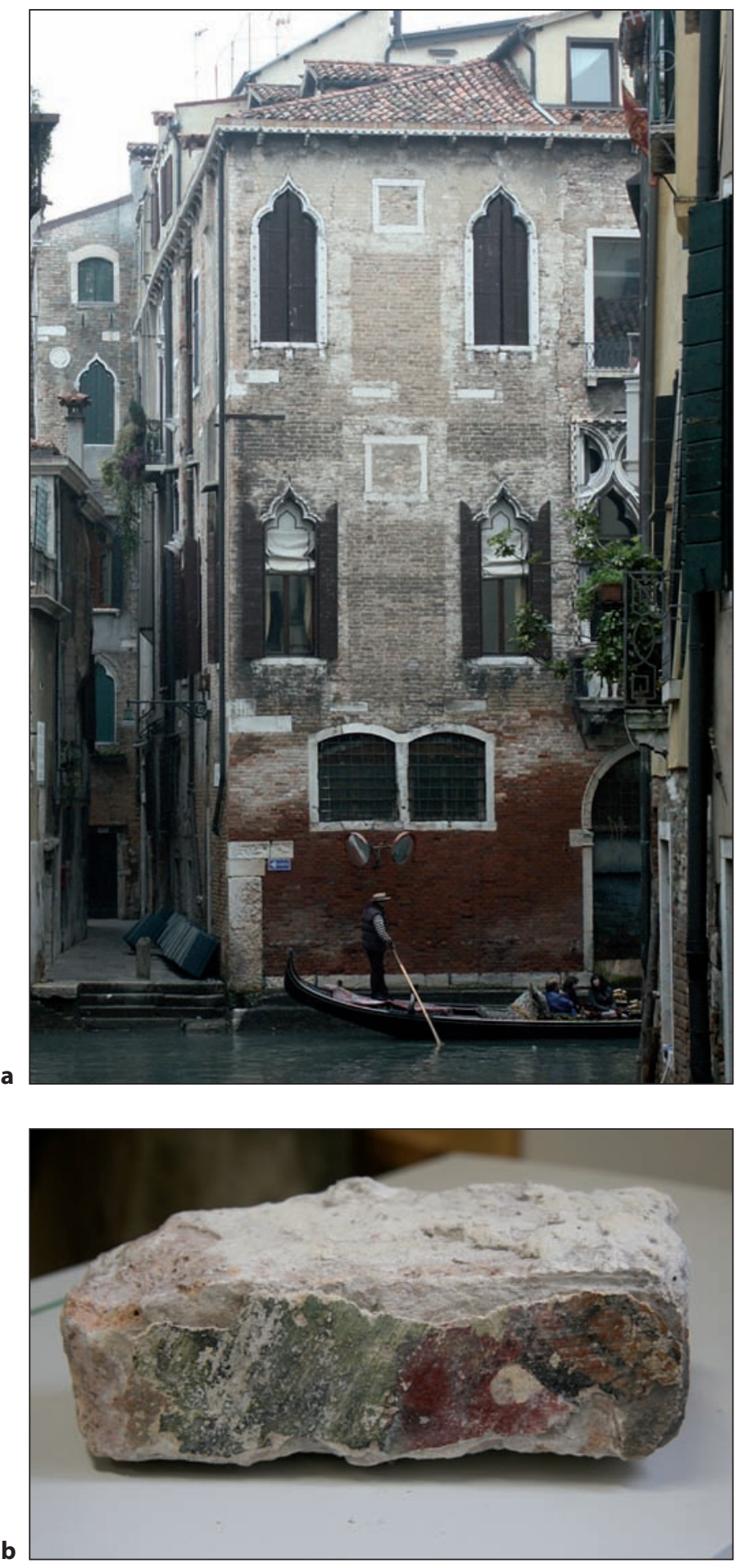

Fig. 1a. Venezia: muratura in mattoni faccia a vista e resti di cornici ad intonaco in un edificio gotico; b. Resti di intonachino decorato su un'altinella

MATTONI NEL TEMPO A VENEZIA: LETTURA STRATIGRAFICA DELLE MURATURE DELLA CHIESA DEI CARMINI E PRIMA IPOTESI DI CRONOLOGIA

Uno studio di tipo mensiocronologico dei mattoni utilizzati in passato a Venezia accusa margini di incertezza più

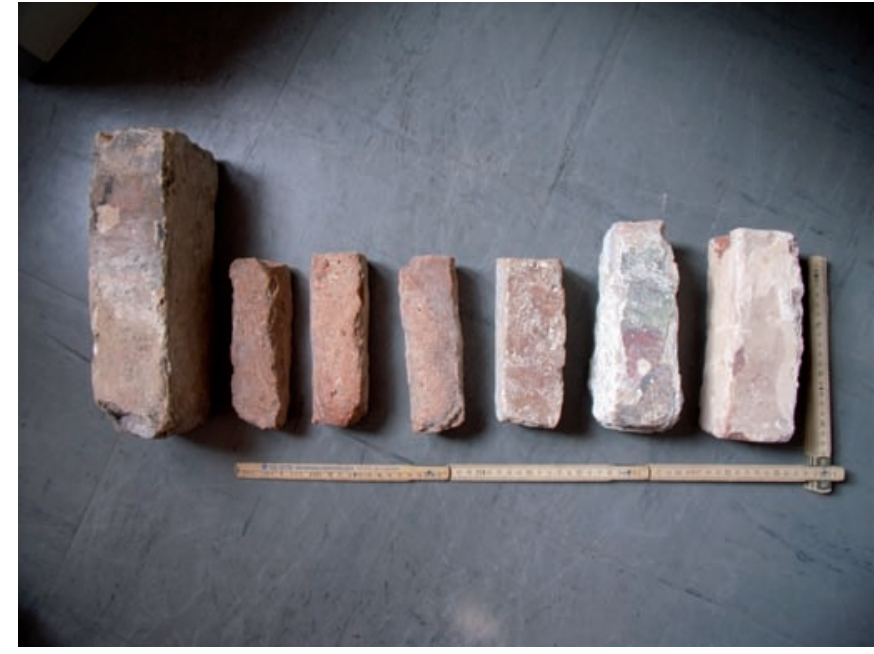

Fig. 2. Mattoni a Venezia: esempio della variabilità dimensionale di una serie di altinelle erratiche accostate, per confronto, a un mattone gotico

elevati che altrove ${ }^{14}$, per un'eterogeneità dimensionale (fig. 2) in parte dovuta a un sistematico riutilizzo di materiali costruttivi nel tempo, in parte a causa del perdurare di un utilizzo contestuale di diversi formati, di cui non sono ancora chiare le condizioni di produzione e provenienza iniziali, in particolare di mattoni di formato ridotto - le altinelle ${ }^{15}$ - e mattoni di dimensioni mag-

${ }^{14} \mathrm{Fra}$ i metodi di datazione diretta assoluta degli edifici, la mensiocronologia, basata sulle variazioni regionali delle dimensioni dei mattoni nel tempo, è il sistema elaborato dal Laboratorio di Archeometria dell'Iscum (Istituto di Storia della Cultura Materiale) dell'Università degli Studi di Genova, frutto di studi condotti sin dagli anni Settanta del Novecento (F.Bonora, 1979, T.Mannoni, 1984, S.Fossati, 1984) che ha prodotto una curva mensiocronologica valida per la Liguria (P.Ghislanzoni, D.Pittaluga, 1989), strumento di riferimento indispensabile alla collocazione cronologica degli edifici sulla base della rispondenza delle loro murature di mattoni ai dati dimensionali contemplati nella curva stessa, soprattutto quando non sono disponibili altre fonti di datazione o è necessario ridurre gli errori di datazione derivanti dall'applicazione di altri metodi. La validità del metodo è stata verificata anche in altre aree con ricerche ad hoc (cfr. per es. gli studi mensiocronologici di J.A.Quiros Castillo in Toscana), trattandosi di un sistema che richiede la formazione di una chiave cronologica locale, in quando legato a dati di riferimento che sono validi soltanto per aree più o meno limitate (T. Mannoni, 1984, p. 398). La sua applicabilità a Venezia è stata oggetto di uno studio specifico (cfr. F. Varosio, nota n. 17), nel corso del quale sono già state rilevate difficoltà, peraltro comuni, correlate alla scarsità di fonti indirette di datazione assoluta per gli edifici civili e alla pratica del reimpiego, limite, quest'ultimo, enfatizzato a Venezia da difficoltà logistiche e di reperimento dei materiali. Altro fattore di disordine nelle tessiture murarie veneziane è l'aggressività del degrado da risalita capillare di acqua salmastra, che ha indotto a pratiche di continua sostituzione muraria, soprattutto nelle parti basamentali degli edifici, maggiormente coinvolte dai fenomeni di degradazione. Ma l'elemento di maggior incertezza è rappresentato dall'utilizzo contestuale di mattoni di diversi formati in paramenti omogenei, stratigraficamente unitari.

${ }^{15}$ Le «altinelle», già riconosciute da Scamozzi come materiale di origine romana, sono piccoli mattoni utilizzati a Venezia in una prima fase come materiale di reimpiego e successivamente, a partire dal XII secolo, con produzione locale («altinelle venete», elementi di dimensioni leggermente superiori rispetto alle altinelle romane; cfr. note n. 39-40). 

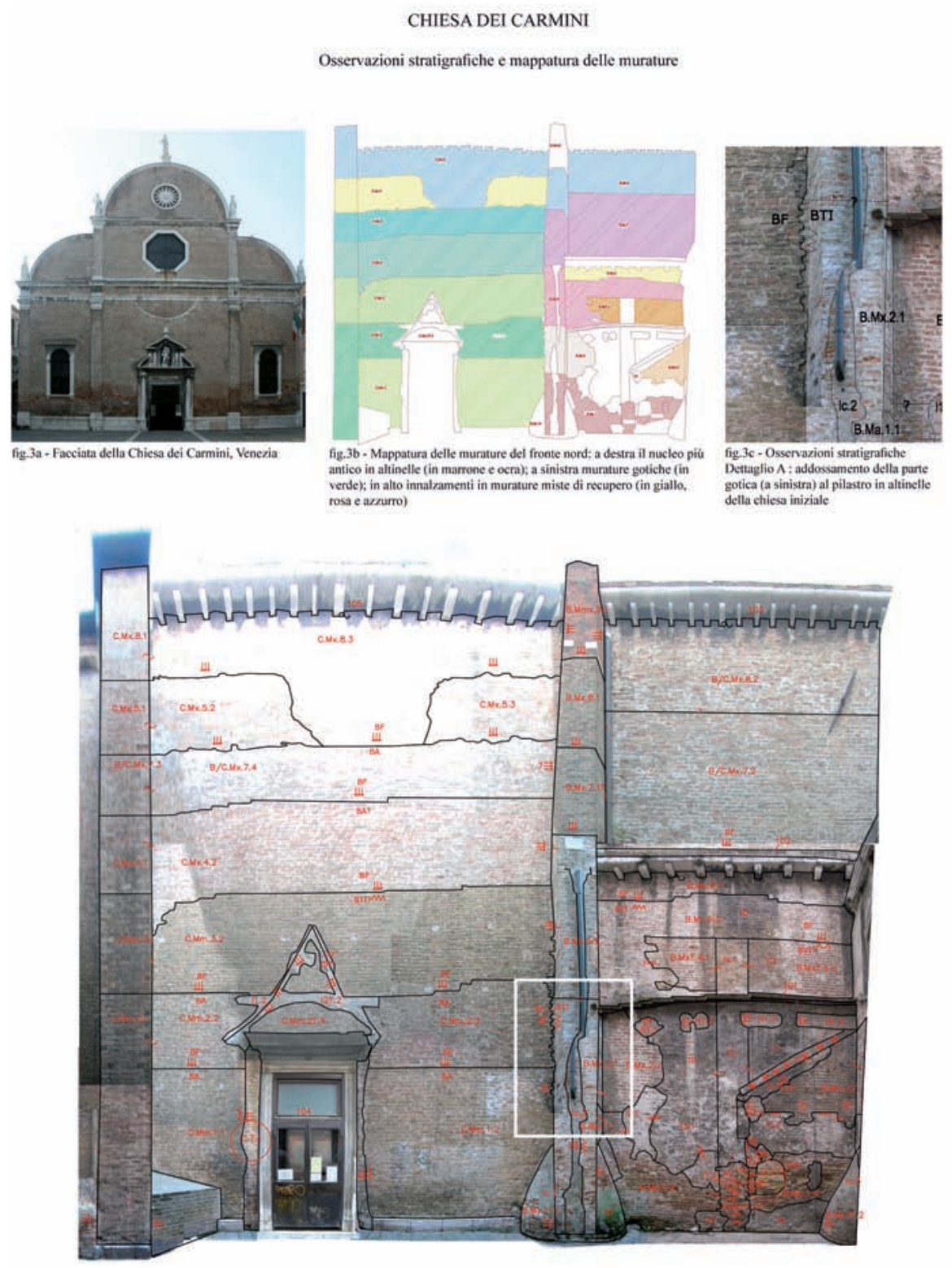

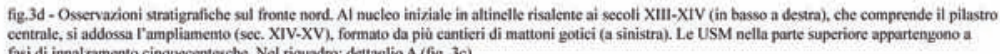

Fig. 3. Chiesa dei Carmini, Venezia: (3a) facciata principale della chiesa; (3b) mappatura delle murature nel fronte laterale nord; (3c-3d) lettura stratigrafica del lato nord con dettaglio dell'addossamento della parte gotica (a sinistra) alla chiesa iniziale in muratura di altinelle (a destra) (fotomosaico: studenti Magagnin, Scapin, Vialetto, del corso Restauro, Clasa, Università luav di Venezia, Prof. F. Doglioni, a.a.2007-08)

giori, una pratica confermata da documenti di cantiere del XIV secolo, che attestano una produzione differenziata di "lapides cocti ad mensuram magnam vel parvam...." ${ }^{16}$. Non sembra trattarsi soltanto di una varietà rispondente a ragioni funzionali, in cui l'uso di altinelle è riservato a parti specialistiche (per esempio le ghiere d'arco) ma spesso si osservano, nello stesso paramento murario, altinelle come elementi di primo impiego, talvolta mescolati

${ }^{16}$ A. S. Ve, Quarantia Criminale, reg.16, 1368, trascritto in F. Marino, «Notizie sul cantiere e sui modi del costruire nel tardomedioevo a Venezia attraverso lo studio di conti di fabbrica», tesi di laurea, relatore F. Doglioni, IUAV, a.a. 1988-89. a mattoni di formato diverso. Campioni di questo genere sono stati osservati sia in edifici monumentali religiosi che nell'edilizia civile e sono riconducibili ad un arco cronologico compreso fra il XII e il XV secolo. Tali consuetudini sembrano ridurre la possibilità di una correlazione inequivocabile fra tipo di materiale e periodo d'uso $^{17}$, rendendo estremamente complessa la stesura di

\footnotetext{
${ }^{17}$ Si ricorda lo studio di Federica Varosio, «Ricerca per una mensiocronologia dei laterizi a Venezia", tesi di Laurea, relatore I.Ferrando, correlatori C.Varaldo, T.Mannoni, Università degli studi di Genova, Facoltà di Lettere e Filosofia, Corso di Laurea in Conservazione di Beni Culturali, a.a. 2000/2001; e F.Varosio, 2001, pp. 49-59.
} 
una curva mensiocronologica, e quanto mai necessario uno sforzo di interazione di conoscenze e competenze di tipo stratigrafico, chimico-petrografico e storiografico.

Un esperimento di integrazione fra stratigrafia e analisi dimensionale è stato condotto su alcuni edifici pluristratificati, sia religiosi che civili ${ }^{18}$; in particolare, è stato approfondito lo studio stratigrafico sulle superfici esterne della chiesa di S. Maria del Carmelo (Carmini) ${ }^{19}$, il cui attuale assetto è il frutto di un processo costruttivotrasformativo che attraversa un arco cronologico esteso dal XIII al XX secolo, rappresentato da un'articolata geografia di tessiture murarie e relative finiture. Fra queste si osservano anche ampi tratti di altinelle, utilizzate in diverse fasi del cantiere iniziale. Sintetizzando l'esito della lettura stratigrafica, sui fronti laterali (soprattutto quello nord, oggetto di indagine specifica) si rimarcano due macroscopiche discontinuità, a formare una sorta di doppia bipartizione dell'edificio; la prima, fra parte anteriore iniziale (in altinelle o altinelle e mattoni sottili) e parte posteriore successiva, dove prevalgono mattoni gotici. Una seconda cesura - che non coinvolge le absidi, frutto di una fase di realizzazione unitaria - divide tutta la parte inferiore, in cui si osservano elementi omogenei e di primo impiego, dalla sommità innalzata a più riprese, nel XVI e nel XVIII secolo, costituita da murature miste con elementi recuperati. In facciata, le pareti di fondo sono in altinelle fino ad un'altezza corrispondente all'interfaccia di demolizione dell'antico rosone; muratura mista con mattoni di reimpiego nel frontone trilobato e mattoni omogenei di $\mathrm{cm} \mathrm{5,7 \times}$ $12 \times 24,5$ nelle paraste dell'assetto cinquecentesco. Sulla base delle osservazioni stratigrafiche svolte (fig. 3) e cono-

${ }^{18}$ Fra gli edifici studiati: Abbazia della Misericordia (Fronte della Scuola Vecchia di S.M.della Misericordia, sec.XV (Arslan, 1970); Basilica dei Frari, (1330-1492, cfr. Concina, 1995; in particolare fianco sud (dal 1330), Cappella di S.Marco (1422), Cappella di S.Pietro (1432), facciata (entro 1440); Chiesa di S.Giovanni e Paolo (1333-1430, Zava, Bocazzi, 1996, in particolare le murature della parte inferiore della facciata e del fronte laterale sud-ovest); abitazioni di origine pregotica in Calle delle Oche e in Crosera S.Pantalon, in S.Basilio e altri campioni più circoscritti (porzioni di edifici e muri di cinta).

${ }^{19}$ Chiesa dell'ordine mendicante de Carmelitani, costruita tra il 1286 ed il 1308 (Dellwing, 1990), con prosecuzione del cantiere fino al 1348, anno della consacrazione (i riferimenti di datazione assoluta qui riportati sono tratti dai testi citati in nota 21). Una descrizione completa dello studio stratigrafico, con note storiche dettagliate è contenuta in A.Squassina, "Le variazioni dimensionali e delle lavorazioni di superficie dei laterizi a Venezia: la chiesa dei Carmini come sequenza cronologica", in F.Doglioni, G.Mirabella Roberti, cit., pp.67-88. Si ringrazia la dottoressa Roberta Battaglia della Soprintendenza per i Beni Architettonici e Paesaggistici di Venezia e Laguna per la disponibilità concessa all'osservazione stratigrafica delle murature interne e del fronte sud esterno, e alla consultazione di materiale documentale nell'ambito dell'intervento di restauro dell'apparato ligneo interno, da lei condotto e tuttora in atto. Alcuni elaborati sono tratti anche dalle esercitazioni dei corsi di Restauro Architettonico, Università Iuav di Venezia, Clasa, Prof. F.Doglioni, a.a.2006-09 e Prof. A.Squassina, a.a.2010-11. scenze acquisite, si ipotizza la sequenza cronologica delle principali fasi costruttivo-trasformative, correlandole alle diverse murature rilevate. La possibilità di stabilire per questo edificio una sequenza stratigrafica di differenti opere murarie in mattoni ha un significato che va oltre la pur importante conoscenza del singolo manufatto, in quanto il gruppo di paramenti cronologicamente ordinati della chiesa dei Carmini confluisce nella ricerca più generale come strumento di raffronto, utile a formulare una prima ipotesi di collocazione cronologica di altre murature rilevate in edifici religiosi e civili veneziani, per correlazione rispetto ad affinità tecnologico-costruttive (tipo di giunti, tessiture, apparecchiature, ecc.) e dimensionali (di mattoni e giunti); infine, per confronto fra i relativi elementi di datazione indiretta, dove reperibili.

\section{CHIESA DEI CARMINI - FASI COSTRUTTIVO- TRASFORMATIVE E MURATURE AD ESSE CORRELATE}

(Nota: nella figura 4 è rappresentata la sequenza stratigrafico-cronologica delle murature (con un modello tridimensionale in cui è schematizzata la relativa mappatura) riconducibili alle fasi costruttivo-trasformative della chiesa, qui di seguito sinteticamente descritte) ${ }^{20}$ :

fase 1. La chiesa iniziale (XII-XIV secolo, Dellwing, $1990^{21}$ ) - muratura mista con elementi di primo impiego costituiti da altinelle poste di testa $(\mathrm{cm} 5 \times 9)$ - e mattoni sottili $(\mathrm{cm} 5 \times 22)$ posti di fascia (fase 1a, fig. 4a); completamento di sole altinelle $(\mathrm{cm} 5 \times 8 \times 16,5)$ con giunto ribadito a calce e stilato ${ }^{22}$ (spessore giunto orizzontale: $\mathrm{mm} \mathrm{10-15/(verticale)} \mathrm{mm} \mathrm{5-10)} \mathrm{(fase} 1 \mathrm{~b}$, fig. 4b).

Nota: nella parte posteriore della chiesa iniziale compare un breve tratto di muratura in mattoni di colore rosato-bruno, con elementi posti prevalentemente di fascia di dimensioni pari a cm 4,7 $\times 13,7^{*} \times 29$; giunto di malta ricca di calce, di colore bianco e dimensioni variabili $(\mathrm{mm}$ 10-23 o./6-10 v.) e finitura a stilatura ampia e concava con tratti ad andamento a battente. Il paramento è riconducibile ad un piccolo edificio, addossato all'interfaccia di demolizione del penultimo contrafforte della chiesa iniziale. Benchè il corpo non sembri appartenere alla chiesa, la sequenza stratigrafica osservata induce ad apparentare que-

\footnotetext{
${ }^{20}$ Le murature sono state rilevate mediante campionamento di un $\mathrm{mq}$ di superficie omogenea (per USM sufficientemente ampie); le misure qui riportate rappresentano la media dei valori rilevati nel campione per ognuna delle tre dimensioni (dove presenti); i valori segnalati da un asterisco corrispondono al caso di campioni in cui una delle dimensioni compare in numero inferiore alla decina (tessiture prevalentemente di testa o di fascia); infine, in caso di campioni in cui la leggibilità è ridotta, si segnalano valori massimi e minimi.
} 


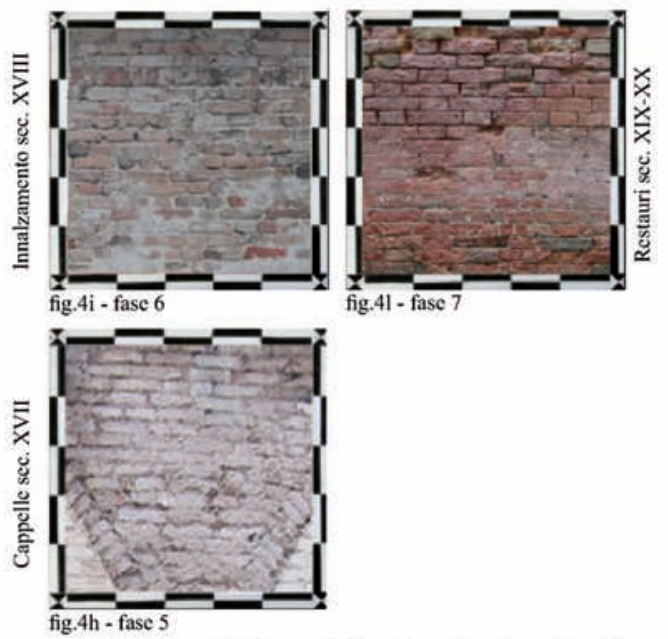

\section{CHIESA DEI CARMINI}

Sequenza cronologica delle fasi costruttive e relative murature, con schemi delle principali apparecchiature, tessiture e profili dei giunti
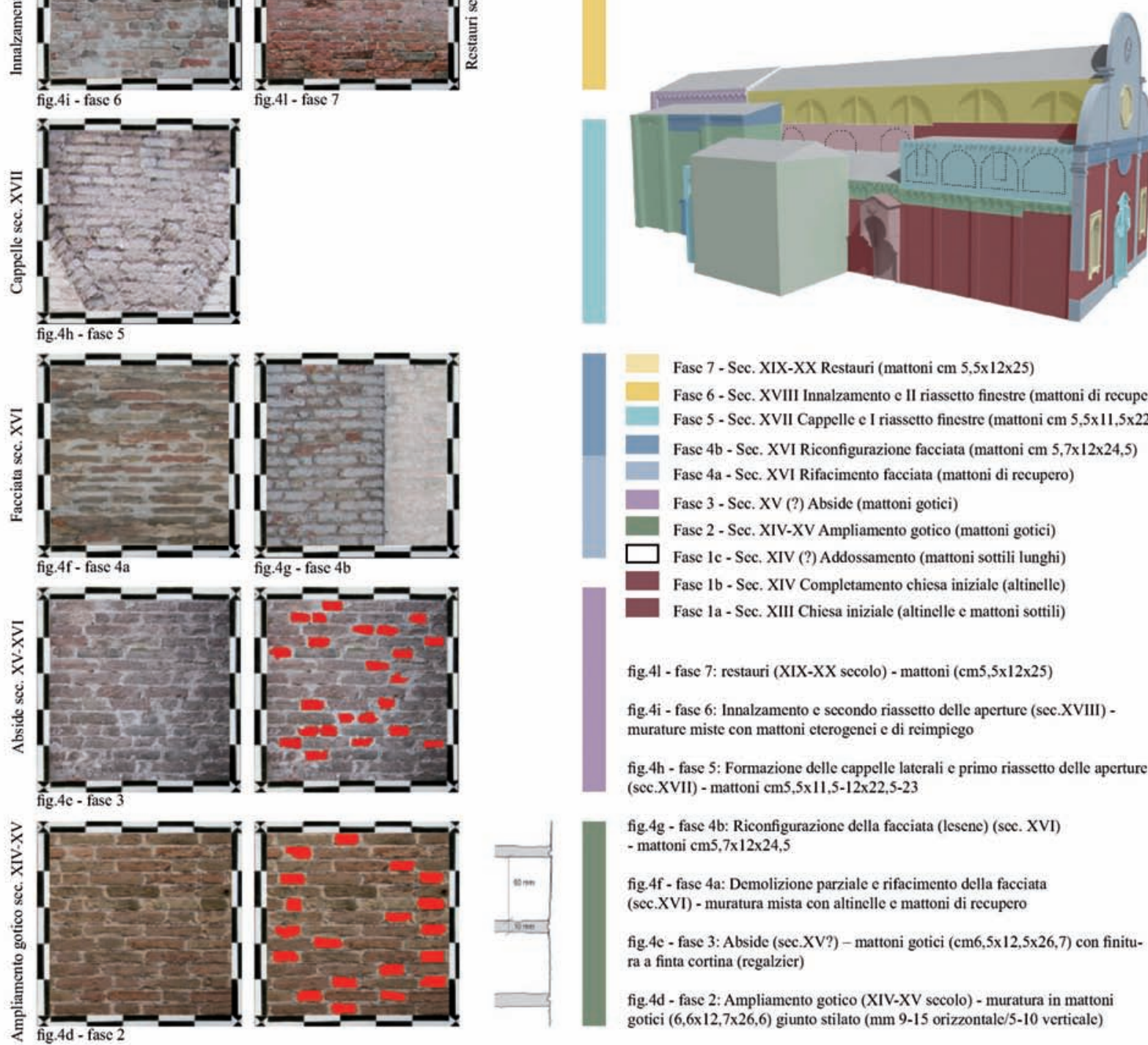

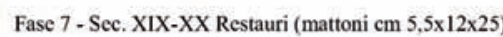

Fase 6 - Sec. XVIII Innalzamento e II riassetto finestre (mattoni di recupero) Fase 5 - Sec. XVII Cappelle $\mathrm{e}$ I riassetto finestre (mattoni $\mathrm{cm} 5,5 \times 11,5 \times 22,5$ )

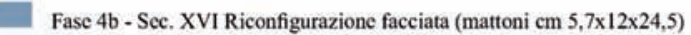

Fase $4 \mathrm{a}$ - Sec. XVI Rifacimento facciata (mattoni di recupero)

Fase 3 - Sec. XV (?) Abside (mattoni gotici)

Fase 2 - Sec. XIV-XV Ampliamento gotico (mattoni gotici)

$\square$ Fase Ic - Sec. XIV (?) Addossamento (mattoni sottili lunghi)

Fase $1 \mathrm{~b}$ - Sec. XIV Completamento chiesa iniziale (altinelle)

Fase 1a - Sec. XIII Chiesa iniziale (altinelle e mattoni sottili)

fig.41 - fase 7: restauri (XIX-XX secolo) - mattoni ( $\mathrm{cm5} 5,5 \times 12 \times 25)$

fig.4i - fase 6: Innalzamento e secondo riassetto delle aperture (sec.XVIII) murature miste con mattoni eterogenei e di reimpiego

fig. $4 \mathrm{~h}$ - fase 5: Formazione delle cappelle laterali e primo riassetto delle aperture (sec.XVII) - mattoni cm5,5x11,5-12 ×22,5-23

fig. $4 \mathrm{~g}$ - fase 4b: Riconfigurazione della facciata (lesene) (sec. XVI)

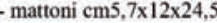

fig $4 \mathrm{f}$ - fase 4a: Demolizione parziale e rifacimento della facciat (sec.XVI) - muratura mista con altinelle e mattoni di recupero

fig. $4 \mathrm{e}$ - fase 3: Abside (sec.XV?) - mattoni gotici (cm6,5x12,5x26,7) con finitura a finta cortina (regalzier)

fig.4d - fase 2: Ampliamento gotico (XIV-XV secolo) - muratura in matton gotici $(6,6 \times 12,7 \times 26,6)$ giunto stilato ( $m$ m 9-15 orizzontale/5-10 verticale)

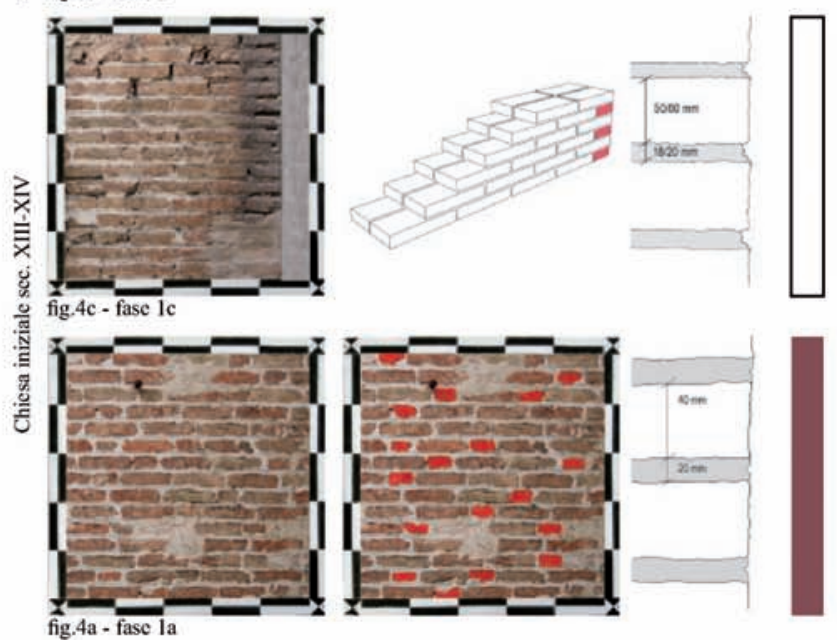

fig. $4 \mathrm{c}$ - faselc - Addossamento corpo alla chiesa iniziale (sec. XIV?) - matton sottili c lunghi $\mathrm{cm} 4,7 \times 13,7 * \times 29$, con giunto stilato ( $\mathrm{mm} \mathrm{10-23} 0 . / 6-10 \mathrm{v}$.)

fig. $4 \mathrm{~b}$ - fase Ib: Completamento della chiesa iniziale (sec. XIV) - altinelle ( $\mathrm{cm}$ $5 \times 8 \times 16,5$ ) con giunto ribadito a calce e stilato (giunto orizzontale: $\mathrm{mm} 10-15$ / (verticale) mm 5-10)

fig. 4a - fase la: Chiesa iniziale (XIII secolo) - muratura mista con altinelle poste di testa $(\mathrm{cm} 5 \times 9)$ e mattoni sottili $(\mathrm{cm} 5 \times 22)$ posti di fascia

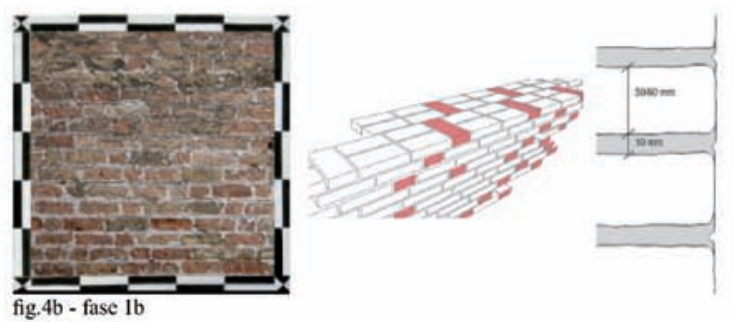

Fig. 4. Chiesa dei Carmini, Venezia: risultati di un esperimento di integrazione fra lettura stratigrafica e analisi dimensionale delle murature (Modello tridimensionale: A.Mansiutti; schemi apparecchiature e profili giunti: N.Moscheni) 
sti mattoni ad una fase d'uso precedente all'introduzione dei mattoni gotici (fig. 4c);

fase 2. L'ampliamento gotico (XIV-XV secolo) - muratura in mattoni gotici $(6,6 \times 12,7 \times 26,6$ con leggere varianti cromatiche dovute a cantieri diversi - fasi di cantiere 2a-2b-2c) con malta di colore ocra chiaro-biancastro, con inerti a granulometria fine e calcinaroli; il giunto è sottile (mm 9-15 giunto orizzontale/5-10 commessura verticale), con tratti in cui emerge la stilatura preparatoria a spiovente ovvero la finitura rifluente a stilatura concava ( $\mathrm{mm} 4-6)$, con ribaditura a calce ed allargamento del giunto verticale rispetto a quello orizzontale (fig. $4 \mathrm{~d}$ );

fase 3. Abside (sec. XV?, Concina 1996) - mattoni gotici $(\mathrm{cm} 6,5 \times 12,5 \times 26,7)$ con finitura a finta cortina (regalzier ${ }^{23}$ ) (fig. 4e);

fase 4. Demolizione parziale (fase 4a) e riconfigurazione della facciata (fase $4 \mathrm{~b}$, prima metà del XVI sec., Concina, 1996) - muratura mista di recupero (fig. 4f) e muratura di mattoni omogenei di cm 5,7 × $12 \times 24,5$ (fig. $4 \mathrm{~g}$ );

fase 5. Primo riassetto delle aperture (sec. XVII, E.Concina, 1996) - mattoni $\mathrm{cm} 5,5 \times 11,5-12 \times 22,5-23$ (fig. 4h);

fase 6. Innalzamento e secondo riassetto delle aperture (XVIII secolo, L.Moretti, S.B. Savini, 1995) - murature miste con mattoni eterogenei e di reimpiego (fig. 4i);

fase 7 - modifiche-restauri (XIX-XX secolo) - mattoni

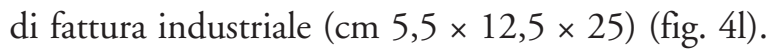

$\mathrm{Si}$ è delineata una panoramica di murature differenti

${ }^{21}$ Gli elementi di datazione assoluta, attribuiti alle diverse fasi stratigraficamente individuate e qui riferiti al secolo, sono stati ricavati da fonti indirette, testi e ricerche specifiche sulla chiesa dei Carmini, di seguito sinteticamente elencati e riportati per esteso in bibliografia: A.Niero, 1956; G.Lorenzetti, 1974; H. Dellwing, 1990; L.Moretti, S.Branca Savini, 1995; E. Concina, 1996; W.Dorigo, 2003; ricerca d'archivio condotta dalla dott.Roberta Battaglia della SBBAAP di Venezia e Laguna, nell'ambito dell'intervento di restauro dell'apparato ligneo interno.

${ }^{22}$ Con il termine "giunto ribadito" si intende una forma di finitura del giunto mediante malta ricca di calce, adeguatamente pressata al fine di far emergere la calce stessa o mediante stesura diretta di un sottile strato di calce; La stilatura consiste in una tecnica di finitura del giunto mediante incisione della malta in corrispondenza di ogni corso di mattoni, praticata con un ferro acuminato (stilo) o con la lama della cazzuola (cfr paragrafo B - Processo costruttivo.

23 «Regalzier» è il termine usato a Venezia per indicare un intonaco sottilemonostrato a finta cortina. Al momento non risultano dati certi sull'origine del termine, né sulla questione se l'etimologia sia locale o allctona (cfr. paragrafo C Processo di finitura). per formato e finiture, poste in sequenza cronologica relativa grazie ad una serie di correlazioni di tipo stratigrafico, successivamente avvalorate da elementi di datazione assoluta tratti da documentazione storica e pubblicistica dedicata $^{24}$.

A partire da questa prima sequenza, verificata e integrata da altre sequenze stratigrafiche di prossimità (costruite sugli altri casi studiati), si è ottenuto un primo repertorio cronologicamente ordinato di murature e relative finiture, uno strumento tuttora in fase di perfezionamento, attraverso il quale possono essere apparentate/distinte per raffronto le diverse murature osservate Venezia:

\section{- Murature con elementi di reimpiego}

Nella chiesa dei Carmini non compiono elementi romani di reimpiego, che si osservano in due dei più antichi edifici della città, la chiesa di S. Giacomo dell'Orio (fig. 5) e contiguo campanile, così come nel campanile di S. Geremia. Scavi archeologici condotti nel centro storico di Venezia e in laguna a partire dagli anni Sessanta del Novecento $^{25}$ hanno permesso correlare le murature eterogenee con materiali di reimpiego all'epoca altomedioevale, penalizzata dalla difficoltà a produrre laterizi fino al XII secolo, «...forse il più difficile periodo dell'edilizia veneziana ... laterizi e pietrame infatti non erano agevolmente reperibili almeno intorno al Mille» ${ }^{26}$. La città era ancora prevalentemente lignea, come ricorda Temanza ${ }^{27}$. Mattoni e pietre caratterizzavano soltanto i principali edifici pubblici, spesso si trattava di materiali di spoglio, provenienti dai centri vicini (Altino, Malamocco, Aquileia), riutilizzati per necessità. Tuttavia non si può negare un ricorso allo spoglio sostenuto da ragioni simboliche, ${ }^{28}$ che vede questa pratica protratta, a Venezia, fino al XII secolo, quando sembrano comparire i primi elementi riconducibili a «una

\footnotetext{
${ }^{24}$ Cfr.nota n. 21

${ }^{25}$ Si fa riferimento, fra gli altri, agli scavi effettuati da Maurizia De Min nell'area della chiesa di S.Lorenzo e di quelli condotti da Ernesto Canal in laguna, in particolare nel piccolo centro monastico benedettino di S.Leonardo in Fossa Mala. In entrambi i casi è emerso come a Venezia sia prevalente, fino agli inizi del XII secolo, il reimpiego di laterizi romani, spesso anche frammentari, assemblati nelle murature insieme a pietrame minuto e calce. (Cfr. M.De Min, 2000; L. Fersuoch, 1995).

${ }^{26}$ L. Fersuoch, cit., p.36.

${ }^{27}$ "Le fabbriche pubbliche murate qui erano magnifiche, incrostate di marmo ... Ma le case dei privati generalmente erano tutt'altro; vale a dire erano quasi interamente di legname, anguste isolate...", T. Temanza, 1781, p.30.

${ }^{28}$ "A un primo periodo, in cui il reipiego ha quasi esclusiva funzione utilitaria, seguirà il progressivo riutilizzo di materiali di spoglio con connotazioni sopratutoo simboliche, alimentato dai numerosi elementi laipidei importati dall'Oriente e da Bisanzio...», F.Doglioni, F.Trovò, in F.Doglioni, G.Mirabella Roberti, 2011, p.34. Questo contributo sulle murature veneziane è un significativo compendio di osservazioni dirette e disanima di fonti indirette.
} 


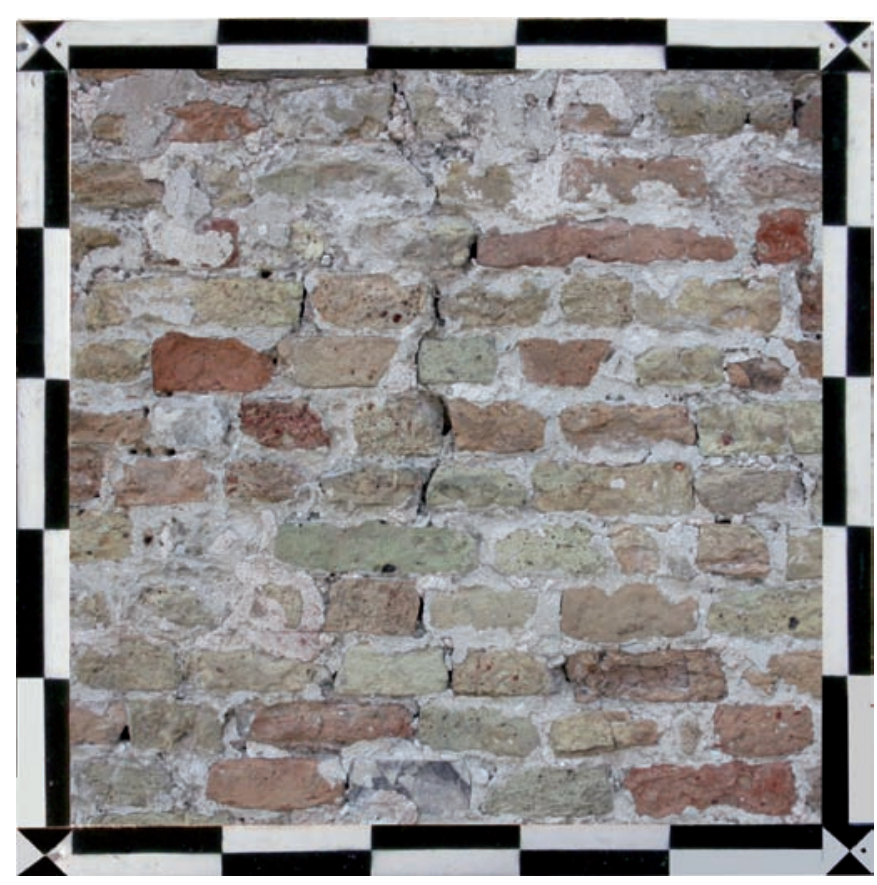

Fig. 5. Campione di muratura eterogenea con mattoni romani di reimpiego (Chiesa di S.Giacomo dell'Orio)

modesta produzione locale, circoscritta comunque a fabbriche monumentali... ${ }^{29}$, e costituita da mattoni tendenzialmente sottili e di dimensioni variabili, che spesso compaiono insieme a quelli romani di recupero.

\section{- Mattoni sottili (in due diverse classi dimensionali, valori min-max riscontrati: $\mathrm{cm} 4,5-5 \times 11 \times 22-23$; $\mathrm{cm}$ 4,5-5 x 13-14 x 28,5-30; secoli XI-XII)}

Murature contenenti i due tipi costituiscono le stratificazioni delle fasi più antiche della chiesa dei Carmini; esempi di entrambe le classi dimensionali si trovano anche in alcuni tratti di muratura nel sestiere di S. Polo (fig. 6). Non è chiaro se si tratti di due formati distinti e successivi ovvero di moduli coevi, le cui differenze possano essere imputabili alla grande variabilità dimensionale che contraddistingue le prime fasi di produzione veneziana, ancora prive di una regolamentazione, che viene attestata solo ai primi decenni del XIII secolo ${ }^{30}$. Lantichità di questi mattoni sembra avvalorata anche dalla connotazione dell'apparecchio murario che li contiene, soprattutto per la consistenza e conformazione del giunto di malta "di ascendenza bizantina» ${ }^{31}$, cioè

\footnotetext{
${ }^{29}$ M.De Min, in AA.VV., 2000, p.125.

${ }^{30}$ G. Monticolo ricorda, fra i primi documenti attestanti una produzione veneziana regolamentata, il disciplinare dei trasportatori di mattoni e coppi del 1222 e il Capitulare de fornasariis del 1229 (G.Monticolo, 1896).
}

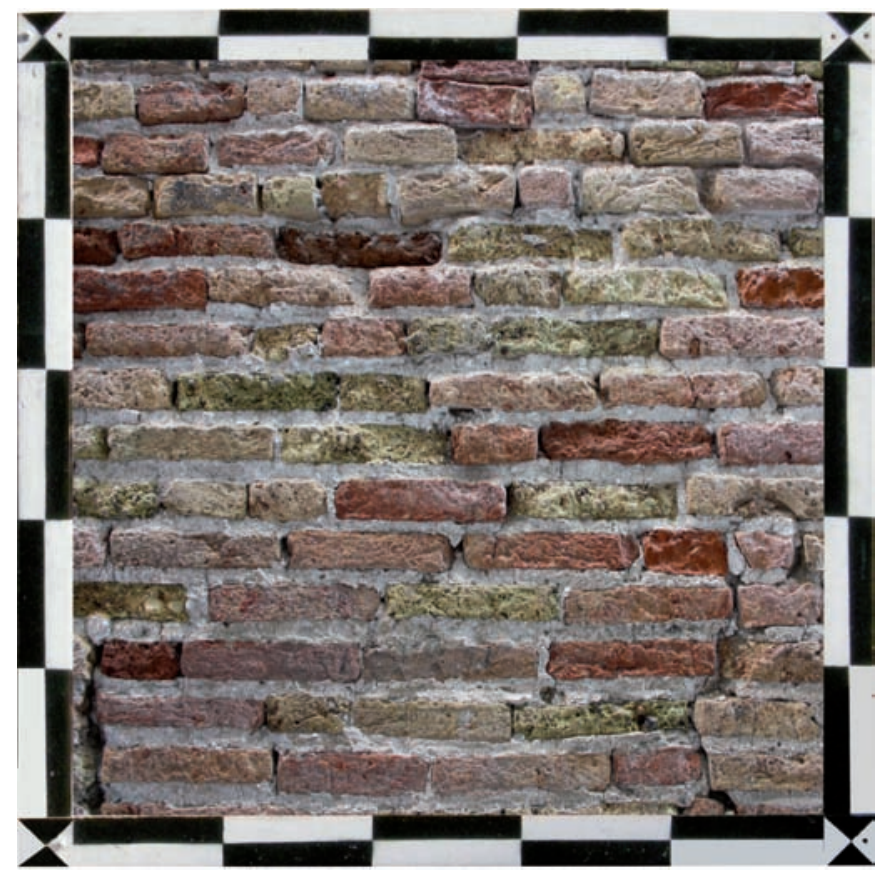

Fig. 6. Campione di muratura con mattoni eterogenei a spessore ridotto e lunghezza variabile, con giunto di spessore maggiore di $\mathrm{cm} 2$ (Edificio in calle Astori, S.Polo)

con spessore notevole, tendenzialmente maggiore di due centimetri, ancorchè variabile, adattandosi all'eterogeneità dimensionale dei mattoni utilizzati.

Anche le sequenze stratigrafiche finora osservate, per quanto insufficienti ad una collocazione cronologica certa, inducono ad apparentare entrambi i tipi di mattoni ad una fase d'uso precedente quella dei mattoni gotici (nel caso dei Carmini, per esempio, la muratura in mattoni $\mathrm{da} \mathrm{cm} \mathrm{4,7} \times$ 29 appartiene al corpo addossato in antico alla chiesa iniziale e già demolito in epoca gotica; mentre all'interno del campanile di S. Giacomo dell'Orio (sec XII-XIV ${ }^{32}$ ) si trovano mattoni di spessore ridotto e lunghezza pari a $\mathrm{cm} \mathrm{33).}$

\footnotetext{
${ }^{31}$ E' interessante il parallelo rilevato da Francesco Doglioni fra le caratteristiche tessiturali delle murature venenziane fra XII e XIII secolo - caratterizzate da un giunto di spessore estremamente elevato, dunque dalla presenza di una quantità di malta quasi equivalente a quella dei mattoni - e paramenti in mattoni in costruzioni costantinopolitane, come S.Sofia o la Torre della Porta d'Oro a Istambul (F.Doglioni, F.Trovò, cit., p.49). Si veda anche più avanti, paragrafo B Processo costruttivo.

${ }^{32}$ Fra i campanili più antichi di Venezia, quello della chiesa di S.Giacomo dell'Orio, insieme a quello di S.Geremia (XII-XIII sec.), contiene murature con elementi di reimpiego e mattoni romani; inoltre, in S.Giacomo, si osservano alcune delle tipologie murarie più antiche, come murature in altinelle (di cui è costituita anche gran parte del campanile dell'Abbazia della Misericordia) e mattoni di spessore ridotto ma con lunghezza di circa $\mathrm{cm} \mathrm{33.} \mathrm{L'osservazione}$ stratigrafica di alcuni campanili di Venezia, effettuata a campione, da chi scrive, nell'ambito della ricerca citata in nota n.8, ha permesso di ricavare alcuni dati utili ad un primo raffronto cronologico.
} 


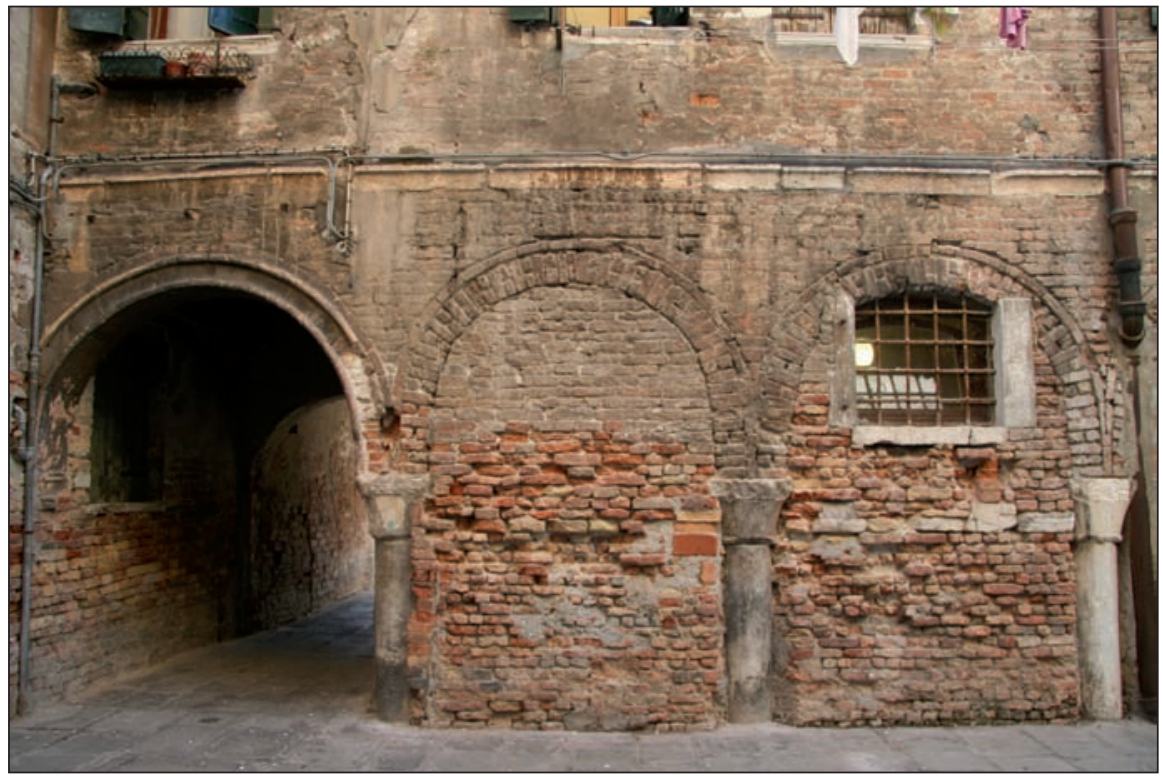

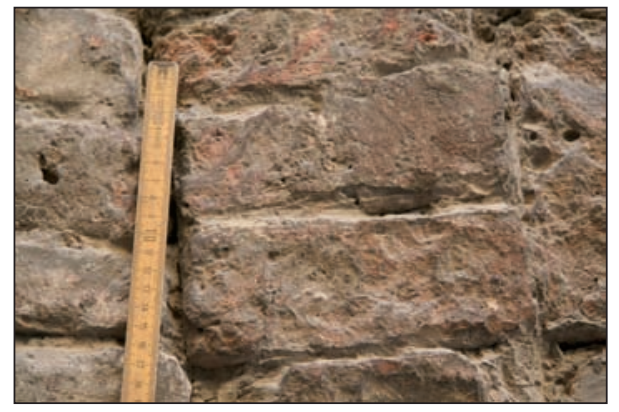

Figg. 7a-b. Corte del Fontego (sec.XII): edificio romanicobizantino con muratura mista in mattoni alti (spessore $\mathrm{cm}$ 7) e altinelle di primo impiego
Questa ipotesi è confortata dalla letteratura, che attribuisce al XII secolo la «rinascita» del laterizio, con la produzione di mattoni di spessore ridotto $(\mathrm{cm} \mathrm{4,5-5 \times 11-}$ $12 \times 22-23$, che possono talvolta raggiungere o superare anche i $30 \mathrm{~cm}$. Esemplari di questo formato, ritrovati anche nelle stratificazioni del XII secolo durante lo scavo archeologico in S. Leonardo, sono considerati «il più antico esempio di laterizio propriamente medioevale ormai scisso da radici e moduli romani ... Spesso di forma irregolare, con impasto non depurato, mal $\operatorname{cott}(\mathrm{o}) »^{33}$. La presenza di elementi delle due diverse dimensioni nelle due murature dei Carmini risalenti alla fine del XIII secolo, può essere considerato segno del perdurare nel tempo di questi formati arcaici. In particolare, il modulo più piccolo sembra confluire, per analogia dimensionale, nel minore dei formati cosiddetti «romanici».

\section{- Mattoni «romanici» (XII-XIII secolo)}

La produzione di nuovi formati non riguarda soltanto a Venezia ma tutta l'Europa, dove emergono due tipi fondamentali di mattone: quello inglese di dimensioni notevoli $\left(\right.$ Great $\left.^{34}, \mathrm{~cm} 26-31 \times 12,50-15 \times 4,5-7\right)$ e quello

\footnotetext{
${ }^{33}$ L. Fersuoch, cit., p.36.

${ }^{34}$ Il mattone inglese definito Great, che compare nel XIII secolo in East Anglia, dove fu utilizzato fino agli inizi del XVI (N. Davey, 1965, p.90) può forse essere ricondotto al Pedale ( $\mathrm{cm} \mathrm{30-35 \times 14-16 \times 6,5-7),} \mathrm{descritto} \mathrm{da} \mathrm{Tiziano} \mathrm{Mannoni}$ come nuovo modulo, distinto dal modulo romano, prodotto in Lombardia a partire dal IX secolo e destinato ad essere un riferimento, anche in altre aree, per i mattoni medioevali (T. Mannoni, 1984, p.400). Studi compiuti dall'Iscum di Genova hanno constatato la presenza di mattoni di questo tipo in complessi religiosi riconducibili al XI-XII secolo, sia in Liguria che in altri paesi europei, per
}

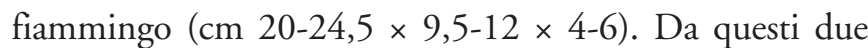
gruppi dimensionali si possono forse far derivare i mattoni veneziani definiti convenzionalmente «romanici» 35 , presenti almeno fino all'introduzione delle altinelle venete, qualche volta utilizzati contestualmente a queste ultime, nell'edilizia civile della fase di passaggio dalla città lignea alla città «petrinea». Se in molte città italiane si può attribuire il superamento del modulo romano prevalentemente alle grandi costruzioni degli ordini monastici, a Venezia sembra riconosciuto, come primo e più importante motore di una cultura costruttiva muraria, la necessità di sostituire con edifici in muratura le costruzioni in legno della città delle origini, ossia la maggior parte delle abitazioni civili, leggere e adatte al suolo lagunare ma estremamente vulnerabili al fuoco ${ }^{36}$. La riconversione edilizia fu graduale, a partire dal XII secolo, con una prima fase caratterizzata da strutture miste e poi pevalentemente in muratura, con utilizzo di mattoni romanici ${ }^{37}$, spesso mescolati alle altinelle. Come sostiene

esempio in Germania, dove questi mattoni sono chiamati Kloster Format, in quanto caratterizzano l'architettura dei monasteri. Una caratterisitca che sembra evidenziare «il ruolo svolto dal monachesimo cluniacense ... nel promuovere e incrementare l'attività edilizia. Ciò spiegherebbe la comparsa nel medesimo arco di tempo in territori anche molto distanti tra loro dello stesso modulo di mattoni..." (D. Pittaluga, 2001, p.74).

${ }^{35}$ W.Dorigo, 2003.

${ }^{36}$ La storia costruttiva di Venezia è pesantemente segnata da incendi, come quelli registrati nel 1106, 1120, 1149 e 1167 che distrussero gran parte della città, costituita prevalentemente da edifici a struttura lignea, coinvolgendo anche molte chiese, compresi S.Marco e il Palazzo Ducale (cfr. "Annales Venetici breves» a cura di H.Simonsfeld citato in G. Cracco, 1986, p. 39).

${ }^{37}$ W. Dorigo, 2003, p.115. 


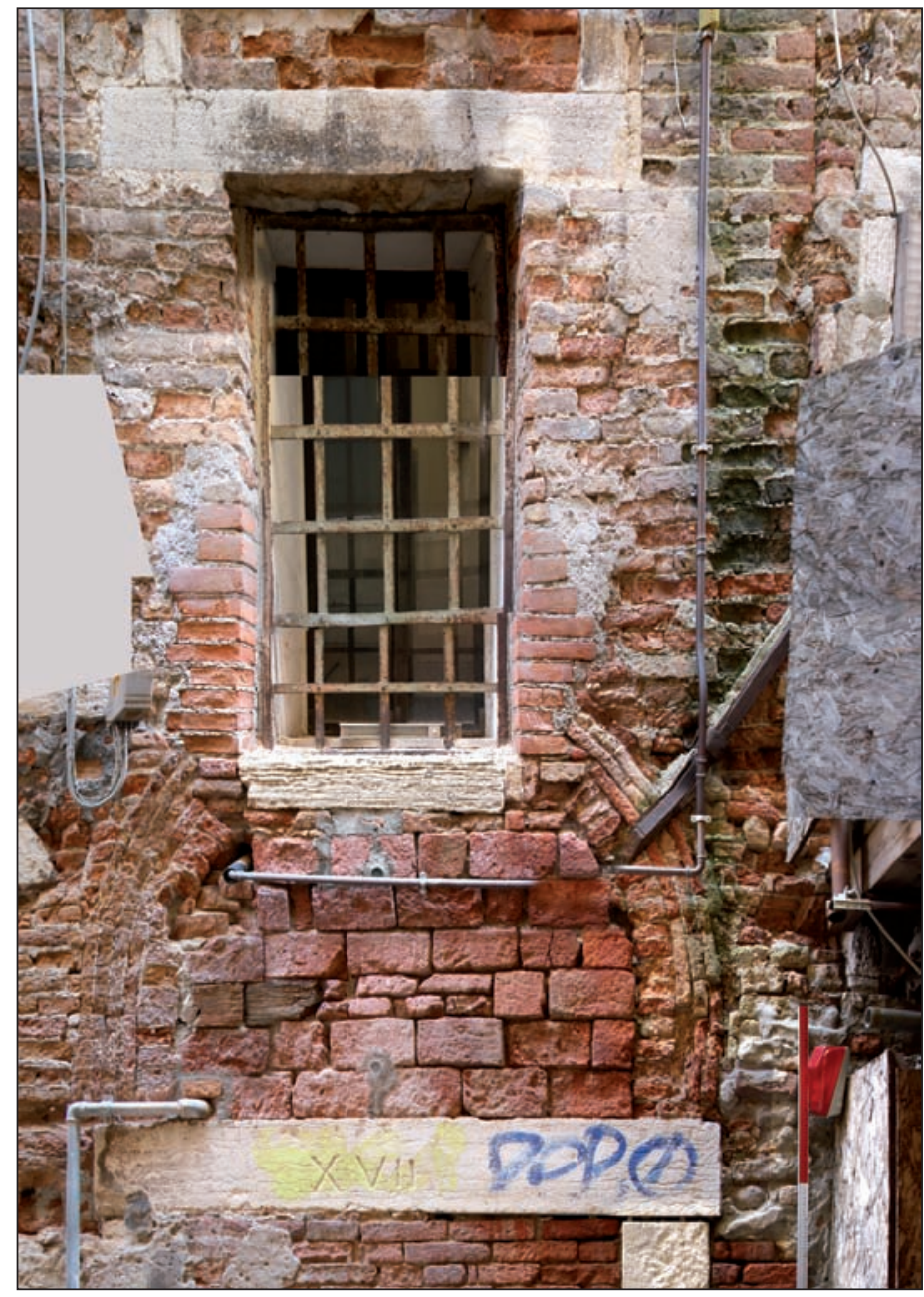

Figg. 8a-b. Calle delle Oche (sec.XIII-XIV): edificio con muratura mista in mattoni romanici grandi nelle pareti di fondo e mattoni sottili nella ghiera dell'arco (fotomosaico: arch.Michele Bondanelli)
F. Doglioni, la specificità veneziana della produzione di mattoni ad mensuram parvam, nella fase di trasformazione del tessuto urbano, può essere anche ricondotta a ragioni tecnologiche, in quanto un formato ridotto era "più facilmente adattabile a ... pannelli ...confinati e portati da strutture lignee con controventi inclinati..." ${ }^{38}$.

Tornando ai due formati romanici — dai quali si può forse far derivare la differenziazione dei mattoni successivamente prodotti e/o utilizzati a Venezia (altinelle e mattoni gotici) — si osserva, in costruzioni in muratura del XII-XIII secolo, la compresenza di entrambi in murature coeve, come quella dell'edificio in Corte del Fontego presso S. Margherita (sec. XII, Arslan, 1970. Figg. 7a-b), nei cui archi compaiono contestualmente altinelle $(\mathrm{cm}$

\footnotetext{
${ }^{38}$ F. Doglioni, F. Trovò, in F. Doglioni, G. Mirabella Roberti, 2011, p.56; "Immaginiamo un passaggio graduale nel corso del XII e XIII secolo, che si conclude sostanzialmente entro la prima metà del XIV secolo».
}

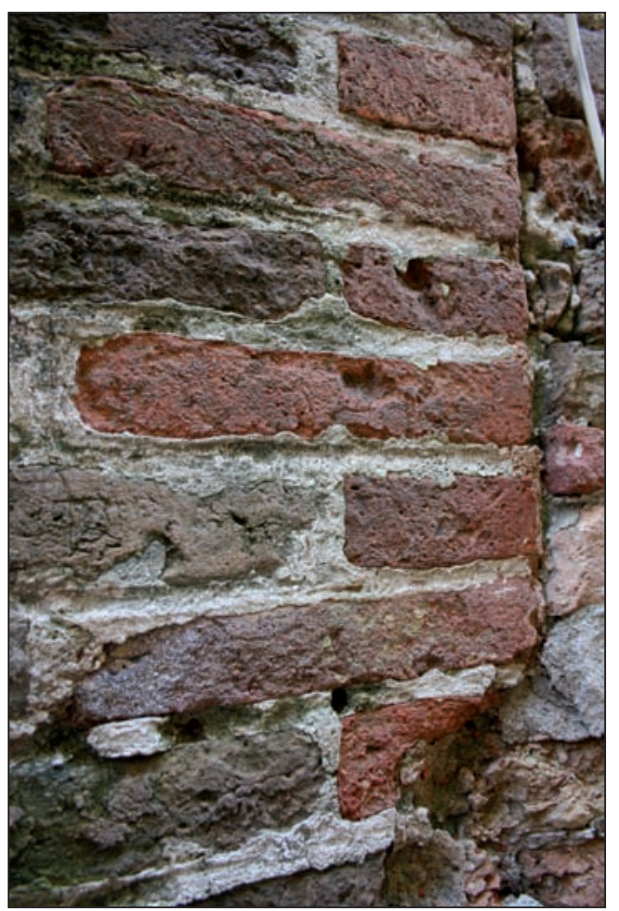

$5,5 \times 8 \times 16)$ e mattoni più alti $(\mathrm{cm} 7 \times 8 \times$ ?,tagliati della lunghezza di $\mathrm{cm} 20$ per adattarli alla misura della ghiera); mentre presso calle delle Oche (sec. XIII-XIV, Arslan, 1970, fig. 7a-b), i mattoni grandi (cm. $28 \times 12,5$ $\times 7,5)$ costituiscono il paramento e quelli sottili $(\mathrm{cm} \mathrm{5,5}$ $\times 11,5)$ la ghiera dell'arco (fig. 8a-b).

Si tratta in questi casi di un utilizzo di mattoni di spessore diverso, per ragioni di natura funzionale, per esempio per connotare archi e pavimentazioni o elementi specialistici come i camini, una pratica diffusa sia in Veneto che in altre regioni italiane, che talvolta può costituire un fattore di «disturbo" per la comprensione della cronologia dei manufatti.

\section{- Altinelle (da cm 5-5,5 x 7-9 x 16-17,5; XII-XIV/XV? secolo)}

L'origine e l'utilizzo di questi laterizi caratterizzati da dimensioni ridotte, è un tema dibattuto sin dal XVII secolo e gli studiosi risalirono all'origine romana e alla provenien- 


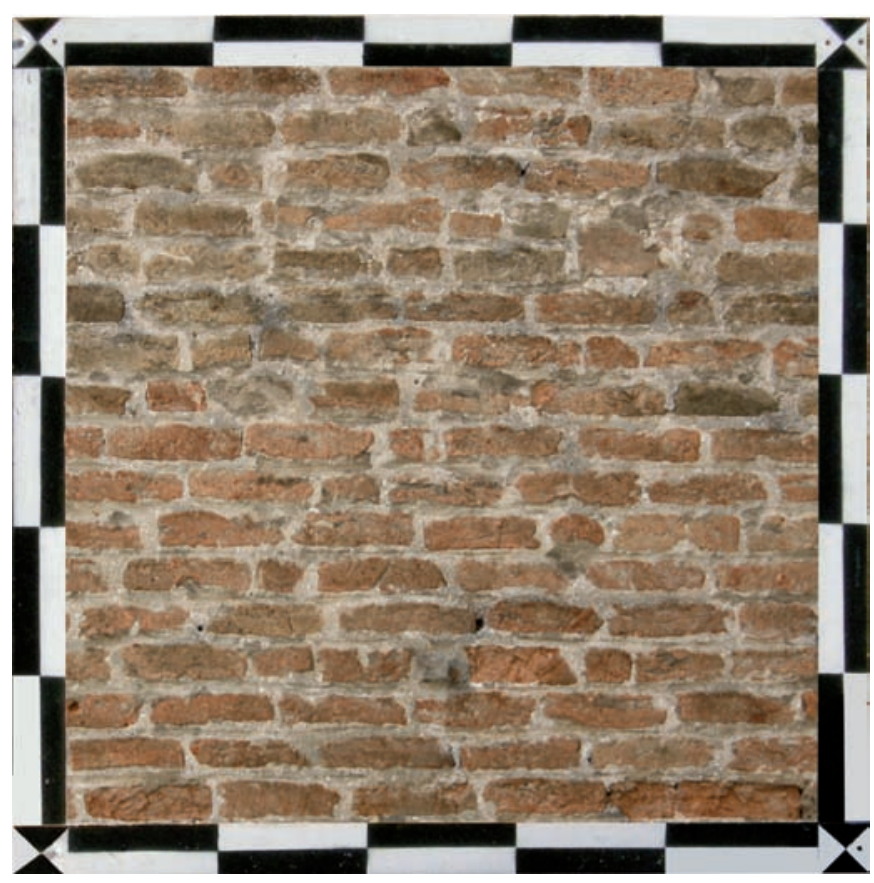

Fig. 9. Campione di muratura in altinelle (Edificio in Crosera S. Pantalon)

za da Altino, da cui derivano la denominazione, come affermano Scamozzi ${ }^{39}$ e Temanza ${ }^{40}$.

Il periodo d'uso delle altinelle è ampio e comprende fasi distinte, cui corrispondono elementi con caratteristiche compositive, dimensionali e di proveneienza differenti. La fase più remota è basata sostanzialmente sul reimpiego di altinelle romane, destinate soprattutto a pavimentazioni ma riutilizzate anche nell'edificazione, come ricordava Giacomo Boni a proposito del Fondaco dei Turchi, o Temanza in relazione alla ricostruzione della zona di Rialto dopo i grandi incendi del XII secolo ${ }^{41}$. Segue una fase di produzione veneziana - con altinelle di dimensioni maggiori rispetto a quelle romane, prodotte con argilla della laguna e non ancora dotate di omogeneità qualitativa ${ }^{42} \mathrm{e}$

39 "... una maniera di muratura di latercoletti cotti assai minori de'loro ordinarii, e lunghi un palmo e larghi per metà, come usiamo adesso nel selciare le piazze in Venezia, ma essi li facevano più sottili, i quali erano spianati e puliti da tutte le facce e da' capi, e poi messi per ordine nelle malte sottilissime, e ben retratte di corso in corso ...", V.Scamozzi, (1615), 1838, Libro terzo, pp. 342-342.

${ }^{40}$ "... gli edificj murati in Venezia nel XII, e nel XIII secolo, sono tutti, o il maggior numero, composti di pietre, che per antica denominazione si chiamano ancor Altinelle», T.Temanza, cit., p. 33.

${ }^{41}$ "(...) Quanto alle murature, gli edifici veneziani dal IX al X secolo (...) erano costruiti di grandi mattoni romani, aquileiesi, opitergini o ravennati che siano. Trovati poscia di troppo grandi dimensioni pegli usi ordinari (...) i veneziani cominciarono ad adoperare le mattonelle d'Altino, fino a tanto che in principio al Trecento incominciarono per loro conto la fabbricazione dei mattoni di modello normale (...)", G. Boni, 1887; T. Temanza, cit., pp. 33-34.

${ }^{42} \mathrm{Si}$ veda più abanti, paragrafo $\mathrm{A}$ - processo produttivo. dimensionale $\mathrm{e}^{43}$ - correlata alla necessità di garantire la completa ricostruzione della città lignea e dei primi insediamenti monastici in laguna. Il protrarsi nel tempo della produzione e utilizzo sistematico di questi piccoli mattoni è una peculiarità veneziana che, se da un lato può essere interpretata come fattore inerziale, trasferimento «di una sorta di inconscio ligneo alle costruzioni in muratura ${ }^{44}$; d'altro canto connota il periodo di prosperità seguito alla caduta di Costantinopoli e al conseguente sviluppo urbano della città mercantile in piena espansione ${ }^{45}$. Il contesto storico e sociale del momento spiega la grande richiesta di materiali da costruzione nel corso dei secoli XIII e XIV e la conseguente diffusa presenza di altinelle, non solo come elementi specialistici ma come componenti principali della compagine muraria di edifici importanti, come i fondaci e i magazzini della Repubblica ${ }^{46}$, così come si attesta al $1327^{47}$ la costruzione di fornaci pubbliche a Venezia per la fornitura dei grandi cantieri come quello dell'Arsenale o anche delle prime basiliche (ancora oggi si osservano murature in altinelle nelle chiese dei Servi e dei Carmini, per esempio). Con la diffusione dell'altinella veneta si assestava in modo sistematico la produzione locale, che giungeva, a partire dai primi decenni del XIII secolo, ad una rigorosa regolamentazione mediante normative capitolari, che definivano ruoli e doveri degli operatori, modalità e aspetti produttivi, qualità e dimensioni dei laterizi prodottii ${ }^{48}$.

\footnotetext{
${ }_{43}^{43}$ Dorigo ha distinto due principali tipi di formato: altinelle romane di dimensioni pari a cm 14,5 × 7,5 (ndr non è indicato lo spessore) $\ldots$ altinelle venete, di $\mathrm{cm} 17,5 \times 8,5 \times 4,5$ e diffuse a partire dal sec. XII di produzione veneziana "che ... sembra espressione dell'avvenuto passaggio fra l'unità di misura romana ... e ... il piede veneto (cm 34,773)» (Dorigo, 2003, p. 115). Il più articolato quadro dimensionale proposto da L.Fersuoch riconduce le differenze dimensionali alle diverse unità di misura adottate dai produttori e dunque ad una diversa area di provenienza che giustificherebbero la compresenza di lunghezze comprese tra $\mathrm{cm}$ 17,5 (metà piede padovano), $\mathrm{cm} 17$ (metà piede veneto), $\mathrm{cm} 15$ (metà piede romano) e cm 16 (metà piede bizantino) (L. Ferdsuoch, cit., p. 41). Sulla diversa provenienza dei mattoni utilizzati a Venezia nel Medioevo si segnala l'interessante studio di Floriana Marino, già citato in nota n. 16.

${ }^{44}$ F. Doglioni, F. Trovò, in F. Doglioni, G. Mirabella Roberti, 2011, p. 57.

${ }_{45}$ "Questa è la vera epoca del primo risorgimento delle nostre Arti. Le Arti sono figliuole della Ricchezza, e della Ricchezza è Padre il Commerzio... ma ci voleva non poco materiale per riedificare quasi unintera città», T. Temanza, cit., p. 33

${ }^{46}$ Sono in altinelle edifici duecenteschi come il Fondaco del Megio sul Canal Grande, e dimore private di nobili-mercanti come i Palmieri da Pesaro, in seguito divenuta Fondaco dei Turchi, cfr. E. Concina e M. Agazzi in F. Valcanover e W. Wolters, 2000, cit., pp. 131-138 e 139-156. In particolare, M. Agazzi ricorda il paramento di facciata del primo edificio, già esitente nel 1321, formato da «mattoni a vista (dalle misure $17 \times 8 \mathrm{~cm}$ )", cioè altinelle $(\mathrm{M}$. Agazzi, cit., p. 152).

${ }^{47}$ Cecchetti ricorda un decreto del Maggior Consiglio del 1327 con il quale si concede di costruire fornaci, indispensabili per la fornitura dell'Arsenale e due comunali sorgono "nella terra vuota che è dietro S.Biagio, e altrove ...", B. Cecchetti, (1845) 1980, p. 67 (vedi anche al paragrafo A - processo produttivo). ${ }^{48} \mathrm{Si}$ fa riferimento ai primi provvedimenti di istituzionalizzazione dell'attività produttiva e distributiva laterizi risalenti al 1222 e 1229 (Cfr. nota n. 30).
} 


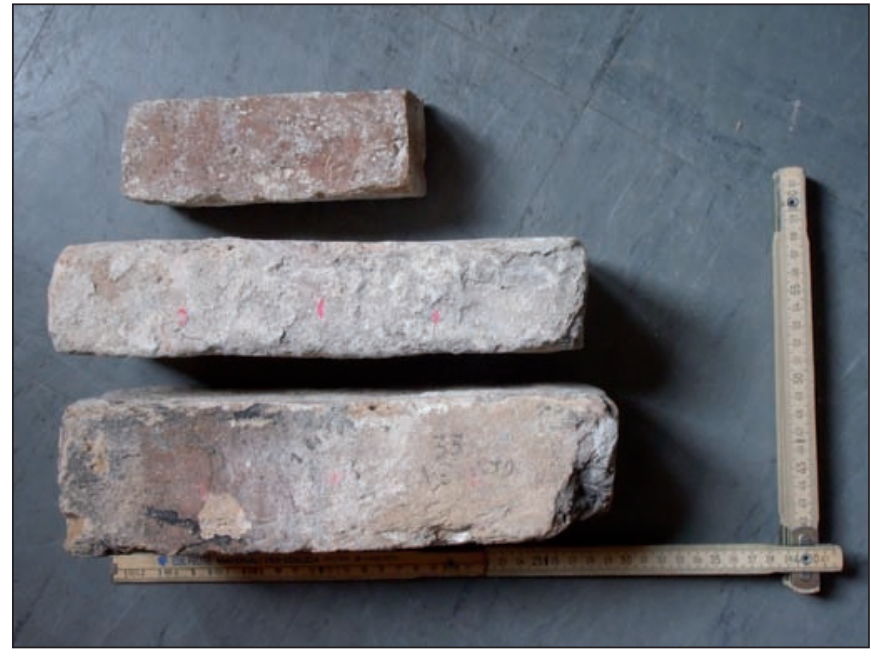

Fig. 10. I due formati diversi del mattone gotico, raffrontati con un'altinella «gotica» (di spessore pari a $\mathrm{cm} \mathrm{6)}$

Tuttavia l'inadeguatezza delle fornaci veneziane a soddisfare la richiesta di materiali, già denuciata agli inizi del XIV secolo, indusse la Repubblica a concedere deroghe alla normativa, per incentivare la produzione locale con l'apertura di nuove fornaci e la possibilità di superare i limiti quantitativi inizialmente imposti, aumentando il numero delle "cotte»" annuali consentite, ma anche consentendo l'acquisto di altinelle e mattoni provenienti dall'entroterra. Il tenore qualitativo andava comunque elevandosi grazie al capillare controllo della produzione, così come si registra un tendenziale aumento delle dimensioni delle altinelle nel tempo, con un picco nella fase finale di produzione, fra XIV e XV secolo, in cui compaiono elementi di lunghezza fino a $\mathrm{cm} 20$ e spessore analogo a quello dei mattoni gotici ( $\mathrm{cm} 6$ circa). Il ritrovamento di tratti di muratura in altinelle di questo tipo e di primo impiego in edifici databili alla prima metà del secolo XV (per es.nella cella del campanile della chiesa di S. Aponal, datata 1407), nonché la compresenza, in edifici gotici, di mattoni gotici e altinelle di spessore maggiore (o altinelle "gotiche» ${ }^{50}$ - Fig. 10) dilata l'usuale confinamento cronologico delle altinelle veneziane oltre la soglia del XIV secolo. $\mathrm{Al}$ tempo stesso sembra confermata la produzione differenziata, ma a tratti contestuale, dei due principali formati medioevali veneziani, l'altinella e il mattone cosiddetto «gotico».

${ }^{49}$ Cfr. G. Caniato, M. Dal Borgo, 1990.

${ }^{50}$ L'impiego contestuale di mattoni gotici e di questi laterizi di dimensioni massime non superiori ai $10 \times 20$ centimetri ma con spessore pari a 6 centimetri sembra una pratica poco diffusa, un esempio è cositutito da un palazzo gotico in campo Nazario Sauro.

\section{- Mattoni gotici (cm 6-7 x 13-13,5 x 26-27, sec. XIV-XV)}

La produzione contestuale di mattoni gotici e altinelle nel corso del XIV secolo sembra attestata dalla già citata deliberazione del 1368, che rivela una specializzazione produttiva in base alla quale si differenziano, «lapides cocti ad mensura parvam» e «lapides cocti ad mensuram magnam», di cui vengono stabiliti distintamente $i$ prezzi $i^{51}$. Lo stesso documento menziona i distretti di Mestre e Treviso come ulteriori luoghi di provenienza dei mattoni.

Il mattone gotico risulta quindi introdotto a Venezia a partire dal Trecento, e sembra correlato alle necessità costruttive delle grandi dimore nobiliari, nonché delle chiese degli ordini mendicanti, per quanto l'osservazione stratigrafica confermi la preesitenza di parti in altinelle in alcuni dei principali edifici religiosi, come le già citate chiese dei Servi e dei Carmini, olte che nell'abside della chiesa dei Frari, per il resto costituita interamente da mattoni gotici. Se l'architettura monumentale ha sicuramente contribuito alla diffusione del mattone di grande formato, una più generale causa di sviluppo di questo tipo è legata a un mutamento di tipo tecnologico, che ha portato all'abbandono delle grandi compagini murarie di ascendenza romana e bizantina a favore di strutture più snelle e meglio intessute, dunque più adatte al suolo lagunare, mediante «una pratica semplificata delle strutture murarie («murus de duabus petris»), condotta sempre più spesso sullo spessore di $\mathrm{cm} 52$ (un piede e mezzo), al posto delle precedenti di $\mathrm{cm} 69,5$ (due piedi) dell'età romanica tarda e dell'età proto gotica, e delle più antiche di $\mathrm{cm} 59$ (due piedi romani) ${ }^{52}$.

Analogamente a quanto osservato per le altinelle, a Venezia si trovano due varianti distinte del formato gotico, collocabili, in base ad osservazioni stratigrafiche, in una sequenza cronologica relativa. Per esempio, nella chiesa dei Frari i mattoni più antichi hanno dimensioni pari a cm 6$7 \times 12-12,5 \times 26,5-27$, mentre nelle cappelle successive compaiono elementi di dimensioni superiori $(\mathrm{cm} \mathrm{7-7,5 \times}$ 13-14 $\times 27,5-29)$. Mattoni con misure analoghe sembrano sistematicamente presenti in edifici tardo gotici (Palazzo Zaguri, 1425; Palazzo Nani Mocenigo, 1460-70, cfr. Arslan, 1970).

\footnotetext{
${ }^{51}$ "Et similiter omnes lapides cocti ad mensuram magnam vel parvam districtu de Mestre predictam qui conducentur Venecias de tota Marchia Trevisana non possint vendi ultra precium ultra scriptum (...)", ASVe, Quarantia Criminale, parti 1347 1475, registro 16, 21 giugno 1368, da F. Marino, cit. (cfr. nota n. 16).

${ }^{52}$ W.Dorigo, cit., p.115. Si veda anche, più avanti, al paragrafo B - Processo costruttivo.
} 


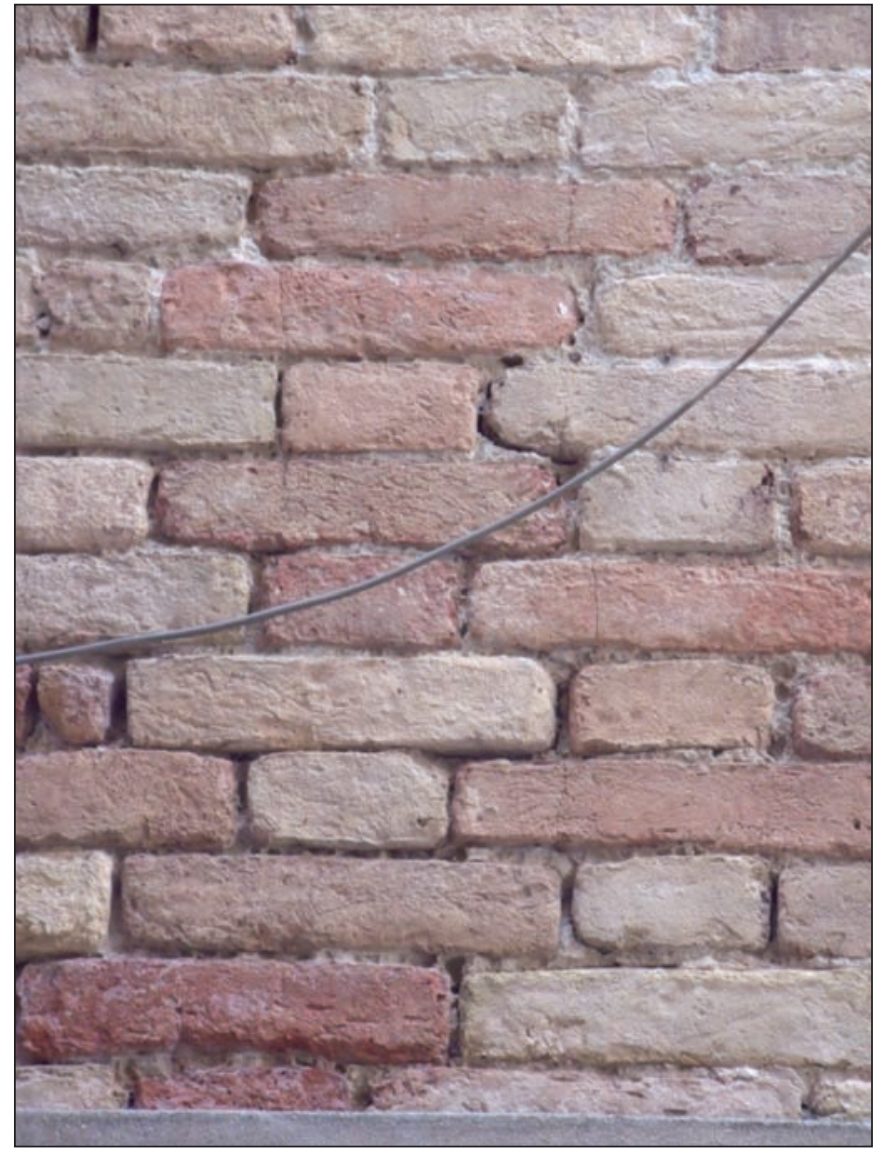

Fig. 11. Venezia, palazzo Molin a S.Maurizio: muratura in mattoni tardo gotici grandi e tessitura regolare «alla gotica»

Se nella chiesa dei Carmini non compaiono mattoni gotici grandi di questo tipo, tuttavia il colore varia e nelle murature più antiche, che compongono i diversi cantieri dell'ampliamento gotico prevalgono mattoni di colore chiaro-limonitico (mattoni albasi), mentre nell'abside, presumibilmente riconducibile alla fine del XV secolo, compaiono elementi più cotti, di colore rosso e bruni. Una caratteristica che potrebbe essere indice di procedimenti di cottura perfezionatisi nel tempo, o di forniture differenziate. Mentre si può escludere in questo caso una policromia intenzionale (peraltro presente a Venezia in edifici più antichi, per esempio $S$. Fosca a Torcello e nel caso più noto della chiesa di S. Zaccaria), in quanto le differenze cromatiche qui non assumono la forma fasce o ricorsi, né connotano angolate, cornici o elementi architettonici definiti; si tratta di unità stratigrafiche murarie riconoscibili costruttivamente come «bancate» o cantieri successivi, evidentemente caratterizzati da materiali di diversa provenienza.

Come è già stato notato, i mattoni gotici sono spesso associati a forme di rivestimento parziale, cornici ad intonaco decorato o intonachini a finta cortina (in effetti presenti nell'abside dei Carmini) e "viene il dubbio che la scomparsa tra XV e XVI secolo di questi paramenti a grandi laterizi sia da collegare al diffondersi, proprio in quel lasso di tempo, degli intonaci a strato consistente, più diffusamente coprenti, che non richiedevano più un paramento accuratamente posato e rifinito.... ${ }^{53}$.

\section{- Mattoni di cm 5-5,5 x 12 x 23-24,5 (dal xVI secolo, fino alla stabilizzazione delle dimensioni sul modulo di produzione industriale)}

Le dimensioni del mattone gotico non vennero più eguagliate e, anche a Venezia come nel resto d'Italia, si assiste ad una tendenziale diminuzione dei formati dal Medioevo verso l'epoca moderna ${ }^{54}$, con affermazione di formati compatibili con il tipo fiammingo, diffuso e smerciato in tutta Europa sin dal XIII secolo, il cui modulo dimensionale sembra ricomparire nelle costruzioni venenziane del XVI secolo. Nella chiesa dei Carmini, per esempio, le paraste della facciata cinquecentesca, con mattoni di $\mathrm{cm}$ 5,5-6 $\times$ $12 \times 24,5$, rispondono a questo tipo ma non si tratta già più di mattoni destinati a rimanere a vista, data la presenza di lacerti di intonaco a cocciopesto e marmorino che, presumibilmente, rivestivano la facciata nella configurazione acquisita con gli interventi del XVI secolo. In attesa di ulteriori riscontri, che richiedono un avanzamento della ricerca, non sembra metodologicamente corretto contemplare per il momento questi mattoni nell'insieme delle murature medioevali a vista, oggetto d'interesse di questo studio.

I dati fin qui raccolti confermano una certa inerzia nell'uso dei diversi formati nel tempo, con frequente compresenza, per utilizzo contestuale di mattoni di dimensioni differenti di primo impiego, ovvero di mattoni rispondenti, al netto di scarti dimensionali, al modulo dimensionale in uso a Venezia ma provenienti da altri luoghi e dunque dotati di differenti impasti e/o lavorazioni. Una consuetudine che conferma produzioni articolate che ampliano il panorama dei mattoni antichi presenti a Venezia, con una "gamma di dimensioni, ognuna delle quali dovrebbe poter essere ricondotta al proprio contesto di produzione, che tuttavia non è noto a priori ${ }^{55}$ ». Sul piano dimensionale, inoltre, è stata osservata la presenza di

\footnotetext{
${ }^{53}$ F. Doglioni, F. Trovò, in F. Doglioni, G. Mirabella Roberti, 2011, p. 58.

${ }^{54} \mathrm{La}$ tendenziali diminuzione delle dimensioni nel tempo è stata già rilevata a Genova, Pisa, Venezia (cfr. Mannoni, 1984). La diminuzione dimensionale a Venezia è indicata anche da F. Varosio, 2001, p.55.

${ }^{55}$ F. Doglioni, F. Trovò, cit., p. 38.
} 
"più cicli di incremento e decremento delle misure»" ${ }^{56}$ nell'arco compreso fra il XII e il XVI secolo, ossia alcune dimensioni sono compatibili con più epoche (per esempio i mattoni di spessore superiore ai 7 sono presenti in edifici romanico-bizantini ma misure analoghe caratterizzano anche il mattone gotico tardo; mentre la lunghezza compresa fra i 22 e i 24 centimetri connota sia i mattoni sottili del XIII secolo, che quelli osservati nelle murature costruite a partire dalla prima metà del Cinquecento.

Per questi motivi, benchè i dati finora raccolti sollecitino, se non altro, l'impostazione di un tracciato mensiocronologico (finalizzato alla formazione di curve ad hoc per altinelle e mattoni), tuttavia si ritiene prematura una proposta, allo stato attuale di questa ricerca, poiché la validità del riferimento dimensionale, che resta fondamentale per la datazione, può essere confermata soltanto da ulteriori sforzi, volti a identificare composizione, provenienza e quant'altro utile a «a dipanare l'intreccio ... estremamente complesso, tra formati, epoche e luoghi di produzione ${ }^{57}$. Questo richiede, da un lato, l'apporto di competenze specialistiche, con analisi comparate delle argille e ulteriori indagini dirette e documentali; dall'altro, occorre precisare meglio la natura dei materiali murari direttamente osservati, identificando parametri, non strettamente dimensionali, utili a descrivere le diverse caratteristiche di lavorazione, finitura superficiale e altri elementi distintivi, come tracce e segni, che diventano indizi in base ai quali si può provare a risalire al contesto produttivo, costruttivo e temporale del manufatto.

Lo studio qui di seguito riportato rappresenta un primo tentativo in questo senso, volto a identificare parametri di caratterizzazione delle superfici, utili al riconoscimento dei diversi tipi di laterizi, ripercorrendo a ritroso la sequenza di formazione delle murature a vista, osservate a Venezia.

\section{LA CARATTERIZZAZIONE DI SUPERFICIE DELLE MURATURE A VISTA COME SEQUENZA DI FORMAZIONE}

Una riflessione sull'aggettivazione «a vista» induce, da un lato, a ricondurre la qualificazione di un paramento in mattoni all'origine del processo produttivo dei laterizi

\footnotetext{
${ }^{56}$ Ibidem, p. 40.

${ }^{57}$ Ivi. «Emerge da queste considerazioni come per la conoscenza del laterizio a Venezia sia opportuno non tanto ricercare una singola misura di riferimento per ciascuna epoca, quanto le diverse misure compresenti in un dato periodo o arco temporale; una volta individuate per dimensioni, lavorazione e impasto le tipologie riconoscibili di laterizi, si potrà cercare di seguire la storia di ciascuna di esse, anche sotto l'aspetto dimensionale» (p. 47).
}

stessi, con la scelta iniziale delle argille che contribuisce a determinare consistenza, colore, omogeneità dell'impasto $\mathrm{e}$, insieme ad altri fattori legati al processo produttivo, le principali caratteristiche fisiche e formali del prodotto finale.

D'altro canto si devono coinvolgere nell'accezione di paramento in mattoni a vista anche tutti i trattamenti della superficie laterizia che vengono effettuati a scopo protettivo o decorativo dopo la fase costruttiva della muratura, (trattamenti protettivi, velature semi-coprenti, scialbi e intonaci sottili coprenti).

Il muro a vista presenta quindi una sequenza di formazione che comprende diversi processi ed inizia con la serie di lavorazioni degli impasti — prima e/o dopo la cottura- (A: processo produttivo), per perfezionarsi successivamente con le vere e proprie fasi costruttive della muratura e di lavorazione-rilavorazione di laterizi e giunti dopo la posa (B: processo costruttivo); ed infine giungere a completamento con i trattamenti e i cosiddetti rivestimenti "parziali», che consentono la percezione della muratura sottostante, assecondandone le irregolarità che pure intendono attenuare (C: processo/i di finitura).

L'analisi di singole caratteristiche formali o singole lavorazioni non consente una qualificazione completa del paramento a vista, per la quale, invece, sembra necessario risalire, attraverso il riconoscimento e l'interpretazione di una seie di segni osservabili sulle superfici, le fasi di una processualità operativa e temporale, fatta di lavorazioni concatenate in una successione precisa e dotate di variabili connotanti. Il muro a vista è di solito, non sempre, il risultato di una filiera e sequenza produttiva e di lavorazioni finalizzata, cioè indirizzata sin dall'inizio ad ottenere un paramento regolare, sia per omogeneità dimensionale e di caratteristiche fisiche dei mattoni, che per accuratezza di conformazione e lavorazione del giunto di malta ma anche, infine, per la presenza di lavorazioni di superficie, cromie e trattamenti a rivestimento parziale.

Così, il prodotto finale presuppone sempre le fasi intermedie propedeutiche alla finitura ultima a rivestimento parziale, indipendentemente dal fatto che le superfici infine la ricevano o meno; in quest'ultimo caso, cioè quando il paramento raggiunge solo la fase intermedia e rimane privo del rivestimento ultimo, esso già presenta valenza connotante e la dignità di superficie finita, per l'accuratezza con cui tutte le operazioni delle fasi produttiva e costruttiva precedenti sono state concepite. E' proprio questa intenzionalità $a b$ origine che connota le murature antiche a vista, e che si percepisce nell'osservarne anche solo modesti lacerti. 
Qui di seguito sono riportati i risultati di un primo tentativo di qualificazione degli aspetti tecnologico-costruttivi generali e delle specificità delle murature a vista di Venezia, basato sullidentificazione di caratteri e segni riconoscibili sui campioni di paramenti osservati, che sono stati ricondotti alle tre fasi di formazione (produttiva, costruttiva, di finitura), anche con l'apporto di fonti indirette e manualistica specifica.

Questi caratteri, risultanti dalla sequenza di formazione - cui si aggiunge un insieme di segni, impronte e tracce non sempre intenzionali, che tuttavia possono rivelare particolari condizioni di lavorazione o eventi che hanno condizionato la costruzione e/o le trasformazioni del muro stesso- diventano i parametri utilizzati per il riconoscimento e la descrizione dei paramenti.

Si ritiene che una sorta di codifica di questi parametri possa essere funzionale alla comprensione delle murature a vista e confluire in un più ampio e complesso sistema conoscitivo e mensiocronologico.

\section{A - Processo produttivo}

Sono riconducibili alla fase produttiva i dati relativi all'origine, alle caratteristiche fisico-chimiche, compositive, cromatiche e di lavorazione delle principali componenti costitutive del muro, mattoni e malta.

Se il colore del laterizio dipende in parte dall'impasto e in parte dal processo di $\operatorname{cottura}^{58}$, (fig. 12) il primo fattore è condizionato prevalentemente dal diverso tenore di biossidi di ferro contenuti nelle argille, che distinguono i depositi di materiali argillosi (depositi alluvionali, con argille grigie o brune; sedimenti marini o argille azzurre; giacimenti eluviali di colore rosso-aranciato) e conferiscono il colore rosso al mattone cotto.

Venezia, dopo il periodo di reimpiego di materiale romano proveniente da diversi centri dell'entroterra ( $\mathrm{cfr}$ nota n. 41), ebbe nella laguna il principale bacino di approvvigionamento di argilla, nella prima fase di produzione autoctona di mattoni, costituiti da «creta della laguna». Con questo termine si può identificare il caranto $0^{59}$, un'argilla compatta, che costituisce il sedimento sovraconsolidato di parte del suolo di Venezia, affiorante nelle parti occidentali della laguna e nel centro storico. La vicinanza dei bacini di approvvigionamento e una discreta plasticità, che rende il caranto adatto alla produzione di

\footnotetext{
${ }^{58}$ Nelle pagine successsive si fa riferimento anche agli aspetti cromatici legati alla cottura o ad altri fattori che incidono sul colore finale del laterizio.

${ }^{59}$ «... una formazione limosa, limoso-sabbiosa compatta e pressoché impermeabile che «si presenta come un sedimento molto duro e compatto, di colore variabile dal marrone chiaro al grigio chiaro, con striature color ocra ... contenente anche noduli calcarei. (da sito Arpav, "Suolo Veneto»).
}

laterizi, hanno indotto ad utilizzare questo materiale, soprattutto nelle prime fasi di produzione locale. Non a caso, nel sestiere di Dorsoduro, il cui nome deriva proprio dalla natura carantosa del suolo, si attestano alcune delle più antiche fornaci veneziane.

L'approvvigionamento nella zona lagunare è proseguito ben oltre il periodo di esordio della produzione locale, come testimonia la decisione del Senato Veneto, nel 1339, di imporre ai fornaciai veneziani di rifornirsi presso Punta Lovi (Puncta canetorum), che dalla zona di Fusina si estendeva verso $S$. Marta ${ }^{60}$. Una consuetudine prolungatasi nel tempo, se lo stesso Vincenzo Scamozzi, fece riferimento alla "creta della laguna...netta e gentile e di buon nervo" che si estraeva dalle "paludi di Venezia, come Marghera, e dove si dice Tessera e Tombello» ${ }^{61}$.

La presenza di caranto nei mattoni più antichi prodotti a Venezia è suggerita dall'osservazione di numerosi inclusi nodulari e impurità nell'impasto, una peculiarità di questo tipo di argilla, ma anche indizio di un processo tecnologico non perfezionato, che caratterizza tutti i mattoni della prima produzione veneziana, come peraltro già ricordava Sagredo, a proposito delle più antiche altinelle osservate a Venezia, «l'argilla della quale sono formati non è bene manipolata ... ed hanno segni di quella concrezione cretacea che noi diciamo caranto» $^{62}$. E come confermano osservazioni dirette e analisi più recenti, come i ritrovamenti durante gli scavi archeologici condotti a S.Leonardo in Fossa Mala (cfr. L. Fersuoch, 1995, p. 39), che denotano una generale insufficiente lavorazione delle argille nei mattoni prodotti nella fase di transizione fra l'epoca di reimpiego di materiale romano a quella di nuova produzione locale (secoli X - inizio XII).

L'importanza della lavorazione dell'impasto sembra confermata infine da alcune analisi di laboratorio eseguite su altinelle di produzione veneziana e di diversa epoca. Pur avendo una composizione simile, le altinelle analizzate sono risultate molto diverse in termini di qualità e prestazioni, a causa di un diverso processo tecnologico di lavorazione delle argille (oltre che di cottura), in un caso «...ben stagionate, forse battute depurate», nell'altro "...ricche di noduli non disgregati ..." ${ }^{63}$.

\footnotetext{
${ }^{60}$ G. Fazio, S. Hreglich, L. Lazzarini, U. Pirredda, M. Verità, «Le altinelle a Venezia", in AA.VV., Il mattone di Venezia, 1982.

${ }^{61}$ V. Scamozzi, cit., p. 239. La debolezza di questo materiale risiede, secondo Scamozzi nella scarsa resistenza alle intemperie: «i lavori di terreno carantoso e ciottoloso quando sentono 'umidità ... le pietruzze già cotte ... si spezzano e fanno delle scaglie ... non si debbono fare né tegole né ... altra cosa che abbia a stare allo scoperto", V. Scamozzi, op. cit., p. 248.

${ }^{62}$ A. Sagredo, 1856, p. 78.

${ }^{63}$ G. Fazio, S. Hreglich, L. Lazzarini, U. Pirredda, M. Verità, in AA.VV., 1982, p. 254.
} 
Un impasto omogeneo è indice di una tecnica produttiva ben sviluppata; il processo produttivo del laterizio comprende infatti fasi che vanno dalla cernita del materiale in cava, estrazione, deposito con «ibernazione» o «estivazione» dell'argilla, in modo da ridurne la compattezza (in caso di argille troppo plastiche) e renderla friabile - operazioni già indicate da Rusconi in una citazione vitruviana - e lavorazioni preliminari delle argille, la disgregazione delle zolle, la setacciatura, l'irrorazione con acqua e la battitura con un ferro per eliminare le bolle d'aria, fino a formare una pasta uniforme e lavorabile, eventualmente aggiungendo sostanze smagranti inerti come quarzo e frammenti di laterizio (per ridurre il ritiro), paglia per aumentare il carattere colloidale dell'argilla, o smagranti fondenti per abbassare la temperatura di fusione ${ }^{64}$.

Un sensibile incremento nella qualità dei laterizi veneziani è dovuto all'introduzione, sin dal XIII secolo di un corpus legislativo e normativo, applicato da apposite magistrature e costituito da più di cinquanta statuti dell'arte o capitolari, redatti fra il 1219 e il $1270^{65}$. Ai fornaciai veneziani venivano imposte le misure dei moduli dei diversi tipi di laterizio ma anche i tempi di lavorazione delle argille (in estate) e di cottura (d'inverno); ai trasportatori di mattoni il controllo della qualità del prodotto distribuito; così come la consorteria dei calcineri, documentata dal XV secolo, regolamentava la qualità della calce (tempi di produzione - in primavera e autunno, mediante cottura nelle calchere- di spegnimento e stoccaggio), unità di misura e modalità di fornitura; addirittura venivano imposti determinati tragitti da rispettare per condurre la calce dai depositi, collocati alle Zattere, ai cantieri edili della città ${ }^{66}$.

Questa regolamentazione si tradusse in una maggior omogeneità compositiva, cromatica e dimensionale, che caratterizza altinelle e mattoni tre e quattrocenteschi; per quanto, l'apertura al rifornimento presso la terraferma, di cui si ha notizia nel corso del XIV secolo, abbia comportato un articolarsi del mercato con conseguente presenza di materiali eterogenei per provenienza, come ricorda Francesco Doglioni, citando il Capitolare de Fornaciariis del

\footnotetext{
${ }^{64}$ U. Menicali, 1972.

${ }^{65}$ "... la storia veneta accenna già alle Consorterie verso la metà del secolo X ... Le istituzioni romane portate fra le isole della laguna, col tempo si adattarono ai nuovi bisogni, e nel trecento e nel quattrocento si ordinarono con intenti speciali e con ispeciali statuti che ebbero nome di Mariegole, dall'antico Matricula (nota: Il Sagredo ... accetta invece la spiegazione di madre regola)», P. Molmenti, 1880, p. 70. Molte consorterie furono sciolte nel XVIII secolo.

${ }^{66}$ A.Sagredo, 1856. Vedi anche G.Caniato, M. Dal Borgo, 1990.
}

1368, dal quale si evince che «i mattoni ad mensuram parvam sono fatti in primo luogo a Venezia, ma anche nel distretto di Mestre, oltre che nella Marca Trevisana, i mattoni ad mensuram magnam non sono cotti a Venezia, ma solo nel distretto di Mestre e nella Marca.... Da Loreo ... in prossimità di Padova, sono portati a Venezia lapides cocti ... di misura intermedia» ${ }^{67}$.

Una varietà rilevata da Francesco Sansovino, quando indicava che "i mattoni ò pietre cotte, e le calcine ci vengono da $i$ territori di Padova, di Treviso, e di Ferrara, ma le più lodate sono quelle del Padovano ... Le harene si hanno dalla Brenta, e dal Lido, ma la dolce è migliore ....." ${ }^{68}$. Un "terreno ... ben macerato", ossia un'accurata lavorazione dell'impasto risulta essere un requisito importante per la qualità finale del mattone, dato che la resistenza finale del mattone viene condizionata dalla presenza di eventuali impurità non eliminate da una prolungata stagionatura dell'argilla, e di inclusi come detriti vegetali, resti fossili e livelli sabbiosi, benché in certa misura alcuni di questi elementi possano svolgere la funzione di additivi utili a conferire struttura all'impasto o limitare fenomeni di ritiro, come ribadito nella manualistica secentesca ${ }^{69}$.

Scamozzi sembra testimoniare la continuità nel tempo dell'utilizzo di bacini di rifornimento nei dintorni di Venezia ${ }^{70}$, oltre che l'avvenuto perfezionamento tecnologico dei laterizi contenenti caranto, grazie alla pratica della correzione degli impasti ${ }^{71}$.

\footnotetext{
${ }^{67}$ F. Doglioni, F. Trovò, cit., p. 44 e nota n. 46. Doglioni fa riferimento a una deliberazione del Maggior Consiglio del 1327 (p. 42) come prima testimonianza di trasporto a Venezia di materiali prodotti nell'entroterra, in deroga alle norme allora in vigore. In seguito è citato il Capitolare de Fornaciariis del 1368, dal quale si deduce la provenienza di altinelle e mattoni utilizzati allora a Venezia (cfr. nota n.51).

${ }^{68}$ F. Sansovino, 1581, p. 383

${ }^{69}$ "Gioverà pure mescolare nella creta resche di canape o paglia minuta ... perché le daranno tenacità e corpo ... acciò l'aria li rasciughi meglio", V. Scamozzi, «Della natura delle crete e varietà de' colori d'esse: e dove propriamente si trovano; e quali siano le migliori per fare le pietre cotte», L. II, Cap XIV, p. 245. ${ }^{70}$ "specialmente da un canto e dall'altro della Brenta per lo spazio di venticinque miglia da Padova e Venezia ... laonde al presente vi sono molte fornaci, dove si cuociono $i$ migliori mattoni che si adoperino nelle fabbriche di Venezia", V. Scamozzi, cit., pp. 237-39.

${ }^{71}$ "I lavori di terreno cretoso molto forte quando si mettono nelle fornaci ... si torcono e si rompono ... restano però molto frangibili ... nel murare non fanno molta presa ... non sono molto porosi. Hanno però questo benefizio, che resistono alla tramontana ed ai ghiacci ... sono migliori ne’ fondamenti, ... non lasciano così trapassare le acque ... (Con) terreno cretoso dolce ... i lavori vengono molto belli ... e dopo cotti rimangono leggieri ... nel murare ricevono assai bene le malte, e fanno grandissima presa per le porosità .... Hanno però questo di contrario, che ... sono corrosi e mangiati dall'aere di tramontana e dai ghiacci ... e perciò è molto bene il metterli in opera nelle volte e nelle mura ed altri luoghi al coperto. ... La creta molto forte, e quella che tiene del caranto, ciò̀ con qualche sassolino ricerca molta macerazione, $e$ vuol essere ben lavorata e maneggiata; e però è bene addolcirla con l'argilla, o terreno più dolce...", V. Scamozzi, cit., pp. 247-48.
} 


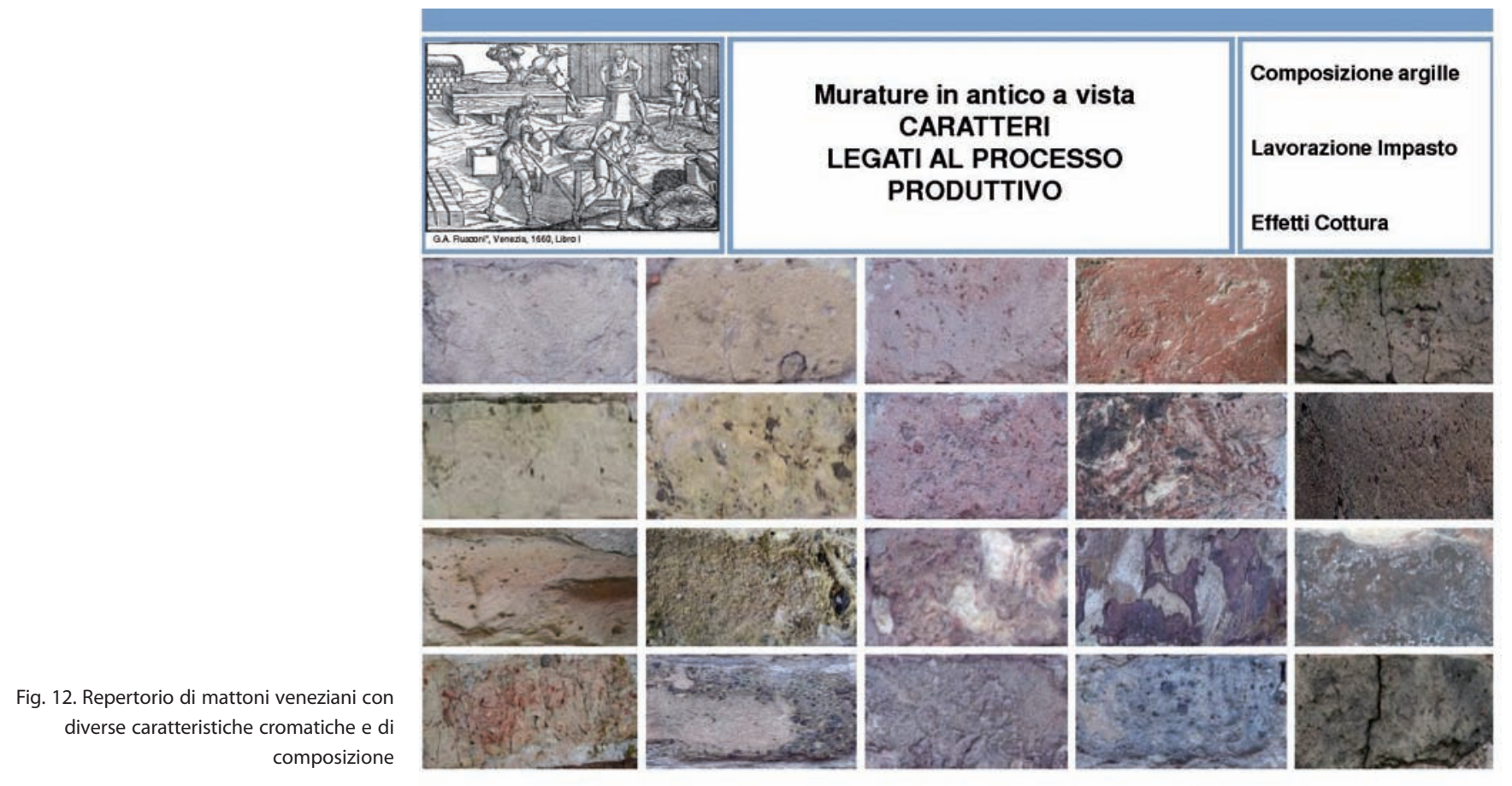

Fig. 13. Repertorio di segni e impronte lasciate sui mattoni dal processo produttivo
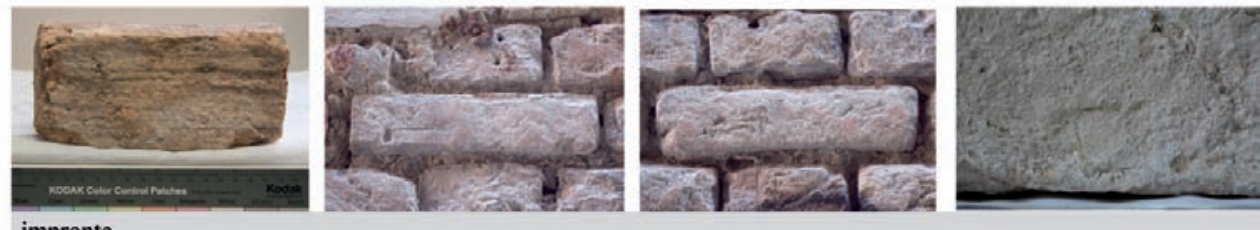

impronte
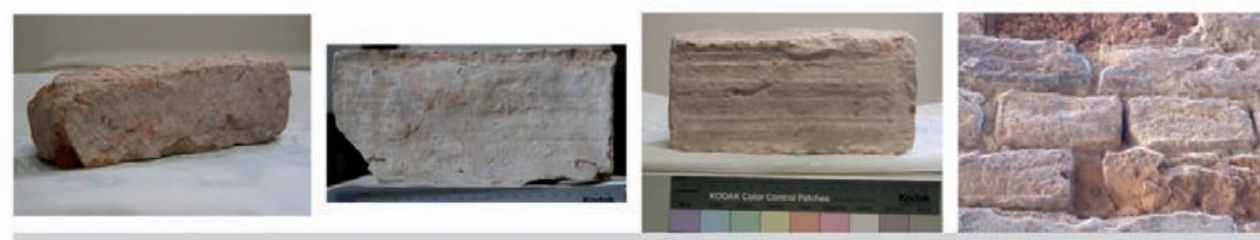

Segni dovuti alle caratteristiche dello stampo
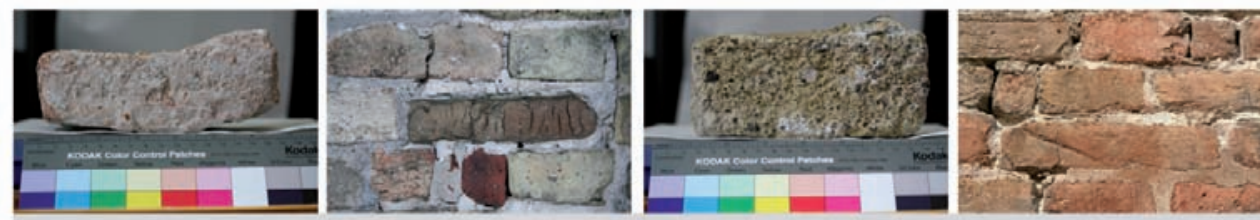

deformazioni e tracce riconducibili all'impasto e a operazioni di essicazione, cottura

\section{- Foggiatura ed essicazione dei mattoni}

Se il formato è la caratteristica principale del mattone, la foggiatura è la prima fase di una serie di lavorazioni, che avvenivano nel periodo primaverile e fino all'autunno, con una produzione di circa 700-800 mattoni al giorno. Effettuata manualmente, la sagomatura dell'impasto di argilla, con pressatura entro stampi, faceva assumere al laterizio facce rettilinee e bordi regolari, tali da garantire tessiture murarie uniformi, con giunti di spessore compreso fra i 5 e $15 \mathrm{~mm}$. Solitamente gli stampi erano in legno e talvolta avevano un bordo in metallo che limitava l'usura della forma e garantiva il mantenimento di dimensioni costanti. A Venezia, dopo un primo periodo di assoluta irregolarità nella produzione, fu introdotto nel 1229 un modello, depositato a Rialto, atto a limitare soprattutto gli arbitrii dimensionali. Tuttavia, solo più 
tardi una disposizione del 1327 stabilì che "I giustizieri vecchi, per togliere le frodi, facciano eseguire delle forme per le fornaci di Venezia,... Da ambi $i$ lati siano ferrate $e$ bollate di quel sigillo che essi vorranno. I fornaciai dovranno attenervisi ${ }^{72}$. La presenza di impressioni «a nastro» lungo i bordi dei mattoni veneziani indica l'utilizzo di questo tipo di stampi con reggetta metallica e può diventare un elemento distintivo.

Infatti, le diverse caratteristiche dello stampo e le operazioni legate alla forgiatura a mano lasciavano segni che spesso permanevano anche dopo la cottura ${ }^{73}$, come le solcature longitudinali sub-parallele sulla faccia superiore per effetto della lisciatura a mano o le irregolarità di conformazione dei profili («creste»), dovute all'utilizzo di un raschiatoio, $\mathrm{o}$ anche le cosiddette eccedenze "fungo" nel caso di scarsa aderenza dello stampo al piano di lavorazione. Gli stampi potevano inoltre essere aperti su due lati o dotati di fondo, si ottenevano mattoni a una o due facce sabbiate («mattoni a due sabbie» o "ad una sabbia»), dato che «al far de' lavori si deve adoperare la sabbia crivellata, affinchè non si attacchi la materia sul desco, o ne' stampi, $i$ quali ogni tratto si rinettano, e si calca bene la materia, acciò $i$ lavori vengano più sodi... $»^{74}$. Solchi e striature di veicolazione di inclusi potevano essere prodotti per trascinamento durante lo stacco del laterizio dallo stampo, che avveniva sul luogo dedicato all'essicatura (fig. 13).

Seguiva una prima fase di riposo e successivo accatastamento su un piano ricoperto di sabbia, in cui gli elementi venivano posti di coltello per una lunga fase di essicazione che impediva al mattone di contorcersi e deformarsi durante la cottura ${ }^{75}$. Alle caratteristiche conferite dalla foggiatura si aggiungono segni e impronte non intenzionali, come le rugosità o tracce di fibre vegetali sulla faccia appoggiata su un piano privo di sabbia o direttamente sul terreno; o ancora le tracce di dilavamento sulle facce esposte alle intemperie, impronte diagonali di accatastamento e, infine, tracce casuali come incisioni, impronte digitali o di animali dovute ad operazioni improprie sui mattoni non ancora sufficientemente essicati.

${ }^{72}$ B.Cecchetti, (1845), 1980, p.67. Anche il Monticolo ricorda l'introduzione a Venezia, nel 1327, di "nuove misure ferrate di mattoni e coppi...", G.Monticolo, "I capitolari delle arti veneziane ..., cit., p.262. La norma integrava quella del 1229 che già prevedeva l'utilizzo di stampi "ad formam factam in pilona, Rivoalto...".

${ }^{73}$ Per la conoscenza del processo produttivo si veda G.Caniato, M. Dal Borgo, 1990, p. 270; U. Menicali, 1972 e P. Boucheron, H. Broise, Y. Thebert, 2000.

${ }^{74}$ V. Scamozzi, op. cit., p. 243

75 "I lavori stiano nell'are fin tanto che siano azimi, e si possano maneggiare senza torcersi o rompersi ... si levano e mettono in fila intrecciati in coltello un dito distante l'uno dall'altro ... e con questordine si vada seguendo a lavorare e a metterli in fila, cuoprendo di sopravia con paglie segaline legate in modo che facciano coperto elevato alla parte di mezzodì e piendente a tramontana», V. Scamozzi, cit., pp. 243-45.

\section{- Lavorazioni prima e dopo la cottura}

I mattoni ricevevano diverse lavorazioni oltre alla sagomatura, la maggior parte delle quali era effettuata a crudo o semi-crudo/essicato (intaglio, levigatura, graffiatura, ecc.), data la fragilità del laterizio cotto. Tuttavia alcune delle operazioni più diffuse avvenivano a cotto e fuori opera come, per esempio, la scalpellatura, l'arrotatura, il taglio; mentre i rivestimenti e alcuni trattamenti come la sagramatura e la rettifica della molatura avevano luogo dopo la messa in opera.

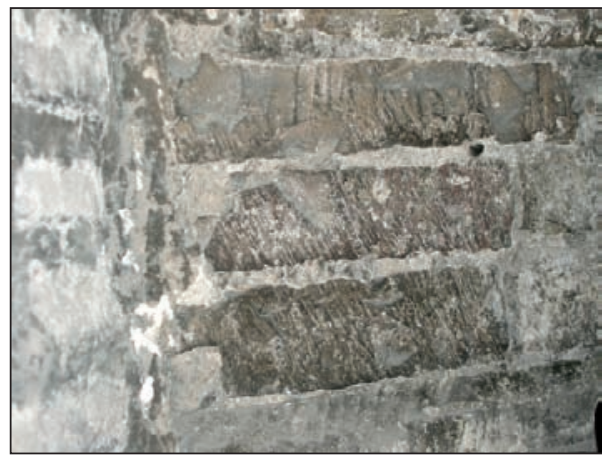

Fig.14. Venezia, campanile di S.Geremia: mattone romano rilavorato a scalpello. Lavorazioni a mattone cotto caratterizzano il periodo più antico, basato sul reimpiego, in cui i materiali venivano rilavorati a martellina o mediante scalpellatura e successiva rifinitura-limatura

Gli studiosi concordano sul fatto che la graffiatura avvenisse prima della cottura ${ }^{76}$ incidendo solcature parallele o sub-parallele nel paramento, mediante raschietto o altro attrezzo acuminato (punteruolo, lama o pettine, per lavorazioni di tipo seriale), con motivi anche raffinati a spina-pesce o a triangolo. Mentre non è ancora stata chiarita la natura e funzione di queste rigature, talvolta correlate alla tecnica produttiva o ricondotte a forme di decorazione. E' comunque innegabile una valenza connotante, così come è probabile la natura preparatoria o sussidiaria della graffiatura rispetto ad altre lavorazioni, come per esempio la molatura, comprovata da riscontri sistematici di compresenza di entrambe le lavorazioni, soprattutto in parti specialistiche come angolate, cornici, spigoli di contrafforti, ecc.

La molatura (o arrotatura) (figg. 15-16) era un trattamento di levigatura del mattone per abrasione superficiale,

\footnotetext{
76 "dopo aver ruotato di 90 gradi, "a coltello", i mattoni crudi, uno per volta, o preferibilmente in serie affiancando un certo numero di mattoni», F. Redi, in P. Boucheron, H. Broise, Y. Thebert, 2000, pp. 211-12. La graffiatura eseguita dopo la cottura è una pratica che sembra caratterizzare l'Alto Medioevo, quando non era ancora specializzata la produzione seriale di elementi fittili (Varagnoli, 1996).
} 


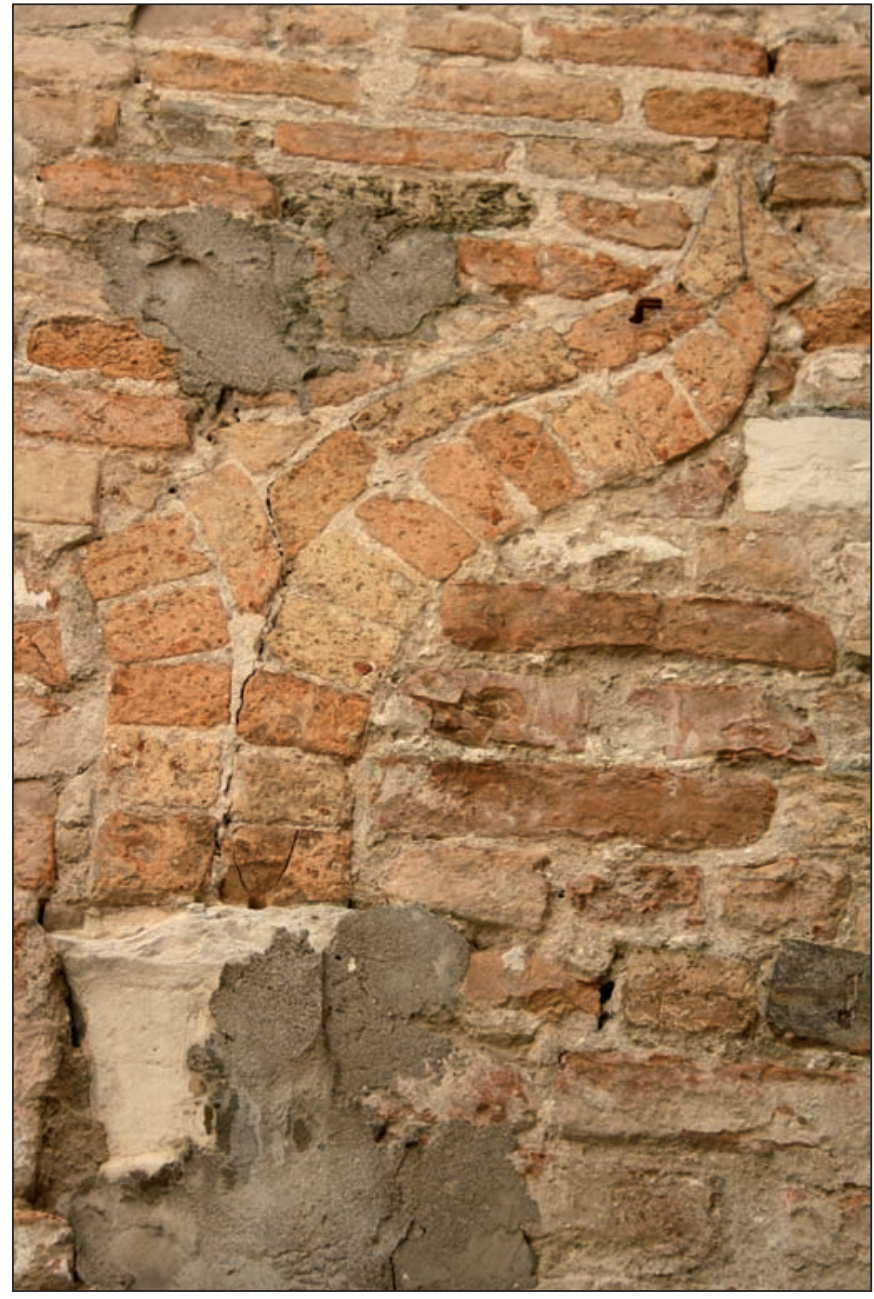

Fig. 15. Venezia: altinelle molate nei resti di una «bifora-fossile» in calle delle Oche

dovuto a sfregamento con altri laterizi e con sabbia, che poteva essere eseguita a secco o veicolata con acqua o acqua di calce e che ne rendeva le facce più lisce, lucide $\mathrm{e}$ dall'aspetto omogeneo (F. Gabrielli, R.Parenti, 1992, p. 30). Il processo avveniva solitamente fuori opera, alla fine del ciclo di lavorazione sul laterizio ancora caldo, prima che l'evaporazione ne comportasse il definitivo indurimento $^{77}$. La molatura aveva, oltre ad una valenza formale e decorativa - che consentiva la formazione di un paramento estremamente regolare, con giunti molto sottili- anche una funzione protettiva, in quanto l'eliminazione delle asperità riduceva la percentuale di superficie esposta alle intemperie e aggredibile da parte del gelo.

\footnotetext{
77 «Si pensa che $i$ mattoni in cotto debbano essere ripuliti o subito dopo essere stati estratti ... o ... prima che si asciughino ... Difatti un mattone di terra cotta, una volta bagnato e poi asciugato, sindurisce a tal punto di consumare anche il ferro .... Riputiamo più conveniente levigare il mattone appena cotto e ancora caldo....", L.B.Alberti, Libro II, cap.X, in C.Varagnoli, 1996.
}

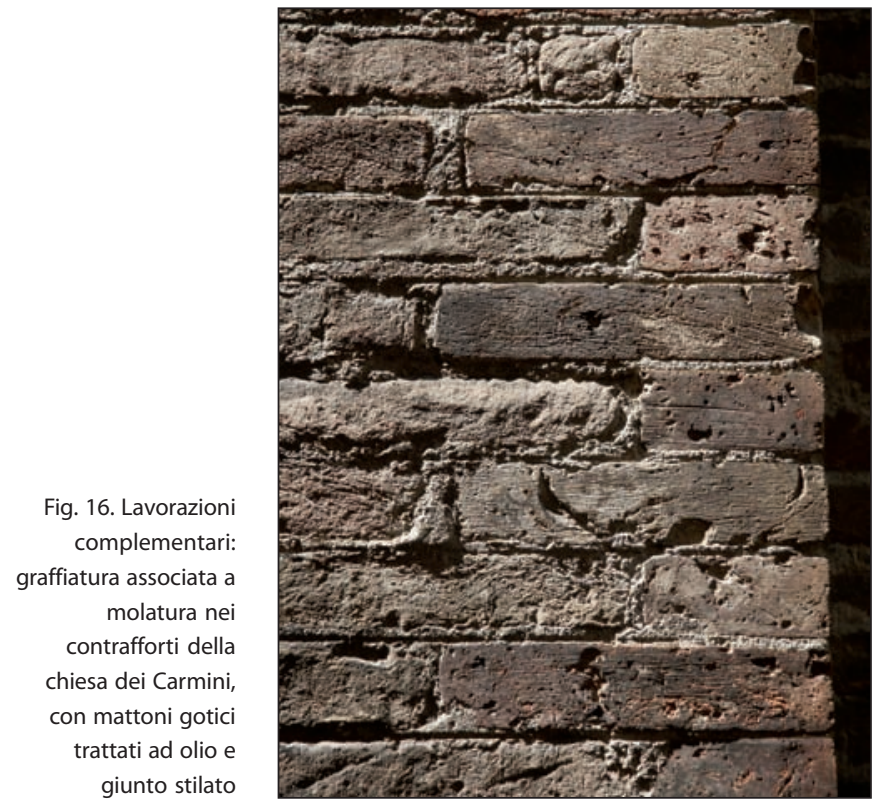

\section{- Cottura}

La scarsità delle fornaci veneziane nel periodo compreso fra il IX e il XII secolo, sembra giustificare l'utilizzo sistematico e prolungato di materiali di reimpiego ${ }^{78}$. I già citati provvedimenti del 1327 e del 1368, che disposero rispettivamente la costruzione di fornaci comunali e la possiblità di acquisto di laterizi dall'entroterra, sono indici di forte sviluppo commerciale, cui è sotteso un altrettanto sensibile miglioramento tecnologico-produttivo. Tuttavia il funzionamento non omogeneo delle fornaci tradizionali, che potevano essere stabili o temporanee, cioè formate sul luogo in cui i mattoni sarebbero successivamente stati utilizzati, implicava spesso variazioni di esposizione al calore e dunque prodotti con caratteristiche differenti, fra cui il colore, la resistenza meccanica e agli agenti atmosferici, la porosità. La presenza di composti quali il carbonato di calcio o gesso, rendeva biancastro il mattone dopo la cottura, mentre inclusi combustibili conferivano colore nero al nucleo interno del mattone; terre e minerali potevano anche essere intenzionalmente aggiunti per modificare la tinta dopo la cottura. L'atmosfera di cottura costituiva un'ulteriore fattore di variabilità del prodotto finale, come sembrano confermare le analisi di cui al paragrafo precedente, condotte sulle altinelle veneziane di

\footnotetext{
${ }^{78}$ Temanza ricordava che "Di una fornace sul rio de' Saloni presso S. Gregorio ne ho fatto testè cenno. Di un'altra, che nel secolo XV esisteva in Castel forte, presso S.Rocco, ne ho trovato notizia; ma non di altre. Questa di Castelforte fu forse la più antica ...; mentre il già citato decreto del Maggior Consiglio del 1327 stabilì la costruzione di due fornaci comunali per la fornitura del cantiere dell'Arsenale "nella terra vuota che è dietro S.Biagio, e altrove ...", B.Cecchetti, cit., p.67.
} 
analoga composizione ma di epoche diverse, quindi interessate da condizioni di cottura differenti, per cui le altinelle di qualità superiore, sono "cotte in forni chiusi ... (il loro impasto è sempre giallo) ... (nelle) seconde invece ... cotte in forni più ventilati ... l'impasto è quasi sempre più rosso $\ldots ..\rangle^{79}$.

I mattoni poco cotti, detti albasi, erano cotti a distanza dalla fonte di calore con temperature inferiori di $900^{\circ}$; il colore poteva variare dal rosa-marrone pallido al giallo chiaro, a seconda che la cottura fosse avvenuta in atmosfera ossidante o riducente, e limitate erano le caratteristiche di resistenza.

Anche se è necessario un approfondimento analitico specialistico, non si può escludere che il colore chiaro, tendente al giallo o giallo-rosato, che connota gran parte dei mattoni gotici (per esempio quelli più antichi presenti nella chiesa dei Carmini) possa essere dovuto, oltre che a caratteristiche di impasto, anche a condizioni di cottura, soprattutto alla probabile iniziale difficoltà di condurre a completa cottura mattoni di dimensioni notevoli (forse non è un caso che i mattoni gotici più tardi, che costituiscono l'abside dei Carmini, abbiano colore rosso e tonalità più scura, indice di un grado di cottura più elevato).

Mattoni sufficientemente esposti al calore avevano infatti colore variabile dal rosso chiaro al rosso vivo, erano detti mezzanelle e si distinguevano in forti e dolci a seconda del grado di cottura non sempre omogeneo $\left(900^{\circ}-1000^{\circ}\right)$, con conseguente variabilità della resistenza a compressione e all'umidità.

I mattoni ferrioli (a Venezia brustoloni) erano caratterizzati da esposizione al calore eccessiva e ravvicinata e da elevato grado di cottura $\left(>1000^{\circ}\right)$ che conferiva colore scuro (in atmosfera ossidante: rosso scuro, bruno, grigio; in atmosfera riducente: ferrigno, bluastro, spesso con l'interno nero) e consistenza parzialmente vetrificata, con conseguenti caratteristiche di fragilità e scarsa aderenza alle malte ma anche di elevata resistenza alla compressione e limitata porosità. Per questo venivano preferibilmente usati in murature esposte all'umidità (canali, basamenti, pavimentazioni) e sottoposte a notevoli carichi (le cosiddette "piere da leto", destinate al rafforzamento fondale $\left.{ }^{80}\right)$.

79 G. Fazio, S. Hreglich, L. Lazzarini, U. Pirredda, M. Verità, in AA.VV., 1982, p. 254 .

${ }^{80}$ F.Marino, "Notizie sul cantiere e sui modi del costruire nel tardomedioevo a Venezia attraverso lo studio di conti di fabbrica", tesi di laurea, relatore F. Doglioni, IUAV, a.a. 1988-89, p. 392.

\section{B - Processo costruttivo}

L'importanza del magistero murario, ossia di quelle regole operative tramandate dalle maestranze locali che, definendo la sequenza di cantiere, garantivano la qualità esecutiva, è testimoniata dalla presenza a Venezia di norme molto antiche, come quella del 1313 ricordata da Sagredo, che proibiva di costruire «senza licenza dei Giustizieri Vecchi»" ${ }^{81}$, o la norma che imponeva il superamento di prove pratiche per l'ammissione all'Arte dei mureri. L'attività era così strettamente regolamentata, e le disposizioni si applicavano ai muratori veneziani ma anche ai forestieri che volessero esercitare in città, i quali dovevano essere prima autorizzati dalla Consorteria. Le istruzioni successivamente riportate nel trattato di Scamozzi ${ }^{82}$ denotano il perdurare nel tempo di una disciplina costruttiva che richiedeva una profonda conoscenza, non soltanto delle regole edificatorie ma anche delle caratteristiche fisiche e produttive dei materiali impiegati.

I caratteri riconducibili al processo costruttivo riguardano le modalità di posa e disposizione dei mattoni (apparecchiatura, tessitura ed eventuali motivi tessiturali decorativi) e le diverse configurazioni del giunto di malta.

L'apprecchiatura è il tipo di giacitura che gli elementi assumono all'interno della muratura, a formarne lo spessore; le caratteristiche dell'apparecchio dipendono dalla disposizione degli elementi nei corsi orizzontali e dalla diversa combinazione e modalità di successione dei laterizi sulla verticale.

A differenti tipi di apparecchio corrispondono varianti di spessore, connessione e prestazioni, nonchè diverse connotazioni tessiturali; se la predisposizione di corsi di sola fascia implica la formazione di un apparecchio a paramenti separati, la presenza di alcuni elementi di testa garantisce concatenamenti puntuali, che possono essere più o meno diffusi ed efficaci a seconda del numero e omogeneità di distribuzione, così come la presenza di corsi di sole teste indica murature sistematicamente ammorsate.

Le murature osservabili a Venezia raramente consentono la visione diretta dello spessore, dunque dell'apparecchio, tuttavia è possibile distinguere le murature più antiche, che sono caratterizzate mediamente da spessori

\footnotetext{
${ }^{81}$ La consorteria o "arte dei mureri» risulta antichissima, Sagredo cita una la legge del 1313 riportata anche in G. Monticolo, 1896, vol. X, p. 302.

${ }^{82}$ Scamozzi consigliava di "... mettere nelle mura $i$ quadrelli in quel modo che furono posti nell'ara con la sabbia in giù, ed il coltello più grosso all'infuori ed il men grosso all'indentro; onde la parte più dritta e pulita viene all'insù, perché a questo modo le malte fanno maggior presa, e le commettiture dé corsi vengono meglio, e la muraglia riesce piu forte e sicura: e tanto basti», V. Scamozzi, cit., II, p.249.
} 

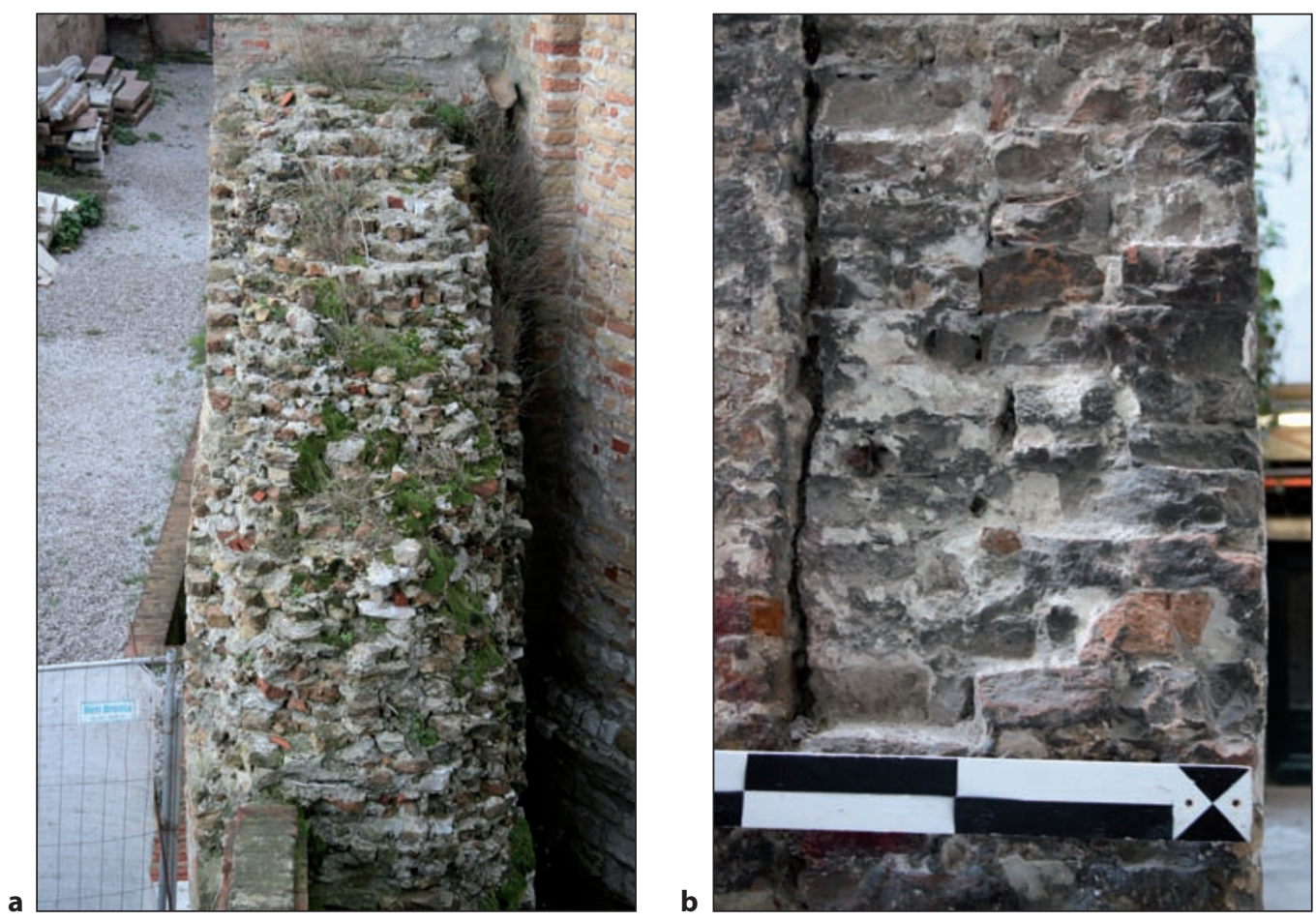

Fig. 17a. Torcello: corpo di strato di una muratura di notevole spessore e formata da laterizi di dimensioni ridotte; b. Apparecchiatura in un muro di cinta di spessore ridotto (foto F.Doglioni)

notevoli e da un'apparecchiatura talvolta disordinata, soprattutto quando si tratta di murature con elementi di reimpiego (come a Torcello, fig. 17a) o delle grandi compagini murarie in altinelle, come quelle osservabili nella chiesa dei Servi), dove alla ridotta dimensione dei laterizi corrisponde la difficoltà a formare ingranamenti efficaci. Le più tarde murature in mattoni gotici si attestano invece su uno spessore di poco superiore ai $50 \mathrm{~cm}^{83}$, compensando la riduzione di sezione con un apparecchiatura più ordinata e coerente, con ammorsamenti efficaci, che le notevoli dimensioni di questi laterizi facilitavano (fig. 17b). Come è già stato fatto notare, il passaggio all'edilizia gotica segna anche il superamento della logica costruttiva "a massa" di ascendenza romana e bizantina, a favore di una struttura muraria «a lama» ${ }^{84}$, più adatta a Venezia, con muri anche molto sottili, paramenti larghi quanto un mattone (circa 25 centimetri), a fronte di un'altezza superiore ai cinque metri, come alcuni muri interni della Ca'd'Oro ${ }^{85}$.

${ }^{83}$ Vedi nota n.52.

${ }^{84}$ «Per quanto possa apparire contraddittorio, i grandi mattoni si prestano meglio dei mattoni piccoli alla costruzione di muri sottili, per il minor apporto di malta, il maggior modulo elastico e la conseguente minore deformabilità», F.Doglioni, F. Trovò, op.cit., p. 49.

${ }^{85}$ Edificio fatto costruire come dimora da Marin Contarini dal 1421 al 1431, «in questa, come in tutte le case veneziane, l'intenzione era di ridurre al minimo il carico della struttura sulle fondazioni», R. J. Goy, in AA.VV., 1993, p. 152.
A partire dall'epoca gotica quindi, gli spessori delle costruzioni veneziane risultano mediamente inferiori rispetto ad altre città, ciò per ragioni di stabilità fondale. Lo spessore era misurato in "pietre», divenute "teste» di mattoni e anche Scamozzi in generale indicava nell'edilizia civile abitativa uno spessore medio pari a una pietra $e$ mezza o due e a due-tre pietre per gli edifici pubblici, attribuiendo la solidità strutturale complessiva ad una apparecchiatura efficace e dotata di concatenamenti, oltre che alla buona qualità delle malte. Al di là delle variabili di apparecchio, la preoccupazione costante, sin dalle epoche più antiche, era quella di inserire adeguati concatenamenti, concepiti come i conci diatoni nelle murature antiche in pietra; legamenti, che a Venezia non coinvolgevano soltanto l'apparecchio murario ma l'intero sistema muraturasolai-copertura, una caratteristica che implicava una stretta collaborazione fra mureri e marangoni da case, i carpentieri che si dedicavano all'edilizia civile ${ }^{86}$.

E. R. Trincanato constatò il mantenimento nel tempo dello spessore medio di tre teste fino ad epoca relativamen-

\footnotetext{
${ }^{86}$ Come il richiamo scamozziano a Vitruvio ricorda, "per la qual cosa aggingne forse le incatenature d'altre pietre vive per lo traverso, ed anche quello che facevano $i$ traviamenti de' palchi e de' tetti, onde a questo modo assicuravano le fabbriche in due o tre piani...», V. Scamozzi, cit., III, p. 341. Sul tema delle connessioni cfr F. Doglioni, A. Squassina, "Legami, connessioni e sconnessioni nella tradizione costruttiva veneziana», in F. Doglioni, G. Mirabella, 2011, pp. 89-110.
} 

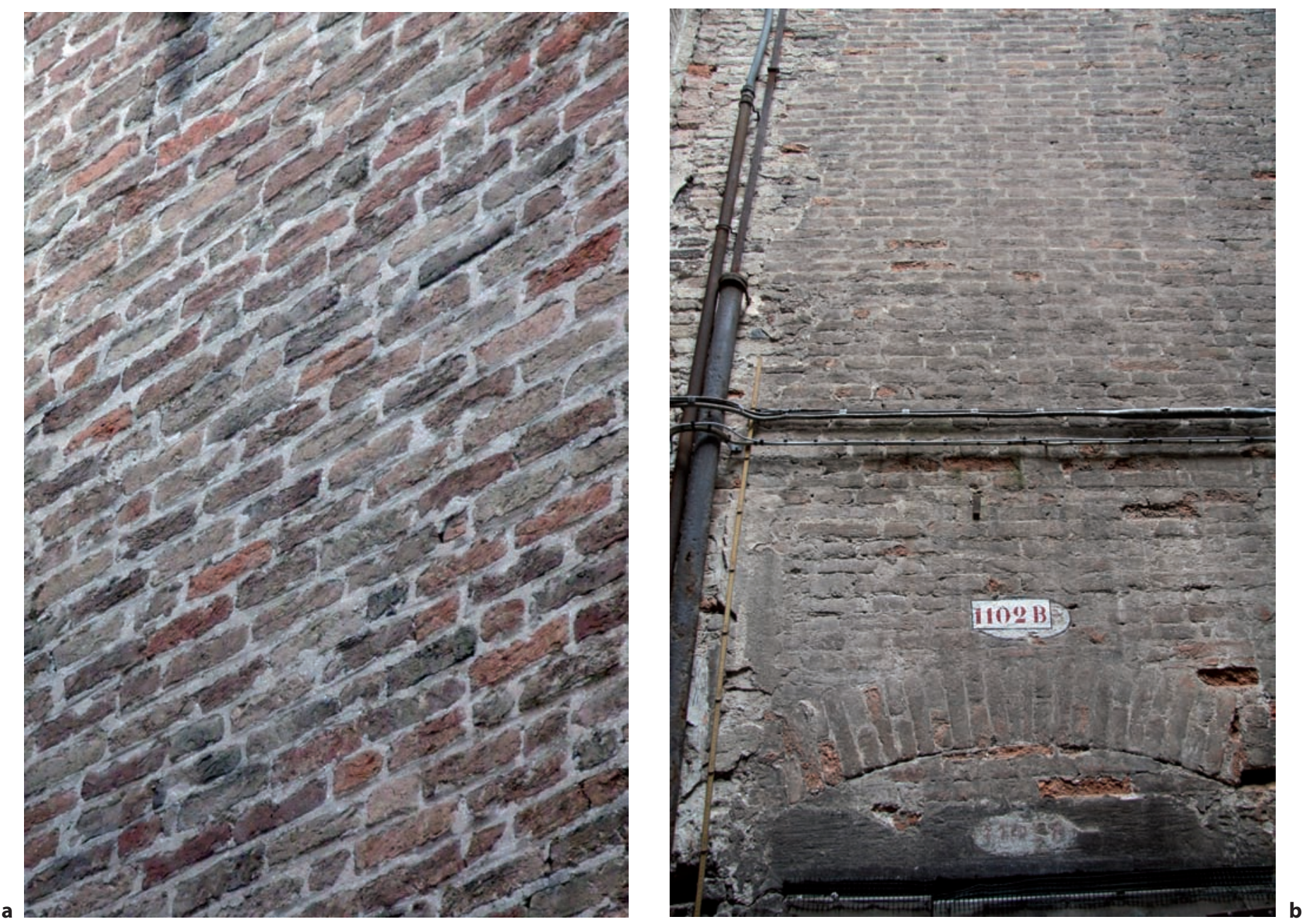

Fig. 18a. I paramenti in altinelle sono spesso caratterizzati da tessitura rgolare e giunto ribadito a calce, con commessure verticali allineate in diagonale, anche nell'edilizia non monumentale; b. Paramento in mattoni romanici con commessure allineate in verticale (edificio in Calle del Traghetto, S.Polo)

te recente ${ }^{87}$, con eccezioni di murature a cinqueteste, anche in ragione del formato dei mattoni, dimostrando la frequente correlazione fra spessore del muro, apparecchio e dimensione dei mattoni.

La tessitura deriva dall'apparecchio, che si rende percepibile sul piano della muratura come configurazione del paramento e la cui regolarità dipende dall'orizzontalità dei letti e planarità della superficie, risultando tanto maggiore quanto ridotto è lo spessore dei giunti.

Analogamente a quanto osservato a proposito della apparecchiatura, anche sotto il profilo tessiturale si osserva la completa eterogeneità delle murature altomedioevali contenenti mattoni di reimpiego in cui, semmai, è il

${ }^{87}$ «La facciata della casa veneziana mostra spesso all'esterno la muratura di mattoni in vista, che costituisce la struttura quasi esclusivamente adoperata per i muri d'ambito di tutte le opoche; ... Normalmente il muro è di tre teste; ma si trovano eccezionalmente muri di cinque teste...», E.R.Trincanato, 1948. giunto di malta alto $(>\mathrm{cm} 2)^{88}$ e sommariamente allisciato a scandire la successione dei corsi (vedi fig. 6). A questa mancanza, nelle murature più antiche, di un motivo tessiturale riconoscibile, succede una regolarizzazione nelle murature in altinelle, soprattutto quando vengono posate in associazione con mattoni di dimensioni diverse, come quelli sottili o i gotici. Si tratta tuttavia di una regolarità estremamente articolata, in cui possono comparire moduli con elementi successivi di testa (da due a quattro) alternati a uno o due di fascia, sfalsati sulla verticale. Anche dove un motivo tessiturale non è immediatamente riconoscibile, possono essere osservate modalità di posa che enfatizzano la resa estetica del muro, come per esempio l'allineamento

\footnotetext{
88 In seguito alle osservazioni effettuate sui giunti dei campioni rilevati, si definiscono convenzionalmente tre classi di spessore:alto $(s \geq 20 \mathrm{~mm})$; medio $(10<s<20)$; sottile $(s<10 \mathrm{~mm})$.
} 
in diagonale dei giunti verticali (fig. 18a), visibile nella muratura di altinelle di palazzo Zane in Campo S. M. Mater Domini, ovvero l'allineamento in verticale alternato delle commessure, come nella muratura in calle del traghetto presso Rialto (fig. 18b) o in palazzo dal Bosso a S.Polo (fig. 25b). Mentre sono frequenti disposizioni di taglio nelle murature che utilizzano altinelle di reimpiego.

Con l'introduzione dei mattoni gotici si osserva una tendenza alla regolarità del tessuto murario con elementi di testa e di fascia in corsi sovrapposti alternati e configurazioni riconoscibili come varianti di concatenamento «alla gotica» $\mathrm{O}$ "alla fiamminga ${ }^{89}$, caratterizzate da una graduale ma sistematica riduzione dello spessore del giunto di malta -rispetto alle murature precedenti, con mattoni eterogenei o altinelle- spesso finite da stilatura sottile.

Nonostante le precise indicazioni contenute nei trattati e benchè Venezia abbia beneficiato, da un lato, della diffusione di modalità costruttive provenienti da altre aree italiane e Europee ad opera del monachesimo, dall'altro dalla fitta rete di scambi commerciali con l'Oriente e il Nord Europa, soprattutto Bruges e le Fiandre, sembra mancare qui la regolarità tipica dei paesi del Nord. Nelle murature osservate a Venezia è stata riscontrata una notevole variabilità tessiturale. Ma se le differenze, talvolta riscontrate nello stesso edificio all'interno di murature di formato omogeneo, possono essere indice di fasi di cantiere differite nel tempo, una pratica diffusa anche in altri contesti geografici, soprattutto nel caso di cantieri di grandi opere monumentali come i complessi monastici (a Venezia comprovata, per esempio, nella basilica dei Frari o nella chiesa dei SS. Giovanni e Paolo, entrambe costruite/ricostruite fra il XIV e il XV secolo, o la stessa chiesa dei Carmini). Più in generale, l'eterogeneità tessiturale delle murature medioevali veneziane rispetto a quelle di altre aree italiane ed europee può forse essere ricondotta alla presenza di maestranze differenziate corso del tempo, provenienti da diverse aree europee e del Mediterraneo.

Il tema della provenienza delle maestranze riveste grande interesse anche se richiede un approfondimento specifico, volto ad intrecciare conoscenze di tipo storicocritico con riscontri, da verificare, correlando caratteristiche delle murature direttamente osservate con documenti di cantiere (peraltro piuttosto rari). Tuttavia si possono fare alcune considerazioni di tipo storiografico sui mutamenti nel tempo delle influenze straniere. Così, nel periodo di transizione fra la città lignea e la città petrinea (XII-XIII

${ }^{89} \mathrm{Cfr}$. A. Acocella, 1989. sec.), sono citati muratori e scalpellini greci ${ }^{90}$ e la presenza di «molti Artefici di Costantinopoli...»" è registrata in seguito alle conquiste veneziane d'Oltremare. Se negli edifici più antichi prevale l'apporto orientale, alcuni autori presumono anche maestranze veronesi e lombarde ${ }^{92}$, oltre che framminghe ${ }^{93}$, per tutta la fase di crescita edilizia e espansione urbana, dal XII al XIV secolo, in parte basandosi su caratteri architettonici di edifici monumentali come le chiese $^{94}$ e i fondaci pubblici ${ }^{95}$, talvolta anche suffragati da testimonianze storiche ${ }^{96}$. Molti scalpellini ammessi all'Arte

${ }^{90}$ "I Falegname ... Marangoni erano numerosissimi ... Non così numerosi dovevano essere $i$ muratori e gli scalpellini. E questo fu il vero motivo ...per cui Leone IV, imperatore d'Oriente, mandò una partita di tali artefici al Doge Giustiniano Partecipazio, affinchè se ne servisse per la costruzione della chiesa di S. Zaccaria... I Greci vivevano in stretta amicizia con $i$ Veneziani...", T. Temanza, 1781, p. 31.

Anche Cecchetti ricorda «nel sec. XIV: i greci, e soprattutto i tedeschi, spesso a ammessi alla nostra cittadinanza. ... « (B. Cecchetti, cit., pp. 145-46).

${ }^{91}$ "molti Artefici di Costantinopoli si rifuggirono qui... Seguì un periodo molto florido per Venezia, che comportò il completamento della chiesa di S.Marco e il rifacimento del Palazzo Ducale...", Tommaso Temanza, op.cit., 1781, p. 36.

92 "L'unico edificio del secolo XII a Venezia del quale abbiamo, benchè scomparso, una sicura documentazione storica e figurativa sono le Procuratie erette dal Doge Sebastiano Ziani (1172-1178) e ben visibili nel dipinto di Gentile Bellini ... Si tratta, a nostro parere, di una fabbrica eseguita da un architetto di terraferma... il capitello a cubo ... scantonato, con collarino a toro ... ha una lunga e fitta tradizione nell'architettura romanica veronese .... Il ritrovarlo, abbastanza spesso, a Venezia ... accredita veramente l'idea che sulla laguna avessero stanza consorterie di tagliapietre veronesi e che a questi lapicidi-costruttori si debbano alcuni edifici del XII-XIII secolo che, nelle modanature e capitelli, dimostrano l'assenza totale di caratteri bizantineggianti, pur mantnenendo, a volte nel taglio delle finestre, l'arco sopraelevato di origine bizantina. E' insomma molto probabile, che l'attività di questi tagliapietre veronesi (o lombardi) si svolgesse a partire dalla fine del XII secolo e per tutto il Duecento», E. Arslan, cit., pp. 13-14.

Arslan data al XII secolo, attribuendolo a lapicidi lombardi, anche il noto portale nella corte seconda del Milion (p. 16).

93 (Bruges) «... era il rifugio dei lombardi e di altri italiani, il grande magazzino delle loro merci... Tuttavia non aveva ancora raggiunto il suo apogeo, ma doveva raggiungerlo con Venezia e decadere con essa... Perciò non ci si deve sorprendere se, come risultato di queste strette relazioni fra Venezia, le Fiandre e l'Inghilterra, la tecnica della fabbricazione dei mattoni ed altri metodi costruttivi, uniti all'uso di mattoni di dimensioni più o meno uniformi, divennero infine comuni in tutta Europa prima della fine del XIII secolo», ...", N. Davey, 1965, p. 90.

Influenze reciproche sono attestate anche nel corso dei secoli successivi, come sembra confermare Scamozzi: «I parigini usano di far le mura delle loro fabbriche pubbliche e private parte di sassi e parte di mattoni fatti all'uso d'Italia...", V. Scamozzi, cit., p. 233.

94 «il presbiterio tripartito (della chiesa dei Carmini, ndr) è ... molto interessante dal punto di vista della storia dell'architettura e notevole artisticamente nel grandioso impianto ... Nell'assetto sono senz'altro introdotti elementi di ispirazione lombarda», Hubala citato in H. Dellwing, 1990, cap. "L'architettura del XV secolo a Venezia».

95 «... i due diversi tipi di fondaco sembrano da altrettanti modelli ... Certamente il fondaco realtino della farina (di impianto longitudinale, ndr) presenta affinità di funzionamento con la Domus frumenti, la Kornhaus e così via del settentrione europeo ... Il modello diretto del fondaco dei Tedeschi (impianto a corte, $\mathrm{ndr}$ ) ... va ricondotto piuttosto ... ai tipi architettonici vicino orientali e nord-africani, ... «, E. Concina, «I fondaci del Medioevo veneziano», in F. Valcanover e W. Wolters, 2000, pp. 134-136.

${ }^{96}$ Dellwing ricorda come entri a Venezia, fra 1220 e 1240 , "lo stile nordico dentellato nei mosaici di S.Marco» ma anche che «scultori fiorentini e francesi lavorano nella chiesa» (H. Dellwing, 1990). 
a Venezia erano lombardi e svizzeri ${ }^{97}$. E se Arslan ritiene i Campionesi, o comunque maestranze lombarde, i principali tramiti attraverso i quali giunse a Venezia, nel primo Trecento, l'arco gotico inflesso di ascendenza inglese, preludio dello stile fiorito ${ }^{98}$; più documentata e certa è la presenza di artefici bresciani e padovani - insieme a tagliapietra e scalpellini locali, che a loro volta erano in contatto con i cavatori istriani - nella ricostruzione quattrocentesca della chiesa di S. Zaccaria ${ }^{99}$; di capomastri e maestranze lombardi, insieme a capomastri e muratori veneziani e veneti, nel cantiere della Ca'd'Oro durante i primi decenni del Quattrocento ${ }^{100}$; di analoghi gruppi eterogenei (con artefici veneti e lombardi) nei cantieri di Palazzo Ducale, cui si aggiungono maestranze toscane, soprattutto scalpellini ${ }^{101}$, nella fase di completamento del XV secolo.

Benchè in forma di cenno, questo breve escursus sembra avvalorare l'ipotesi di una complessità di influenze e apporti, in grado forse di offrire una prima spiegazione alla mancanza di omogeneità tessiturale riscontrata nelle murature medioevali veneziane.

Alla regolarità tessiturale si aggiunge la configurazione dei giunti di malta come ulteriore elemento a valenza decorativa. Il ruolo della malta nel processo di edificazione era articolato in fasi progressive caratterizzate da diverse tecniche e da una diversa denominazione del giunto, a seconda della sua natura funzionale (di allettamento, di completamento o finitura, di rifugatura). Alla prima fase, in cui avveniva la costipazione e l'assestamento dei letti di malta (malta di allettamento), corrispondeva un giunto sommariamente spianato o privo di lavorazione, arretrato o anche debordante (giunto preparatorio o grezzo). Seguiva la regolarizzazione sia dei giunti orizzontali che di quelli verticali, detti commessure, con rilavorazione o allisciatura prima della presa, o mediante rigiuntura, cioè rimozione delle eccedenze di impasto effettuata con un ferro sagoma-

\footnotetext{
${ }^{97}$ A. Sagredo, cit., p. 95.

${ }_{98}$ «In quel periodo l'arte della composizione architettonica raggiunse in Inghilterra un livello (tale per cui) non è da stupirsi se ... parte dei maestri murari e lapicidi del continente stesso e se maestri inglesi vennero ricercati e ndotti a attraversare la Manica. ... L'arco inflesso compare dunque a Venezia prestissimo, nel Trecento. Le vie, tuttavia, che ve l'hanno portato non sembrano attraversare la terraferma ... (ma attraverso) i campionesi (che) elaborano a Venezia e in Lombardia, motivi che erano in auge, nella prima metà del Trecento, in Inghilterra...", E. Arslan, 1970, pp. 80-86.

${ }^{99}$ S. Connel, 1994 , pp. 73-83.

${ }^{100}$ Si tratta dell'architetto e capomastro Matteo Raverti e Marco d'Amadi, lombardi, che lavorarono insieme a gruppi locali, diretti da Zane Bon, alla costruzione della dimora di Marin Contarini dal 1421 al 1430 circa, vedi R. J. Goy, in AA.VV., 1993, pp. 93-157.

${ }^{101}$ E.Trincanato, "Architetti e maestranze», in 1948, p. 117.
}

to ad unghia e l'applicazione di una malta grassa con inerte più fine, stesa e rifinita ulteriormente a ribadire il giunto.

La malta utilizzata nelle due prime fasi doveva essere frutto di una equilibrata mescola di calce aerea (calce spenta o calzina desfata o trita) e sabbia, con un rapporto fra le componenti variabile a seconda della qualità e provenienza delle stesse, ma veniva utilizzata anche calce idraulica, o calce negra, proveniente dall'area compresa fra Padova e Este, nota sin dall'antichità per le sue proprietà idrauliche, il cui uso è confermato da alcuni conti di fabbrica risalenti al XV secolo ${ }^{102}$.

In particolare, per ottenere la malta utilizzata in fase di rigiuntura, volta a enfatizzare la tessitura muraria con elementi di regolarizzazione geometrica e contrasto cromatico fra il rosso del laterizio e il biancore del giunto, era utilizzata presumibilmente calce viva (calce da spongia), materiale costoso — «... due mastelli di calce di spugna computandosi per cinque dell'altra ${ }^{103}$ - la cui vendita era strettamente regolamentata da licenze e destinata ad un utilizzo specialistico, come sembra rivelare un documento del 1372, che elencava «... mastellis XXVIII calzine de spongia per imbocare et dealbare murum..." ${ }^{104}$.

L'uso differenziato di diversi tipi di calce è comprovato da fonti più tarde, per esempio Scamozzi che distingueva, in ambito veneziano: la dolce, cavata dai monti vicentini e nelle Prealpi lombarde, la forte, ricavata dal «sasso bianco e del selice ... di color bianco e di rosso ... o color della terra ... la quale riesce ottima ad uso delle malte da murare...» ${ }^{105}$ e suggeriva anche tipo e quantità ottimali di aggregati al fine di ottenere quel «certo temperamento, acciò che non siano né troppo grasse né anche molto magre» ${ }^{106}$.

\footnotetext{
102 «Chalzina de più sorte ... chalzina negra e bianca... chalzina da Padoa ... da Venezia ... da Treviso ... (e)... terra da savon», un'argilla impiegata per rivestire cisterne e pareti umide, da F. Marino, cit., tesi di laurea, a.a. 1988-89, p. 392.

${ }^{103}$ La locuzione calzina da spongia deriva dal termine veneziano spongia (sponza, sponcia, sponzia) che indica la cisterna (E. Concina,1988, p. 141), alludendo ad una delle consuetudini d'uso della calce viva, di solito riservata ad usi specialistici, utilizzata nelle malte che dovevano garantire alte prestazioni e proprietà idrauliche, ma anche, come si evince da documenti di fabbrica trecenteschi, per finiture e intonaci. Una delle norme tecentesche sulla produzione e vendita dei materiali da costruzione impediva ai fornaciai di vendere liberamente calce viva, «...calcina de qua data est licentia specialibus personis ... calcina de sponzia que extinta veniat esse ...» (1384, Collegio Notatorio 10, citato in B. Cecchetti, 1885, p. 66).

${ }^{104}$ A.S.V., Procuratori di San Marco, de Citra, busta 168, fascicolo 3, Commissaria di Marino Zorzi Doge - Expense facte pro monasterio Sancti Dominici et expensae comun(is) -M.III.LXXII. (1372), trascritto da F. Marino, cit.

105 "... perché avendo molto nervo porta tre quarti di sabbia di cava e una sola di calce; ovvero due parti di quella di fiume o di mare», V. Scamozzi, cit., pp. 249-50. 106 V. Scamozzi, cit., pp. 263-69. Anche la forma degli inerti era ritenuta determinante per le caratteristiche finali dell'impasto, così «la calce si fa più tenera crivellandosi con sabbia, più spessa con la sabbia angulare",, (D. Barbaro, 1556, citato in C. Varagnoli, 1996, p. 392).
} 

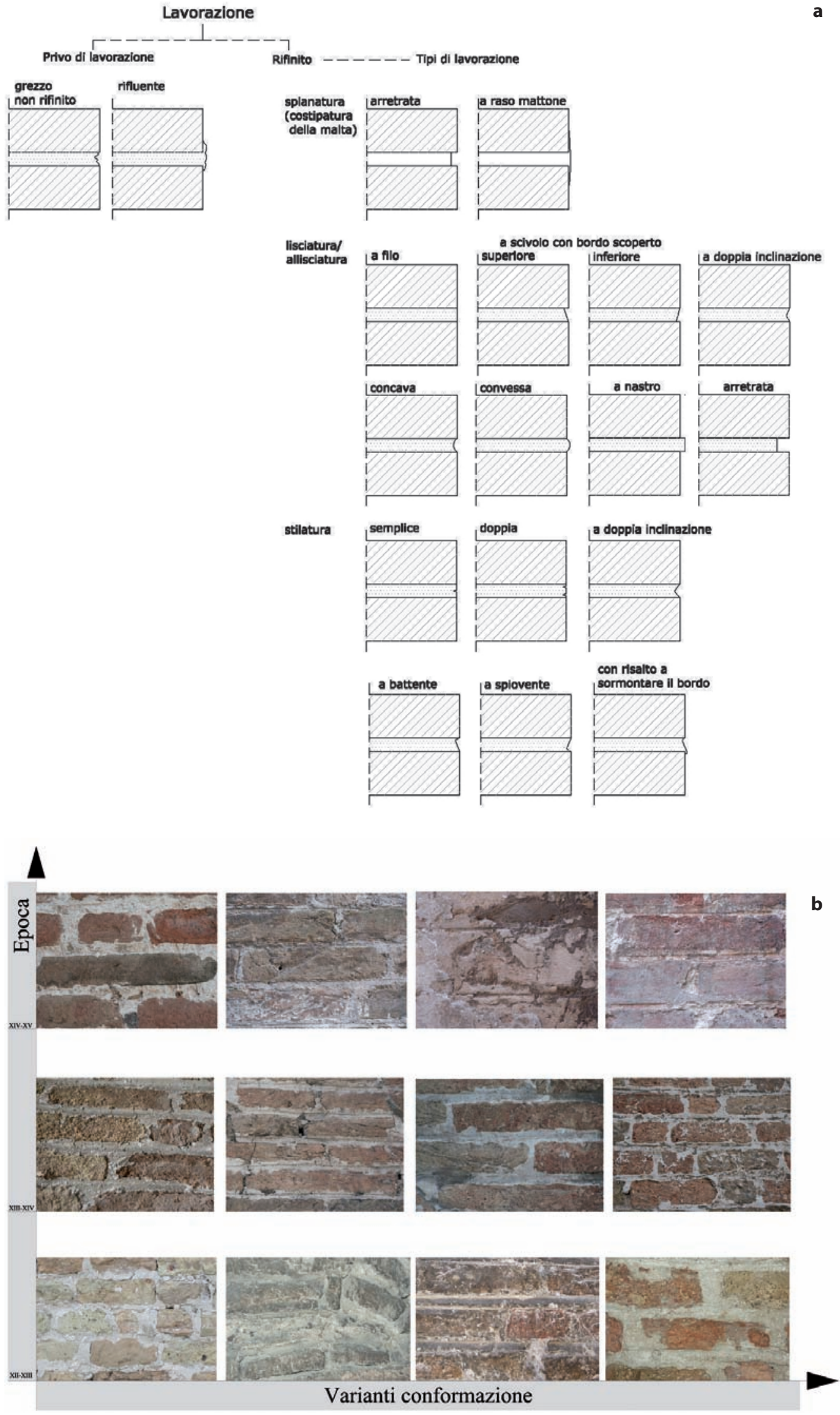

19 a. Schema riepilogativo delle diverse configurazioni e lavorazioni del giunto di malta; b. Primo repertorio cronologico di giunti veneziani caratterizzati da diverse conformazioni e lavorazioni di finitura. 
La capacità di evidenziare l'assetto tessiturale, così come caratteristiche di orizzontalità, omogeneità, planarità, erano demandate al rapporto mattoni-giunto, in particolare all'assetto del giunto rispetto al piano della muratura, soprattutto quando posto in rilievo o, al contrario, arretrato, mentre il giunto rifluente o a raso mattone era adottato in caso di mattoni eterogenei o con profili irregolari (fig. 19a)

Il giunto poteva subire due tipi di profilatura ulteriore, la cui ampiezza era determinata dallo spessore stesso e dalla sezione dell'attrezzo utilizzato: l'allisciatura prevedeva una regolarizzazione del giunto mediante pressatura con la cazzuola o con un ferro a sezione circolare (o manico della cazzuola). L'allisciatura era spesso associata alla stilatura, un'incisione del giunto di malta, eseguita con un ferro acuminato, come la punta della cazzuola, un punteruolo o stilo, o semplicemente con l'aiuto di un chiodo e di un regolo di legno per mantenerne l'orizzontalità. Entrambe le lavorazioni potevano assumere profili variamente configurati; attrezzi acuminati o a sezione tonda conferivano profili, rispettivamente, a scivolo (a battente o a spiovente con uno dei bordi in vista; a doppia inclinazione con spigolo convesso, nei casi di giunti molto alti) o concavo. In caso di giunto molto sottile le operazioni di allisciatura e stilatura coincidevano, mentre i giunti alti potevano avere doppia stilatura o stilatura a sezione rettangolare rettificata con un regolo. Raramente anche la commessura verticale poteva essere stilata, mentre soprattutto nei muri in altinelle, ma talvolta anche in paramenti con mattoni gotici, la commessura era spesso più larga e ribadita a calce. La maggior parte dei giunti riscontrati a Venezia risulta essere il frutto di configurazioni combinate, cioè caratterizzate da un associazione di due o più lavorazioni diverse (per esempio, spianatura preparatoria arretrata e rigiuntura con allisciatura concava ampia e stilatura sottile) (fig. 19b).

Infine, anche lo spessore del giunto, le cui pur minime variazioni determinavano prestazioni meccaniche ma anche carattere diversi, partecipava alla trama tessiturale. Spessori superiori ai due centimetri e allisciatura concava, compensavano il disordine delle murature più antiche con mattoni eterogenei o di reimpiego, riferibili alla tradizione costruttiva bizantina, in cui «il giunto raggiunge spessori prossimi o di poco inferiori a quelli del laterizio...» ${ }^{107}$. Un

\footnotetext{
107 «Possiamo stimare che nei muri a giunto più spesso il volume complessivo della malta sia pari a quello dei laterizi impiegati, mentre nelle murature gotiche più tarde, con grandi mattoni regolari e accostati a giunto più sottile,la malta rappresenti solo un sesto del volume del laterizio ... «, F.Doglioni, F.Trovò, in F.Doglioni, G.Mirabella Roberti, 2011, p.49.
}

giunto alto connota spesso anche le murature in altinelle, $\mathrm{e}$ talvolta risulta ribadito a calce, come nella cosiddetta configurazione "alla cappuccina» ${ }^{108}$, fino ai più regolari giunti «a nastro», rettificati e lisci con bordo in risalto, che si riscontrano anche in murature con mattoni gotici.

Generalmente però queste ultime avevano un assetto compatto e omogeneo conferito dai profili regolari dei mattoni che, pur con qualche eccezione, consentivano un giunto tendenzialmente uniforme e sottile $(<10 \mathrm{~mm})$, di solito stilato (fig. 20a).

Il «panorama» dei trattamenti decorativi delle facciate veneziane in antico a vista comprende la distribuzione delle lavorazioni di superficie dei mattoni. Se elementi fittili e ricorsi con effetti cromatici sono di solito disposti per fasce o ricorsi (e caratterizzano soprattutto gli edifci più antichi, come $S$. Fosca a Torcello o $S$. Donato a Murano, ma compaiono anche in edifici più tardi, per esempio nella chiesa di S. Zaccaria, dove la disposizione dei laterizi policromi sembra ricalcare i motivi a losanga di Palazzo Ducale, o nelle cornici di gronda di chiese come S.Stefano), la molatura, raramente diffusa sull'intero paramento, era spesso destinata a parti specialistiche, come angolate, cornici di aperture, mensole di cornicioni e aggetti. Questa tecnica — che perdura nel tempo, caratterizzando sia le architetture romanico-bizantine che gli edifici gotici, al tempo stesso nobilitando sia i paramenti di architetture monumentali che le parti più significative di edifici comuni (vedi figg. 15-16) — è stata definita infatti una delle chiavi più significative per l'individuazione del paramento a vista, o meglio "quella chiave che ci lascia capire una ricerca dell'effetto coloristico non legato all'intonacatura vera e propria, ma, forse, al solo velo di legante $e$ polvere di mattone... ${ }^{109}$.

\section{C - Processo di finitura}

I rivestimenti parziali sono tipi e forme di finitura a rivestimento della superficie muraria, già definiti stabiliture $^{110}$, di cui è interessante sottolineare i caratteri di parzialità, da cui deriva la definizione, e di complementarietà rispetto al paramento murario. La parzialità è intesa nella duplice accezione di rivestimento semi-coprente

\footnotetext{
${ }^{108}$ Giunto «alla cappuccina» («alla cristiana»): giunto alto, lisciato a filo del muro con la cazzuola usata di punta per ottenere una parete completamente piana e ribadito a calce (E.R.Trincanato, 1948; Menicali, 1972).

109 R.Parenti, 1990 , p.52.

110 "Nella classe [A] delle stabiliture ricadono $i$ più antichi rivestimenti della tradizione costruttiva lagunare .... da stesure pittoriche... con legante organico od oleoresinoso, a sottili strati di intonaco, dipinti a fresco e talvolta arricchiti da fasce policrome di sottogronda e marcapiano o incornicianti porte e finestre», M. Piana, E. Danzi, 2003, vol.2, pp. 65-78.
} 

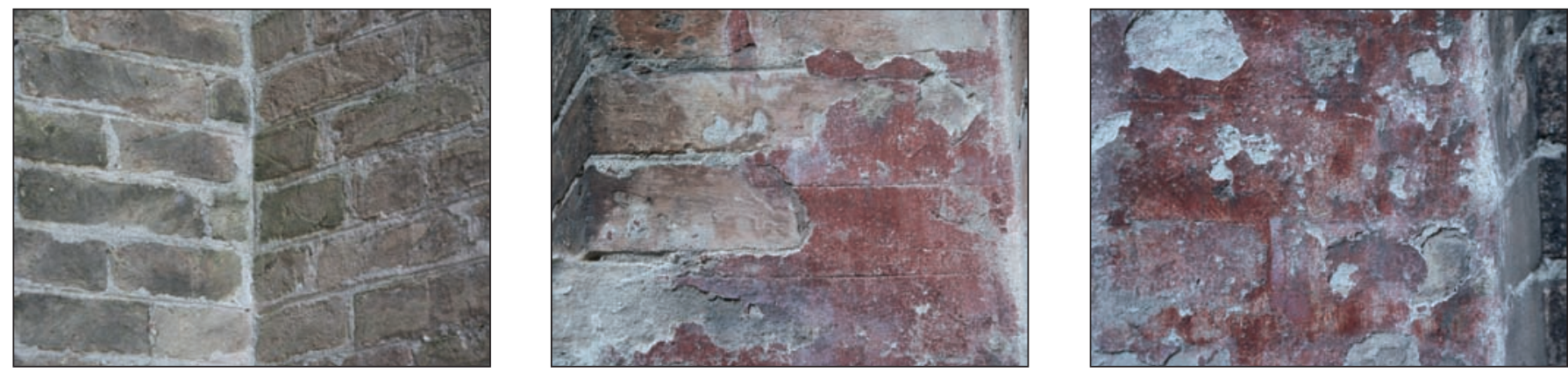

Fig. 20a-c. Complementarietà funzionale e rimandi figurativi fra muratura costruita e muratura simulata nelle finiture medioevali veneziane: la stilatura sottile nella muratura gotica (20a) viene ripresa dall'intonaco a finta cortina (regalzier) che presenta finti giunti stilati (20b), ripassati con colore nero che conferisce effetto chiaroscurale (20c)

(trattamenti protettivi, cromie, velature e scialbi) o monostrato coprente sottile (intonachini monocromi o policromi) che consente la percezione dei motivi tessiturali della muratura sottostante, ovvero il rivestimento limitato a parti specialistiche (cornici e fasce sottogronda). La complementarietà di questi trattamenti rispetto al paramento murario riguarda la natura funzionale degli stessi, destinati alla protezione e rafforzamento cromatico e percettivo della tessitura muraria che rivestono, nonché ai frequenti rimandi che si osservano fra muratura costruita e muratura simulata come motivo decorativo ${ }^{111}$. In tal senso è ragionevole far rientrare questi tipi di rivestimento nell'accezione di muratura di mattoni a vista, di cui rappresentano la facies immediatamente percepibile (figg. 20a-c).

Trattamenti semi-coprenti: nella prima categoria rientrano i composti organici/oleosi a funzione protettiva, rafforzativa del colore e parzialmente omogeneizzante, soprattutto quando associati a pigmenti. In questo caso l'olio essicativo (di solito olio di lino cotto) diventava il veicolo del pigmento stesso ${ }^{112}$. Un composto protettivo a base proteica era ottenuto con l'aggiunta di uova, derivati del latte o altre sostanze organiche. Oltre alla pigmentazione, il trattamento era quasi sempre associato alla molatura dei mattoni, soprattutto in corrispondenza di angolate o

111 «La presenza di superfici protettive dipinte rafforzative del colore naturale dell'argilla, o più limitatamente fittizie e alternative rispetto ai materiali costruttivi, va considerata comunque parziale rispetto alla totalità della superficie che, nel complesso, tendeva ad esaltare il paramento rosso unitario ma continuamente mutevole del laterizio», G. Donato, «Medioevo policromo: l'edilizia civile in Piemonte», F. Tolaini, 2005, p. 157.

112 «... sul paramento asciutto si spalma a pennello una mano di olio di lino cotto e sopra questo strato, con funzione di aggrappante, se ne stendono altre due composte con biacca e pigmenti rossi, gialli e neri, mescolati in dosi appropriate al colore che si vuole ottenere», U. Menicali, 1972, p. 84.

Giacomo Boni riporta la descrizione i motivi decorativi della Porta della Carta, «unti con olio e vernice in guisa che mostrino il colore rosso ... su uno sfondo nero, pure «ad olio» (.... ) Infine gli archetti del cornicione e i merli in pietra d'Istria erano ricoperti di biacca ad olio ...», G. Boni in «Archivio Veneto»,1887, pp. 115-132. cornici. Questo tipo di trattamento è diffuso durante tutto il Medioevo, in quanto si ritrova sia in edifici romanicobizantini, come quello in corte del Fontego, edifici civili con murature in altinelle, come quello in calle dello Spezier presso S. Zan Degolà, ma anche nei grandi palazzi gotici e nelle chiese formate da murature in mattoni gotici, come quella dei Frari e di S.Giovanni e Paolo (fig. 21).

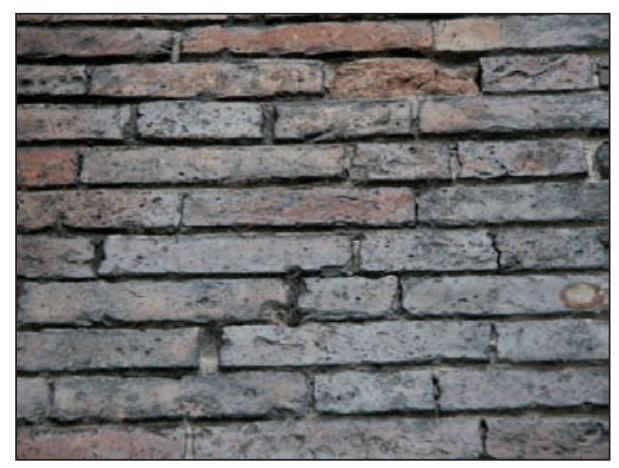

Fig. 21. Mattoni gotici sottoposti a trattamento oleoso trasparente e leggermente ambrato (facciata della chiesa di S.Giovanni e Paolo)

Le cromie, spesso associate al trattamento oleoso e talvolta ottenute mediante semplice aggiunta di pigmenti all'olio essicativo, erano solitamente prodotte da pigmenti e coloranti sciolti in acqua, eventualmente additivate con sostanze proteiche, ed erano stese a pennello, a strati o velature successive; nel caso di associazione a latte di calce si otteneva la scialbatura, già citata da Vitruvio e caratterizzata da minor trasparenza e per la quale veniva usata calce dolce e trita, cioè di ottima qualità e spenta, fatta "passare per due o tre mani di graticci sottili e ben tessuti ... (e) diventa come biacca stemperata ed ottima alle smaltature» ${ }^{113}$ ma, come già visto, anche calce de spongia, cioè calce viva,

\footnotetext{
${ }^{113}$ V. Scamozzi, op. cit., pp. 249-50.
} 


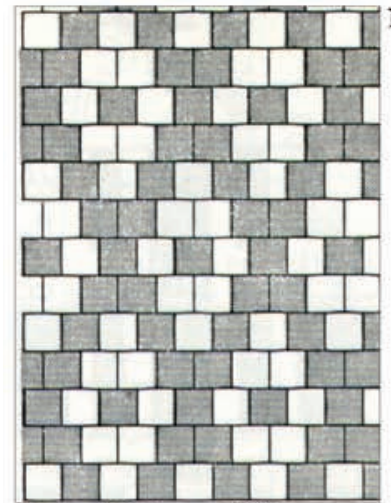

Bruges (J.C.Hoquet, 1999)

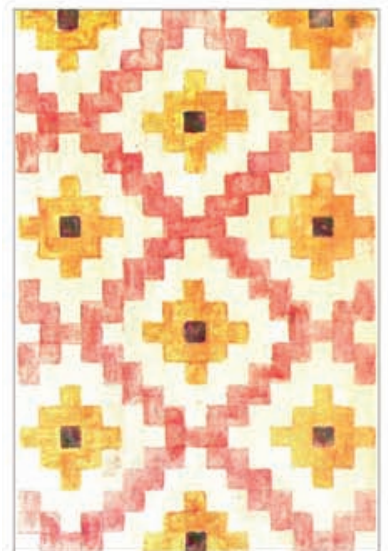

Treviso (M.Botter, 1979)

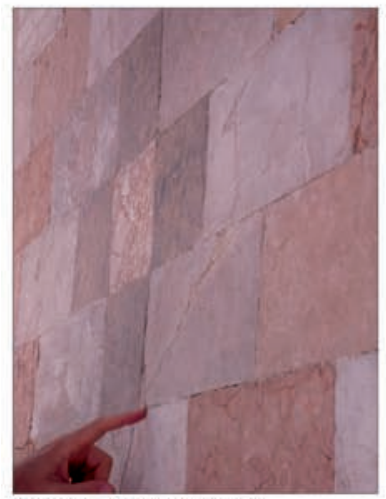

Venezia, Palazzo Ducale
NORD EUROPA
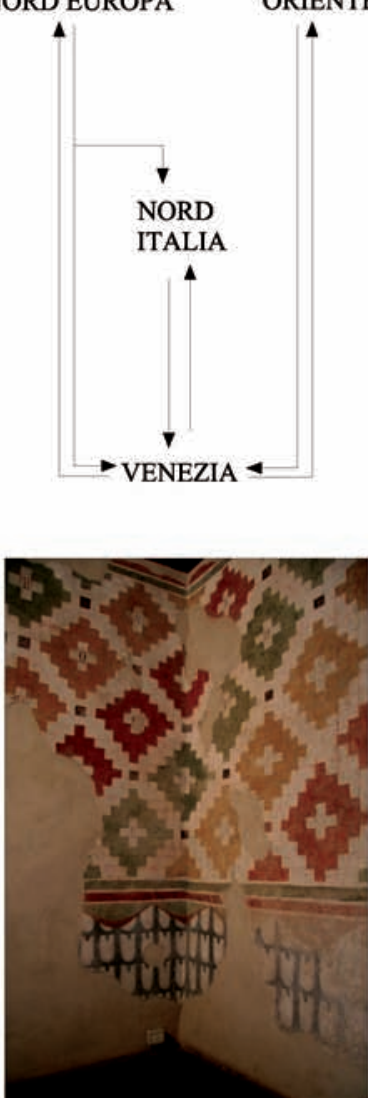

Avio (Tn) (foto F.Doglioni)

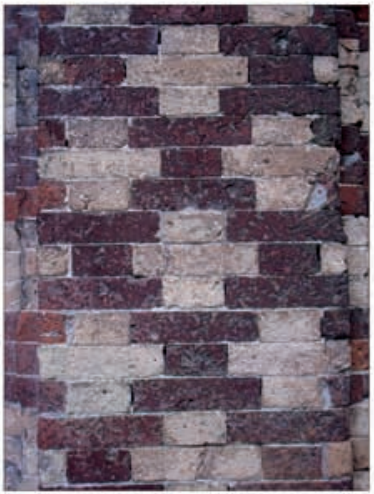

Venezia, Chiesa di S.Zaccaria

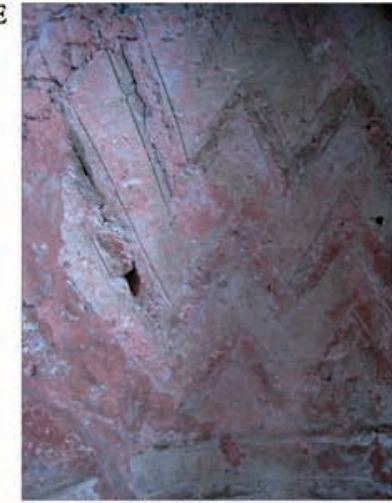

Istambul (foto F.Doglioni)

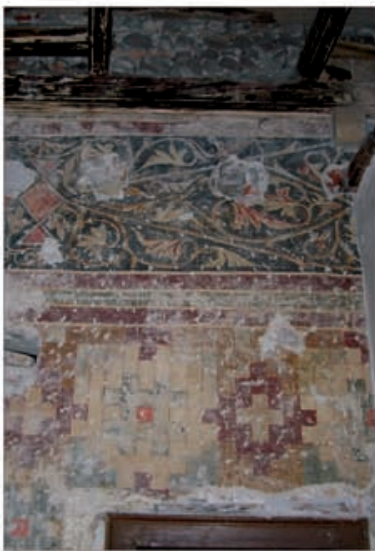

Verona (foto F.Doglioni)

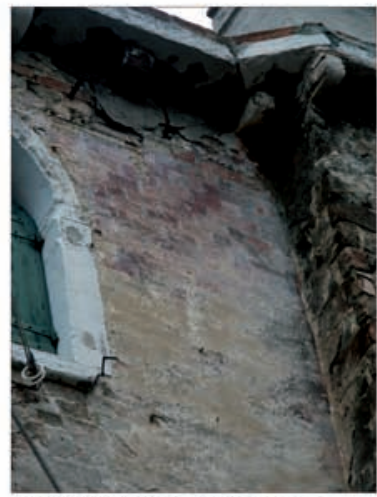

Venezia, Corte Nova S.Lorenzo
Fig. 22. Intonachino a finta cortina (regalzier): ipotesi su origine e influenze culturali era utilizzata anche per dealbare murum, quindi per interventi di finitura ${ }^{114}$.

I pigmenti avevano diverse provenienze, come riportato nei trattati di Cennino Cennini e di Rusconi: così, per esempio, venivano utilizzati il nero-vite o nero-fumo, la biacca e il verderame; per il blu i lapislazzuli ma anche l'azzurro ottenuto cuocendo una mescola di sabbia ... fiore del Nitro ... rame di Cipro finemente tritata; mentre per i colori purpurei veniva seguita una ricetta vitruviana che

\footnotetext{
${ }^{114}$ Cfr. note n.92-93.
}

raccomadava l'impiego di radici di Ruggia, e Hisgino o la viola secca ${ }^{115}$.

Intonachini sottili monostrato: si tratta di rivestimenti a strato unico di spessore medio pari a $2-3 \mathrm{~mm}$, di malta di calce e sabbia fine, steso a coprire la muratura oppure rasato ad occludere le imprecisioni dei paramenti murari. Gli intonachini potevano essere monocromi o, più frequentemente, imitativi di una cortina laterizia, detti regalzier e caratterizzati da fondo dipinto a fresco (di colore

\footnotetext{
${ }^{115}$ G. A. Rusconi, 1660, VII, pp. 111-14.
} 
rosso, ocra o rosato) con finti giunti bianchi dipinti a calce, enfatizzazione delle commessure verticali, di solito ampie e ripassatura dei giunti orizzontali con pigmento nero e stilatura a simulare gli effetti chiaroscurali della trama tessiturale ${ }^{116}$ (vedi figg. 20b-c).

Se la cronologia generale dei regalzieri a Venezia è stata generalmente compresa fra il XIV e il XVI secolo, con anticipazioni al XII secolo in aree archeologiche e rifacimenti tardi (Piana,Danzi, 2003); l'origine del termine regalzier viene talvolta ricondotta ad un lessico di cantiere locale ${ }^{117}$, anche se la pratica trova esemplari arcaici, forse prototipi, nel Veneto, come quelli trecenteschi documentati a Treviso da Mario Botter, o quelli rilevati da Francesco Doglioni in una dimora trecentesca veronese e nel castello di Avio (fig. 22). Tuttavia la possibilità di influenze nordiche e orientali ${ }^{18}$ è avvalorata dalle comprovate relazioni culturali e commerciali che Venezia intrattenne con entrambe le aree, dove si osservano intonaci a finta cortina e decorazioni con motivi a losanga. Suggestioni in questo senso derivano anche da assonanze che suggerirebbero un'etimologia nordica comune, come per esempio con i temini tedeschi die Regel (regola) e die Zier (termine arcaico per Gezierde, cioè «decorazione»), da zieren (adornare, decorare), la cui composizione potrebbe ben rappresentare la regolarità esibita di questo tipo di rivestimento decorativo. Il motivo a finta cortina poteva essere monocromo o bicromo, quest'ultimo con tonalità che sono di solito varianti del rosso e del rosa e motivo a losanga. Allo stato attuale della ricerca, la possibilità di stabilire una cronologia attendibile dei diversi tipi di regalzier osservati rischia di essere aleatoria, e sicuramente subordinata al raffronto di un numero maggiore di casi rispetto a quelli finora individuati. Inoltre, trattandosi di rivestimenti, dunque stratificazioni sovrapposte alla muratura, diventa dirimente il ruolo della stratigrafia per poter effettivamente correlare l'intonachino al paramento che lo sostiene (caso in cui il rivestimento costituisce effettivamente la finitura ultima della muratura, ad esso coeva anche se costruttivamente precedente), ovvero ad una fase successiva di ricon-

\footnotetext{
${ }^{116}$ Renata Trincanato cita l'intonaco di tipo rovigno, pigmentato con nero di vite e terra d'ombra, come base per decorazioni policrome o ad imitazione della cortina muraria (E. R. Trincanato, 1948, pp. 94-95).

117 Il tema è stato sistematicamente studiato da M.Piana, che fa riferimento anche agli scavi archeologici condotti da M. de Min in S. Lorenzo.

118 «L'orditura lignea è costituita da travi poggianti su mensoloni sagomati policromi, con tavolato e listelli decorati a motivi geometrici di tipo scalare, non molto dissimili dai così detti «regalzier» che con grande frequenza erano affrescati sulle facciate delle case coeve. Queste particolari soluzioni decorative traggono una probabile ispirazione dai motivi ricorrenti nelle architettutre Selgiuchidi o IU.'hanidi dell'asi a minore», F. Velluti, 2002, p. 30.
}
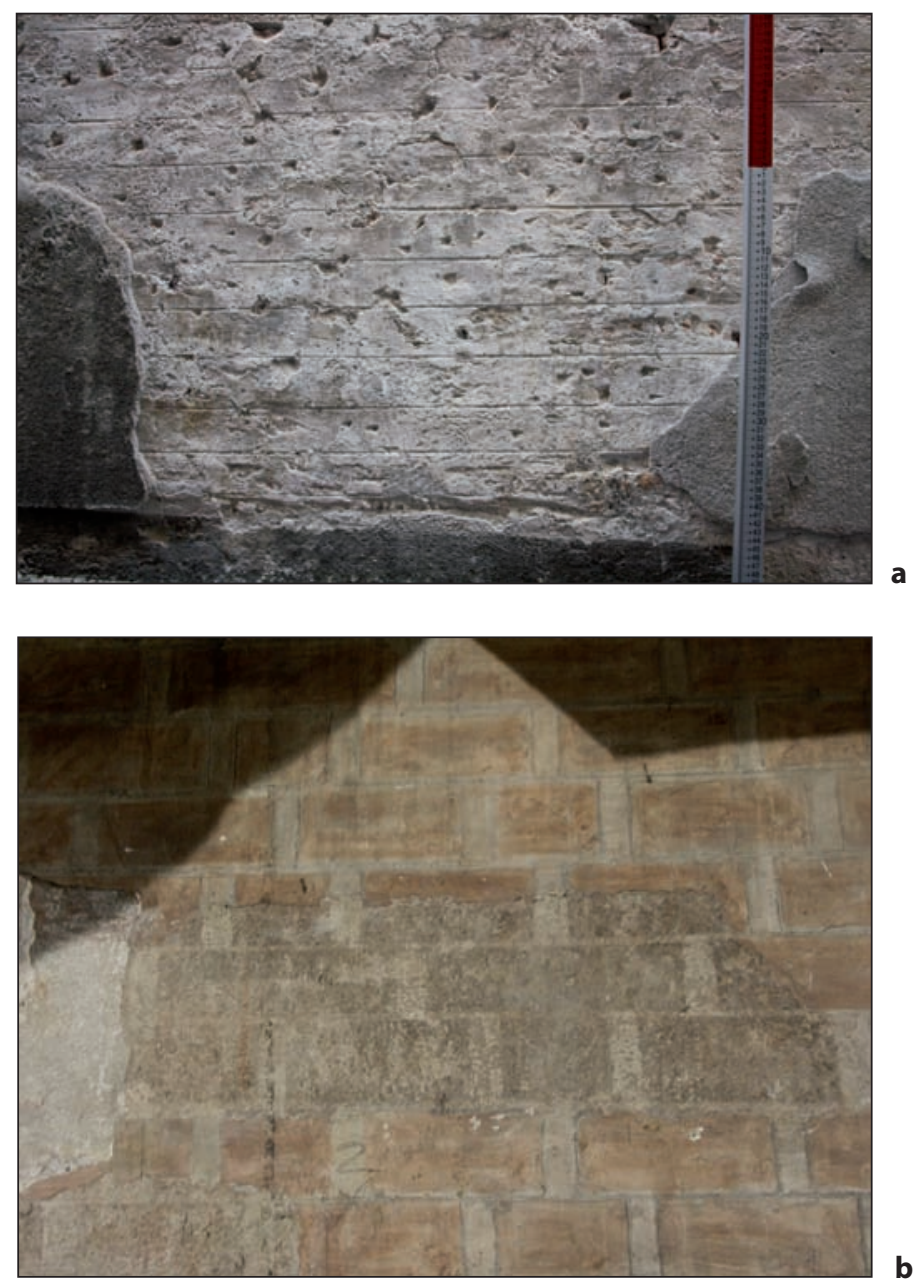

b

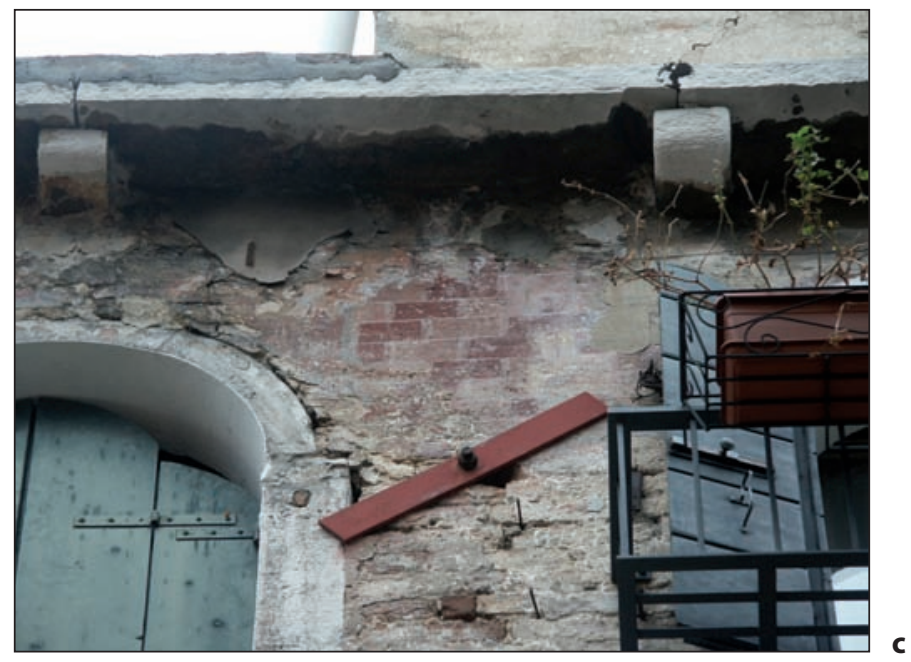

Fig. 23a-c. Esempi di regalzier: (a) regalzier bianco in un edificio in salizada S.Stae; (b) regalzier a velatura sul campanile della chiesa dei Frari; (c) regalzier bicromo in corte Nuova S.Lorenzo

figurazione dell'edificio (caso in cui l'intonachino può essere cronologicamente molto distante dalla muratura sottostante). Stanti questi limiti, alcune osservazioni strati- 

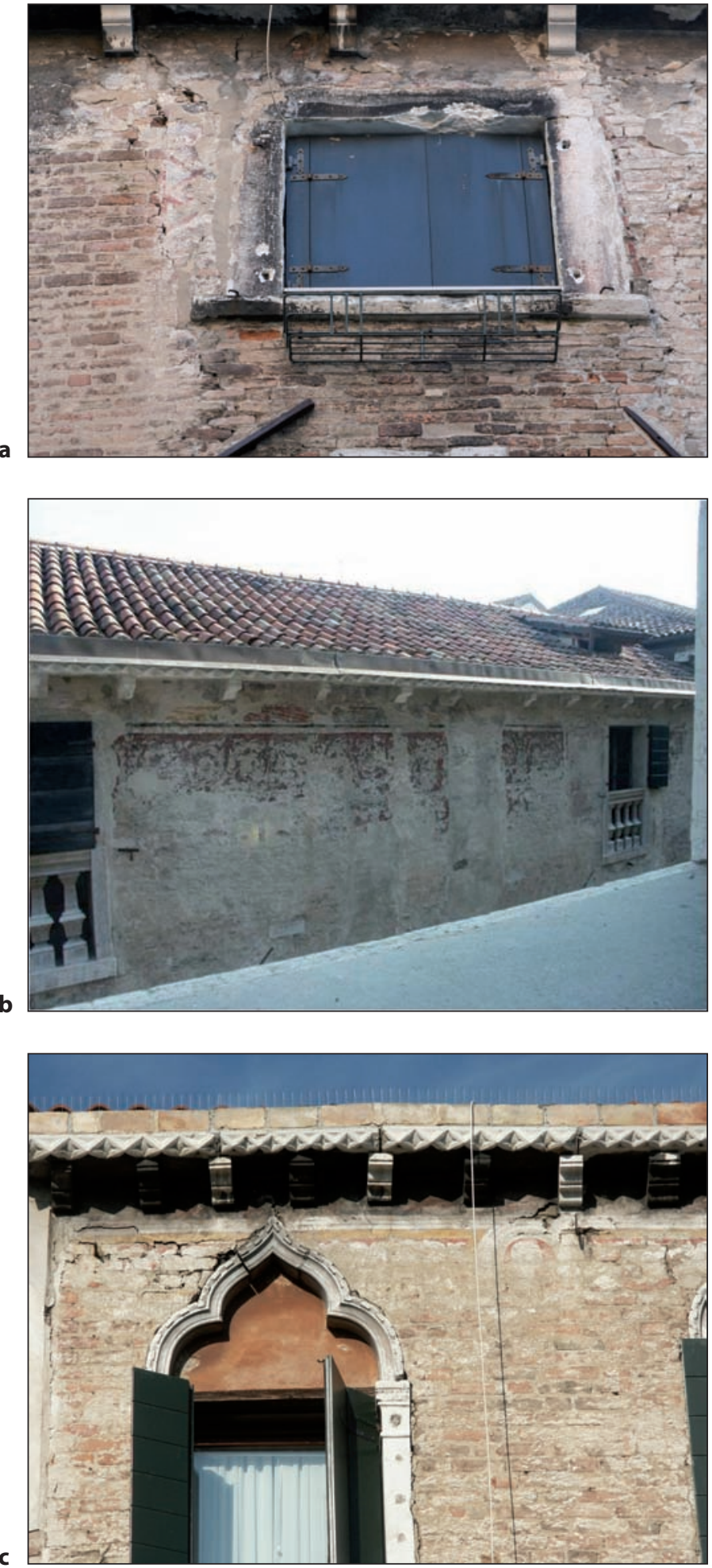

Fig. 24a-c. Motivi decorativi di fasce e cornici sottogronda: (a) motivi geometrici nell'edificio in corte Bottera; (b) motivi fitomorfi a girali nella fascia sottogronda di Palazzo Barbaro; (c) tondi con decorazioni figurative (Palazzo Odoni)

grafiche eseguite a campione, e dunque suscettibili di ulteriori riscontri, inducono a considerare più antichi il regalzier monocromo e quello a velatura (l'unico caso di colore bianco compare su un edificio veneto-bizantino con murature in altinelle, fig. 23a; mentre è un regalzier a velatura - sottostante un secondo intonachino a finta cortina- quello osservato sull'angolata interna del campanile dei Frari, terminato nel 1396, fig. 23b), rispetto a quello bicromo, che si osserva, per esempio, in un edificio seriale in corte Nuova S.Lorenzo, che presenta una configurazione cinquecentesca, pur attestandosi su una preesistenza gotica (fig. 23c). A favore di questa ipotesi si può forse osservare che il regalzier monocromo poteva avere la finta commessura bianca più o meno enfatizzata, un evidente rimando alle cortine in altinelle con commessure ampie e ribadite a calce (vedi fig. 25a); tuttavia bisogna rilevare come anche sull'abside dei Carmini (fine sec. XV?, vedi figg. 20b-c) compaia un regalzier monocromo rosso scuro. La questione cronologica è dunque tuttora aperta.

Così come non è certa la successione cronologica dell'articolata gamma decorativa dei rivestimenti di parti specialistiche come le fasce sottogronda ${ }^{119}$ o le cornici intonacate di monofore e polifore, che si prolungavano talvolta a formare un marcapiano ed erano dipinte a fasce e tondi, con motivi che quasi sempre avevano sia una componente geometrica che quella fitomorfa. Nei casi più arcaici sembrano prevalere motivi geometrici con assetto a triangoli, rombi, ed andamenti a zig zag (edificio in corte Bottera, con impianto romanico-bizantino e innalzamento con riconfigurazione delle aperture nel primo gotico, cui appartiene la fascia decorata, fig. 24a); seguono motivi geometrici più lineari, alternati a motivi fitomorfi, come girali e singoli elementi vegetali, o figure di animali (palazzo Barbaro a S. Stefano, fig. 24b); nei casi più tardi si osservano riquadri e tondi con decorazioni figurative (Palazzo Odoni, fig. 24c).

\section{PROBLEMI DI RICONOSCIMENTO E CONSERVAZIONE}

La complessa geografia dei diversi trattamenti, talvolta associati fra loro, come la molatura dei mattoni angolari con trattamenti protettivi oleosi pigmentati e ribaditure a calce dei giunti e delle commessure, è indicativa della complementarietà di muratura e finiture di superficie nell'architettura veneziana pre-rinascimentale, dove tutti i singoli elementi che compongono la facciata appartengono allo stesso lessico, formato da elementi architettonici e rilievi

\footnotetext{
119 "Le fasce orizzontali, sottogronda elo corrispondenti alle quote di divisione dei piani, di solito sono perimetrate da sottili bande policrome, bianche, rosse, verdi o nere. Talvolta le fasce riproducono modanature architettoniche e, quando ornate di girali e racemi vegetali monocromi stagliati su fondo rosso, tendono a riprodurre gli ornati in bassorilievo presenti su qualche fabbrica maggiore», M. Piana e altri, "Un GIS-Web per la catalogazione degli intonaci esterni veneziani», Iuav-Corila, Research Programme, op. cit.
} 

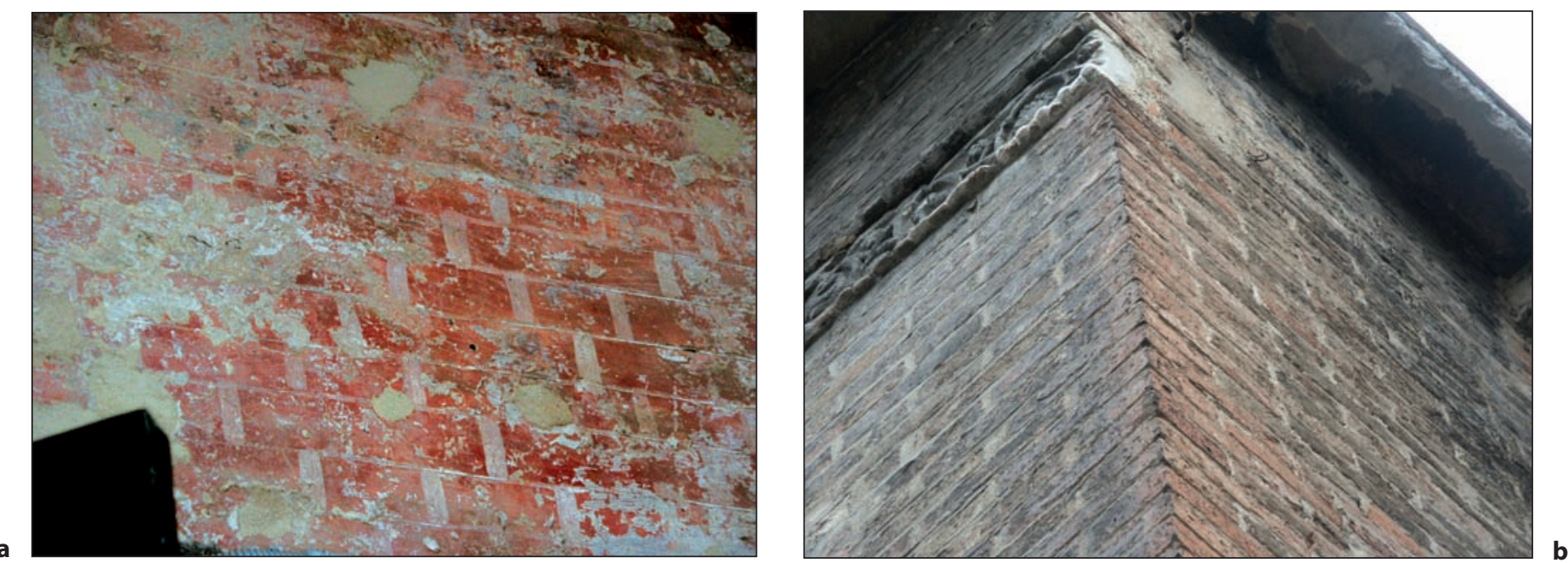

Fig. 25a-b. Rimandi fra muratura costruita e muratura simulata nelle finiture medioevali veneziane: regalzier monocromo con finte commessure bianche di dimensioni enfatizzate (Palazzo Moro in S.M.Mater Domini, S.Croce) che richiamano la commessura ampia di una muratura in mattoni molati (Palazzo del Bosso, S. Polo)

lapidei ma anche da pannelli murari di pari dignità formale grazie alle diverse lavorazioni di laterizio e giunti di malta, infine da trattamenti e strati decorativi sovrapposti e variamente articolati a formare un unicum architettonico-figurativo. Di questa unitarietà espressiva non si può non tener conto affrontando il tema della conservazione di edifici che sono in realtà contesti connotati da continui rimandi fra costruzione e decorazione, fra muratura costruita e muratura simulata (come nel regalzier) e per cui risulta inadeguata la consueta tendenza operativa a tenere distinte strutture e superfici (figg. 25a-b). Le murature in antico a vista veneziane e relative finiture di superficie pongono, sul piano conoscitivo, un problema di riconoscibilità, che richiede uno sguardo attento ai dettagli materiali e che si traduce operativamente nella necessità di un cambiamento di attenzione conservativa dai soli caratteri macroscopici all'insieme di tutti quegli elementi connotanti minuti, di cui anche un'operazione apparentemente innocua, come una scialbatura o la rifugatura dei giunti, può alterare irreversibilmente il delicato equilibrio. Un'altra questione sorge in ordine ai criteri di valutazione di queste testimonianze di un sapere antico, di cui non è facile ricostruire oggi i passaggi tecnico-costruttivi e che raramente conservano assetti completi (figg. 26a-c). Più spesso si tratta di lacerti e parti non sufficientemente integre da soddisfare le aspettative comuni di decoro. Tuttavia la possibilità della loro tutela passa per una variazione di prospettiva che richiede di non guardare "a ciò che manca", come accade quando si valutano le lacune di un intonaco da integrare ma, piuttosto, di decifrare i significati di «quel che resta», che continua a riservare una forte valenza informativa e capacità evocativa, ancorchè in condizioni di estrema frammentarietà.
La facies policroma di quella prima e più splendida Venezia, ricondotta a due principali radici culturali, la sacralità del colore di matrice orientale e il Critianesimo, «la sua primitiva, severa religione» ${ }^{120}$, continua ad apparirci attraverso i resti di finiture che rendevano "un muro di mattoni più prezioso che se fosse di smeraldi. (...) Tutto lo sforzo è di rendere ... un muro preparato per ricevere la pittura a fresco ... tutta la facciata del palazzo veniva considerata come la pagina di un libro pronto per essere miniato» ${ }^{121}$.

Benchè, in verità, non tutti i paramenti medioevali veneziani fossero destinati a ricevere un rivestimento completo, l'immagine evocata da Ruskin conferma l'assoluta complementarietà e reciproca sussidiarietà di compagine muraria e finitura superficiale sovrammessa nella connotazione dei paramenti a vista di Venezia gotica. Quell'Urbs picta, in cui la vigorosa arte dell'accumulo decorativo era tale da legittimare la contraddizione in termini che si verifica quando, come qui, si includono nella locuzione «muratura a vista, trattamenti, cromie e finiture a rivestimento parziale della superficie laterizia.

Un'impostazione, non priva di qualche ambiguità ma condivisa, almeno in alcuni altri contesti medioevali italia$\mathrm{ni}^{122}$, e che richiede un approccio analitico unitario, in cui murature e finiture di superficie sono da considerarsi un

\footnotetext{
${ }^{120}$ J. Ruskin, (1853), 1987, p. 203.

121 "Appena si cominciò ad adoperare il colore su superfici vaste, si vide che la massa ne distruggeva lo splendore, ed allora fu temperato con sfumature di altri colori mescolati ad una piccola quantità di bianco puro ... Le finestre e gli spazi intermedi fra loro erano considerati come oggetti posti in rilievo e variamente inquadrati in colori vigorosi...", J. Ruskin, op.cit., p. 351.

${ }^{122} \mathrm{La}$ complementarietà di muratura in mattoni e trattamenti sovrapposti nell'accezione di paramento a vista sembra trovare conferma in studi eseguiti in altre aree italiane, cfr. ad esempio F. Tolaini, 2005.
} 

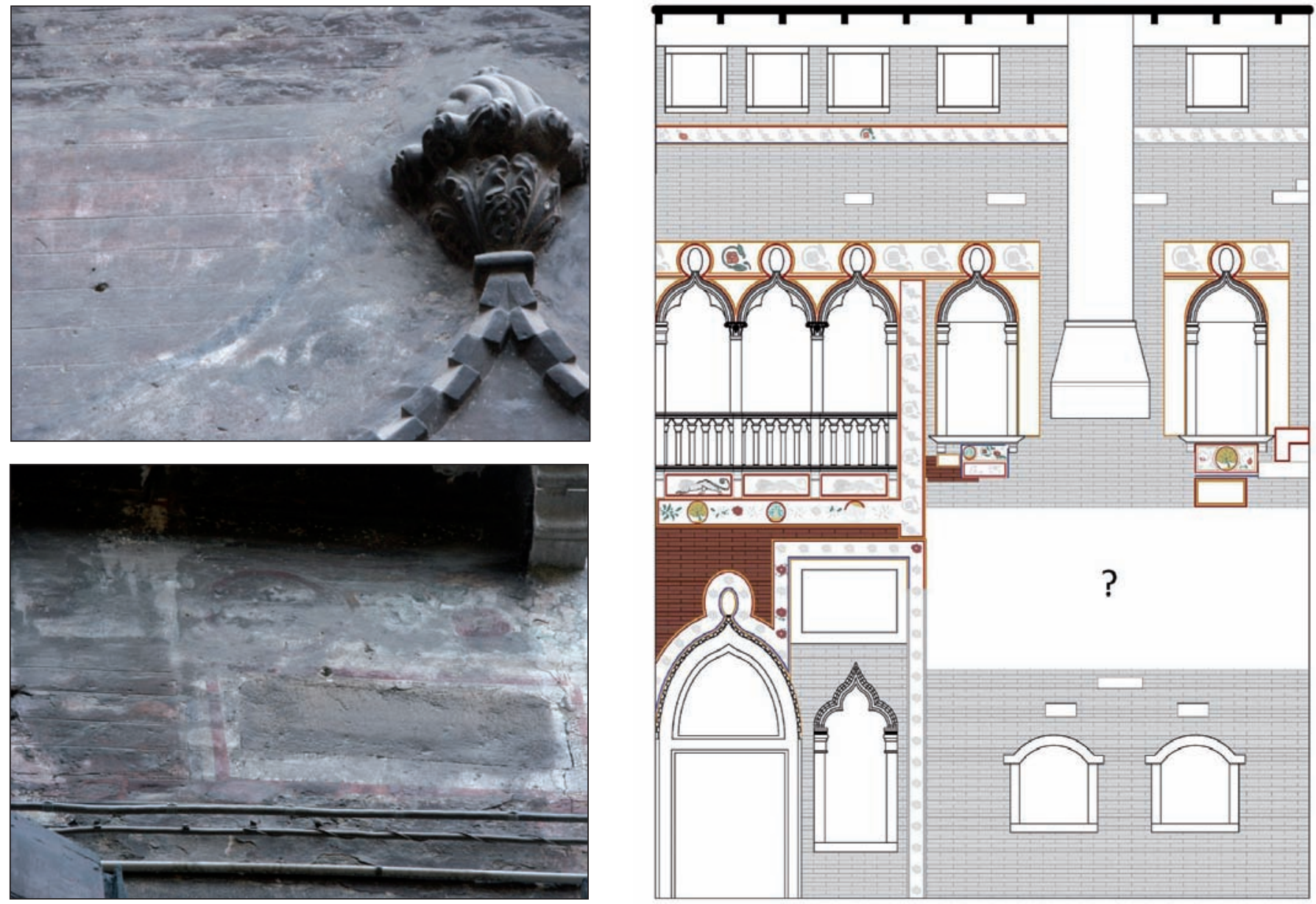

Figg. 26a-c - Venezia, corte Gherardi: palazzo gotico che conserva, benché quasi illeggibili, parti estese di un sistema decorativo articolato. Dettagli delle decorazioni annerite e ricostruzione dell'assetto decorativo rilevato (elaborato: studenti Chiavegato, Moschino, Negriolli, corso di restauro, Clasa-Università luav di Venezia, a.a.2010-11)

unicum espressivo. Questo non può non avere ricadute sulle strategie conservative e, soprattutto, rende più che mai incongrua, in questo tipo di manufatti, la consueta divisione - concettuale e operativa - fra struttura e immagine, supporto e superficie connotata.

\section{Bibliografía}

AA.VV., «Il mattone di Venezia», atti del Convegno a cura CNR-Università di Venezia, Venezia, 1979 e 1982.

A. Acocella, «L'architettura del mattone faccia a vista», Ed.Lateroconsult, Roma, 1989.

E. Armani, M.Piana, «Primo inventario degli intonaci e delle decorazioni esterne dell'architettura veneziana: indagine e classificazione degli intonaci colorati di una città che fu policroma, in "Ricerche di Storia dell'Architettura", n.24 (1984), pp. 44-54.

E. Arslan, «Venezia Gotica», Electa, Milano, 1970

H. P. Autenrieth, «Il colore dell'architettura», in E. Castelnuovo, V.Fumagalli, A.Peroni, S.Settis, (a cura), «Lanfranco e Wiligelmo: il duomo di Modena», Modena, Panini, 1984, pp. 241-263.

A. Bruschetti, F. Doglioni, «Le superfici dei grandi ambienti nell'ex Convento di SS. Cosma e Damiano alla Giudecca, Venezia», in «Archeologia dell'Architettura - supplemento ad Archeologia Medievale XXV», IV, 1999, 215-223.

G. Boni, «Il restauro del Fondaco dei Turchi», in «Venezia Imbellettata», Roma, Stabilimento Tipografico Italiano, 1887.
G. Boni, «La Ca' d'Oro e le sue decorazioni policrome», in «Archivio Veneto», n.34 (1887), pp. 115-132.

F. Bonora, «Proposta metodologica per uno studio storico dei mattoni, in AA.VV., «Il mattone di Venezia», atti del Convegno a cura CNR-'Università di Venezia, Venezia, 1979, pp. 229-238.

P. Boucheron, H.Broise, Y.Thebert (a cura), «La brique antique et medieval. Production et commercialization d'un matériau», Actes du colloque international par le Centre d'histoire urbaine de l'Ecole supérieure de Fontenay/Saint Cloud et l'Ecole francçaise de Rome», Roma 2000.

G. Caniato, M. Dal Borgo, «Le arti edili a Venezia», Edilstampa, Roma, 1990.

B. Cecchetti, «La vita dei veneziani nel 1300», 1845, ristampa con introduzione di U.Stefanutti, Arnaldo Forni Editore, Bologna, 1980.

B. Cecchetti, «La vita dei veneziani nel 1300», cap.1 «La città, la laguna», in Architettura Veneta, n.s. 27, 1885.

E. Concina, «Pietre, parole e storia. Glossario della costruzione nelle fonti veneziane», Marsilio, 1988.

S. Connel, «Gli artigiani dell'edilizia», in AA.VV., Dal Medioevo al tardo Rinascimento.Ricerche di storia del costruire a Venezia, Canal Libri, 1994, pp. 73-83.

G. Cracco, «Venezia nel Medioevo dal secolo XI al secolo XIV», Utet, Torino, 1986.

N. Davey, «Storia del materiale da costruzione», (1961), Saggiatore, Milano, 1965.

M. De Min, «Venezia. Chiesa di San Lorenzo di Castello: un esempio di scavo correlato al restauro architettonico", in SBBAA di Venezia, «Ritrovare restaurando. Rinvenimenti e scoperte a Venezia e in laguna", Grafiche Antiga, Treviso, 2000. 
M. De Min, «Edilizia altomedievale e medievale nel territorio lagunare», in AA.VV., "Tra due elementi sospesa. Venezia, costruzione di un paesaggio urbano», Venezia, 2000.

E. De Minicis, «I laterizi in età medioevale. Dalla produzione al cantiere», Atti del Convegno Nazionale di Studi, Roma 4-5/06/1998, Edizioni Kappa, Roma 2001.

F. Doglioni, G.Mirabella Roberti (a cura), «Venezia. Forme della costruzione forme del dissesto», Iuav-Corila, Cluva, Venezia, 2011.

F. Doglioni, F.Trovò, «Mutamenti dei laterizi e delle murature veneziane tra XII e XVI secolo», en Doglioni e Mirabella Roberti, «Venezia», 2011, pp. 33-66.

W.Dorigo, «Venezia Romanica. La città medioevale fino all'età gotica», Venezia, I.V.S.L.A., 2003.

L. Fersuoch, «S.Leonardo in fossa Mala e altre fondazioni medioevali lagunari», Jouvenice, 1995.

D. Fiorani (a cura), «Finiture murarie e architetture nel Medioevo», Gangemi Editore, Roma, 2005.

V. Fontana, «Proposta di rilevamento periodico delle superfici esterne dell'edilizia veneziana», in «Superfici dell'Architettura: le finiture», atti del convegno «Scienza e Beni Culturali», Padova, 1990, pp. 719-723.

S. Fossati, «la possibilità di datare complessi di mattoni», in «Archeologia Medioevale», XI, 1984, pp. 731-737.

F. Gabrielli, R.Parenti, «La decorazione in laterizio. Osservazioni sulle tecniche di produzione», in "Le superfici dell'Architettura. Il cotto», atti del convegno «Scienza e Beni Culturali», Padova, 1992, pp. 23-35.

P. Ghislanzoni, D. Pittaluga, «Un metodo di datazione del patrimonio edilizio: la curva mensiocronologica dei mattoni in Liguria», in Archeologia Medioevale, XVI, 1989, pp.675-682.

G. Gianighian, P. Pavanini, «Dietro i palazzi. Tre secoli di architettura minore a Venezia, 1492-1803", Itinerari di storia e arte, Arsenale Editrice, Venezia, 1984.

R. J. Goy, «La fabbrica della Cảd'Oro», in AA.VV. «Dal Medioevo al tardo Rinascimento. Ricerche di storia del costruire a Venezia», in Ricerche Venete/ 2, Venezia, Canal Libri, 1993, pp.93-157.

T. Mannoni, «Metodi di datazione dell'edilizia storica», in «Archeologia Medioevale», XI, 1984, pp.396-401.

P. Maretto, «L'edilizia gotica veneziana», Venezia, 1959.

F. Marino, «Notizie sul cantiere e sui modi del costruire nel tardomedioevo a Venezia attraverso lo studio di conti di fabbrica», tesi di laurea, relatore F.Doglioni, IUAV, a.a. 1988-89.

U. Menicali, «I materiali dell'edilizia storica», Roma, Nis, 1972.

P. Molmenti, «La storia di Venezia nella vita privata dalle origini alla caduta della Repubblica», Torino, Roux et Favalle, 1880.

G. Monticolo, «I Capitolari delle Arti Veneziane sottoposti alla giustizia Vecchia dalle origini al MCCCXXX, vol. X, Roma, (1896), 1914.

S. Muratori, «Studi per una operante storia urbana di Venezia», Roma, Istituto poligrafico dello Stato, 1960.

R. Parenti, «Sulla possibilità di datazione e classificazione delle murature», in "Archeologia e restauro dei Monumenti», a cura di R.Francovich, R.Parenti, Firenze, 1988, pp.280-304.

R. Parenti, «Intonaci, coloriture e stucchi. Contributi alla comprensione del processo di formazione delle strutture murarie», in «Superfici dell'Architettura: le finiture», atti del convegno «Scienza e Beni Culturali» di Bressanone, Libreria Progetto Editore, Padova, 1990, pp.47-55.

M. Piana, «Un'esperienza di restauro sugli intonaci veneziani», in AA.VV., «Il colore dell'edilizia storica», supplemento a "Bollettino d'arte», Roma, Istituto Poligrafico e Zecca dello Stato, suppl. al n.6/1984.

M. Piana, E. Danzi, «The catalogue of Venetian external plasters: medieval plasters", in CO.RI.LA Research Programme 2001-2003, vol.2, pp.65-78.

D. Pittaluga, «La storia dei mattoni medioevali vista dalla Liguria», in E. De Minicis (a cura) I laterizi in età medioevale. Dalla produzione al cantiere, Ed.Kappa, Roma, 2001, pp. 65-79.

J. A. Quirós Castillo, «La mensiocronologia dei laterizi della Toscana: problemati- che e prospettive di ricerca», in Archeologia dell'Architettura, n.2/1987, pp. 159166.

G. A. Rusconi, «I dieci libri di architettura di Gio Antonio Rusconi», in Venezia, 1660 appresso Nicolini.

J. Ruskin, «The Stones of Venice», London, 1853, trad.it. «Le pietre di Venezia», Rizzoli, Milano, 1987.

A. Sagredo, «Sulle consorterie delle arti edificative a Venezia», Venezia, 1856.

F. Sansovino, «Venetia città nobilissima et singolare», Venezia, 1581.

V. Scamozzi, «L'Idea di Architettura Universale di Vincenzo Scamozzi» (1615), Milano, 1838.

A. Squassina, «Le variazioni dimensionali e delle lavorazioni di superficie dei laterizi a Venezia: la chiesa dei Carmini come sequenza cronologica», en Doglioni e Mirabella Roberti, «Venezia», 2011, pp. 67-88.

T. Temanza, «Antica pianta dell'inclita città di Venezia delineata circa la metà del XII secolo, Ed ora per la prima volta pubblicata, ed illustrata. Dissertazione topografico-storico-critica di Tommaso Temanza architetto ed ingegnere della serenissima repubblica di Venezia», Venezia, stamperia C. Palese, 1781.

F. Tolaini (a cura), «Il colore delle facciate: Siena e l'Europa nel Medioevo», Atti del Convegno, Siena 2-3.03.2001, Pacini. Siena, 2005.

E. R. Trincanato, «Venezia Minore», Venezia, 1948.

F. Valcanover e W. Wolters (a cura), «L' architettura gotica veneziana», atti del Convegno internazionale di studio, Venezia, 27-29 novembre 1996, Istituto Veneto di Scienze, Lettere ed Arti, Venezia, 2000.

C. Varagnoli, «La materia degli antichi edifici», in G. Carbonara (a cura), "Trattato di Restauro Architettonico», Utet, 1996, vol. I, pp. 358-412.

F. Varosio, «Mensiocrologia dei laterizi a Venezia: ricerche,verifiche di applicabilità, stesura di una prima curva", in Archeologia dell'Architettura, VI, 2001, pp. 49-59.

F. Velluti, «Larredo domestico fisso dal gotico al rinascimento nel territorio cenedese, trevi giano e nel basso bellunese», in Interno Veneto, Catalogo della mostra, Vittorio Veneto, 2002.

F. Zago, "Caratteristiche meccaniche dei mattoni e delle murature di Palazzo Foscari a Venezia», Editoria Universitaria, Venezia, 1997.

Testi e studi sulla Chiesa dei Carmini

E. Concina, «Le chiese di Venezia», Udine, 1996.

H. Dellwing, «Die Kirchenbaukunst des spaeten Mittelalters in Venetien», Worms, 1990.

W. Dorigo, «Venezia Romanica. La città medioevale fino all'età gotica», Venezia, 2003.

G. Lorenzetti, Venezia e il suo estuario: guida storico - artistica; Padova, 1974, pagg. 554-557.

L. Moretti, S.Branca Savini, "Chiesa di Santa Maria dei Carmini. Arte e devozione», Marsilio, Venezia, 1995.

A. Niero, «La chiesa dei Carmini», Venezia, 1956.

\section{Studi e ricerche:}

A. Squassina, "Chiesa di S. Maria del Carmelo (Carmini) - Osservazioni stratigrafiche e individuazione delle principali fasi costruttivo-trasformative della navata centrale (lato destro)», nell'ambito dell'intervento di restauro del rivestimento ligneo, progetto e D.L. Dott. R.Battaglia -Soprintendenza per i Beni Architettonici e Paesaggistici di Venezia e Laguna, parte prima (campate 1-6): 2006-2007; parte seconda (campate 7-10): 2008-2009.

Tesi di laurea:

Y. Rossato, «La Chiesa di Santa Maria del Carmelo. analisi dell'edificio medioevale e dei restauri tra Ottocento e Novecento", tesi di laurea in Storia dell'Arte Medioevale, relatore G.Valenzano, Università degli Studi di Padova, a.a. $2004-2005$.

Recibido: 15 de agosto de 2011 Aceptado: 28 de septiembre de 2011 